\title{
Zooplankton Distribution and Abundance in West Greenland Waters, 1950-1984
}

\author{
S.A. Pedersen and E.L.B. Smidt ${ }^{2}$ \\ Greenland Institute of Natural Resources, c/o Dept. of Marine Ecology and Aquaculture \\ Danish Institute for Fisheries Research, Kavalergården 6, DK-2920 Charlotternlund, Denmark
}

\begin{abstract}
Abundance indices of zooplankton obtained from offshore plankton surveys carried out in June-July from 1950 to 1984 off West Greenland were examined for trends and relationships with sea temperature and salinity. The zooplankton displacement volume and most of the zooplankton taxa showed higher abundance indices in the generally warmer period 1950-68 compared to the more variable period 1969-84. Sandeel larvae (Ammodytes sp.) were generally more abundant during cold periods after 1969. Zooplankton displacement volume showed a positive correlation $(r=0.28)$ with temperature, whereas correlations of individual zooplankton taxa with temperature or salinity were weaker. The relationships of zooplankton abundance indices with temperature suggest changes in zooplankton productivity during 1950-84.
\end{abstract}

Key words: distribution, fish, ichthyoplankton, Greenland, shrimp, species interactions, zooplankton

\section{Introduction}

In the twentieth century there have been major changes in the international annual landings of commercially important fish species in West Greenland waters (NAFO, 1995, 1998; Anon., 1998a). Historically, Atlantic cod (Gadus morhua) and redfish (Sebastes marinus and S. mentella) were the most important commercial fish species. In the late-1960s landings of both species declined drastically and have fluctuated at much lower levels since then. A few strong cod year-classes in the 1970s and 1980s were of Icelandic origin (Buch et al., 1994). During the last two decades Northern shrimp (Pandalus borealis) and Greenland halibut (Reinhardtius hippoglossoides) have been the most important fishery resources at West Greenland with annual landings peaking in 1992 at 87000 and 30000 tons, respectively (NAFO, 1998). The shift in landings composition over the last decades is assumed to be due mainly to changes in recruitment patterns driven by changes in oceanographic characteristics. Investigations of climatic variability off West Greenland indicate general decreasing trends in air and seasurface temperatures from the late-1960s onwards (Stein and Borovkov, 1997), which have been related to an increasing trend in the North Atlantic Oscillation index (Buch, MS 1990; Hurrell, 1995; Buch, MS 1998; Stein, 1998). Recruitment overfishing has not been described as an important cause of recruitment variability in West Greenland fish stocks.

Long time-series of plankton samples can be used to identify patterns of variation in marine systems (Aebischer et al., 1990; Mackas et al., 1998; Anderson and Piatt, 1999). Correlations with hydrographic data may reveal processes underlying the patterns. Understanding these processes provides building blocks for better understanding of the dynamics of marine systems, and thereby for better management of marine resources (Cushing, 1995a and b). Retrospective analyses of time-series of fishery-relevant environmental data is important for detection and prediction of climatic changes and their influence on the living marine resources (Anon., 1998b).

This paper presents data from zooplankton surveys conducted in West Greenland waters during 1950-84. The main objectives of the zooplankton investigations were: 1) to obtain abundance indices of larval Atlantic cod and other fish species to predict year-class strengths, 2) to obtain zooplankton abundance indices as indicators of food availability and quality for larval fish, 3) to provide a basis for identifying trends over time in species composition and productivity, 4) to identify indicator species for different hydrographical conditions.

\footnotetext{
2 Retired
} 
The West Greenland survey data represent one of the longest time-series of zooplankton data from the Northwest Atlantic. In this paper we analyse abundance indices of zooplankton for variation and trends, and examine relationships between zooplankton abundance, temperature and salinity, particularly in relation to long-term variations in the ocean climate before and after 1968.

\section{Materials and Methods}

\section{Hydrography and zooplankton sampling}

Annual oceanographic surveys were made in the Labrador Sea and in the Davis Strait off Southwest Greenland during late June-mid-July from 1950 to 1984 by the Greenland (Danish) Fisheries Research Institute. Over the time period the surveys have been made with the two Danish research vessels R/V Dana (before 1967) and R/V Adolf Jensen (after 1967). Zooplankton was sampled and physical and chemical oceanographic observations taken. Generally samples were taken at fixed positions along sections. However, the number of samples and distance from the coast varied greatly among years. In some years additional samples were taken at positions off the sections e.g. during the NORWESTLANT survey in 1963 (ICNAF, 1968; Smidt, 1971). Hydrography and zooplankton samples analysed in this paper were collected along three sampling sections Store Hellefiske Bank (S1), Sukkertop Bank (S2), and Fyllas Bank (S3), nearly perpendicular to the Greenland coast, at approximately $66^{\circ} 45^{\prime} \mathrm{N}, 65^{\circ} 06^{\prime} \mathrm{N}$, and $63^{\circ} 50^{\prime} \mathrm{N}$ (Fig. 1). Analyses include all samples from the three sections (areas) most consistently sampled over the whole time-period (Fig. 2). In some years sampling at the five fixed positions at each section was hindered by bad weather conditions (reduced sampled size); additional samples from other positions (stations) were included in others years (increased sample size) (Table 1).

Sea temperature and water samples for measuring salinity were obtained at standard depths using modified Nansen reversing water bottles equipped with protected reversing thermometers (accurate to $0.01^{\circ} \mathrm{C}$.) (Sverdrup et al., 1946). Temperature and salinity at each sampling station were calculated as means of measurements taken in 10-50 m (usually sampled at 10,25 , and $50 \mathrm{~m}$ or $10,20,30$, and $50 \mathrm{~m}$ ).

The zooplankton sampling gear was a $2 \mathrm{~m}$ (diameter) stramin ring-net with $1 \mathrm{~mm}$ mesh. Tows were made for 30 minutes at about 2 knots. Prior to 1963, and in 1964 and 1966, hauls were horizontal, stratified with two nets on the same wire, in three 10 minutes deployments. In this "step-wise setting" procedure two nets operated simultaneously on the same wire with a distance of $100 \mathrm{~m}$ of wire between them. Wire lengths were 200,150, and $125 \mathrm{~m}$ for the deeper net, and 100 , 50, and 25 for the shallower net. In 1963 all tows were made obliquely with a single net with a maximum wire length at deployment of $225 \mathrm{~m}$ (which corresponds to a depth of approximately $50 \mathrm{~m}$ ). In 1964 and 1966, stratified hauls with two nets were again made, but in all the following years, 1968 to 1984, all tows were made obliquely with a single net as in 1963 . No sampling was done in 1951, 1965, and 1967. To make all zooplankton samples comparable on the scale of a single haul at each station, all samples were standardized to a 30 minutes tow. For the years (before 1963 and in 1964 and 1966) with stepwise settings and two concurrent sampling nets in two depth ranges (200 to 125 and 100 to $25 \mathrm{~m}$ wire length) the catch by each of the two nets was averaged. In the stepwise sampling procedure some extra hauling time was generally allocated. Based on records from the research vessel $\operatorname{logs}$ and data sheets, a conversion factor of 0.75 was used for the stratified hauls before 1963 and 0.85 for hauls in the years 1964 and 1966, to scale these catches to 30 minutes tows. Calibration experiments performed in 1984 on oblique tows estimated that a 30-minute tow at 2 knots filtered approximately $6125 \mathrm{~m}^{3}$ of seawater. We used this sampling unit for volumes and counts of zooplankton and fish larvae.

\section{Preservation and species identification}

Zooplankton samples were preserved in $4 \%$ formaldehyde supersaturated with borax. All large organisms (generally post-larval fish) were picked out from each sample. Because the gear is unlikely to retain salps and schyphomedusae effectively, those organisms were removed from the catch without quantification. The displacement volume of all remaining plankton, scaled to a 30-minute tow, was recorded. Subsamples were taken for counts of the zooplankton taxa. The subsample size in number depended on the size of the taxa and was adjusted so that all or a minimum of about 400 animals was counted per sample. Samples were split in a flat rectangular dish by a metal cross, or subsamples were taken volumetrically. Identification was made to species if possible or at least to family. In some years not all zooplankton taxa in the samples were sorted and counted; however, fish larvae were always quantified.

The zooplankton groups and species selected for analysis in this paper are listed in Table 2. Small animals are not caught by the $1 \mathrm{~mm}$ mesh size ring net 


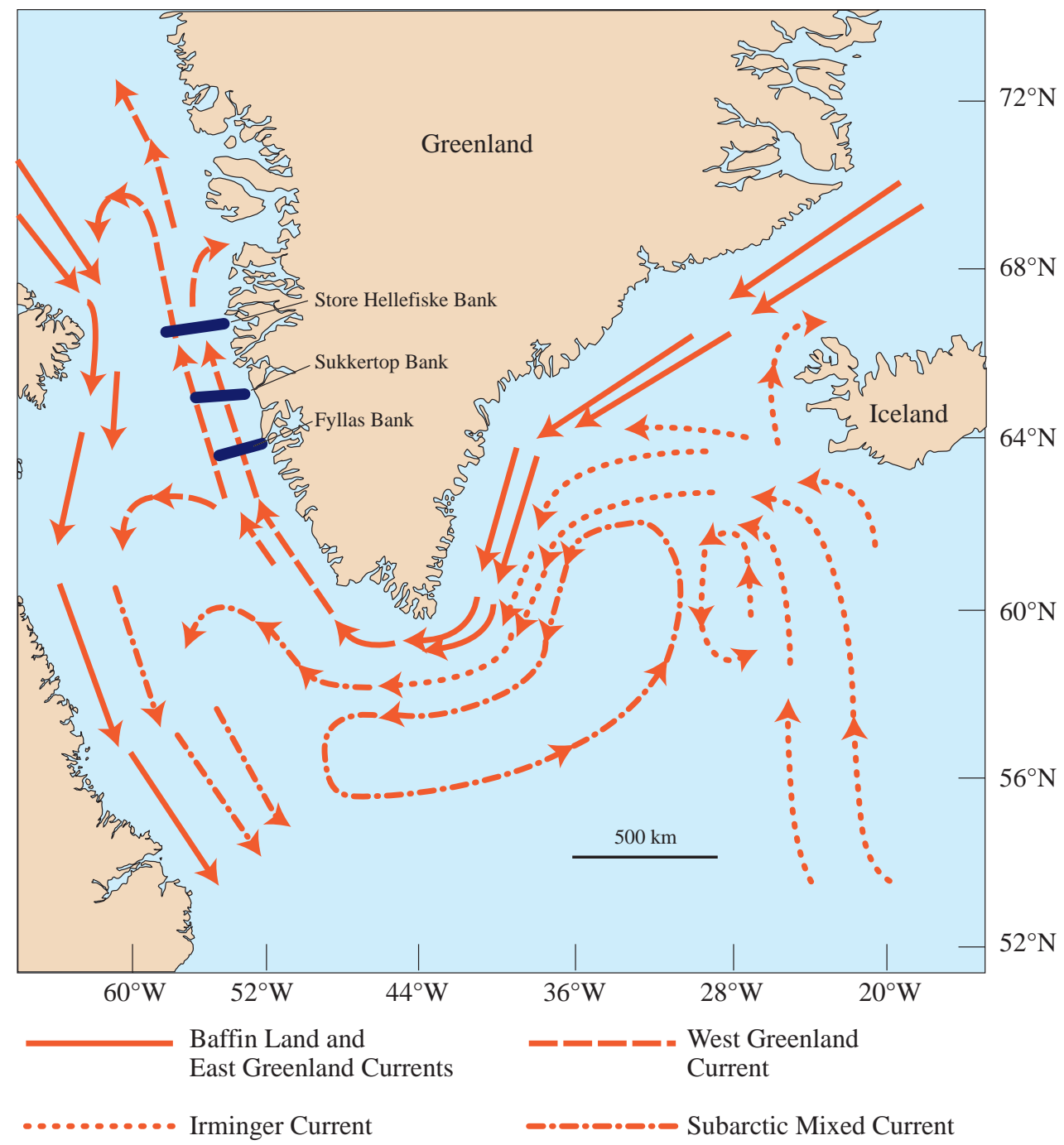

Fig. 1. Surface currents around Greenland and locations of the three hydrographic sections off West Greenland most consistently sampled for zooplankton, 1950-84 (surface currents simplified after Hachey et al., 1954).

used, and many small developmental stages and small species are therefore not included (Table 2).

\section{Analyses}

The distributions of the zooplankton abundance indices by individual hauls and taxa showed nonnormality in the residuals. Therefore, the effects of sampling year, section, depth to bottom, month and interactions were tested using multi-way nonparametric ANOVAs on the ranked dependent variables: temperature, salinity and abundance indices of different zooplankton taxa (SAS RANK and GLM procedures; Anon., 1985). ANOVA $F$ tests on ranked data approximate p-values for large samples (Wannacott and Wannacott, 1985).
The model tested was:

$$
E(r d)=y_{i}+s_{j}+d_{k}+m_{n}+y s_{i j}+y m_{i n}+e,
$$

where $E(r d)$ is the expected value of the ranked dependent variable;

$y, s, d, m, e$ is the effects of year, section, depth to bottom, month of sampling, and error, respectively;

$i \quad$ is the year (1950-84),

$j \quad$ is the section (1-3),

$k \quad$ is the depth to bottom (100 $\mathrm{m}$ intervals), and

$n \quad$ is the month of sampling (June or July). 


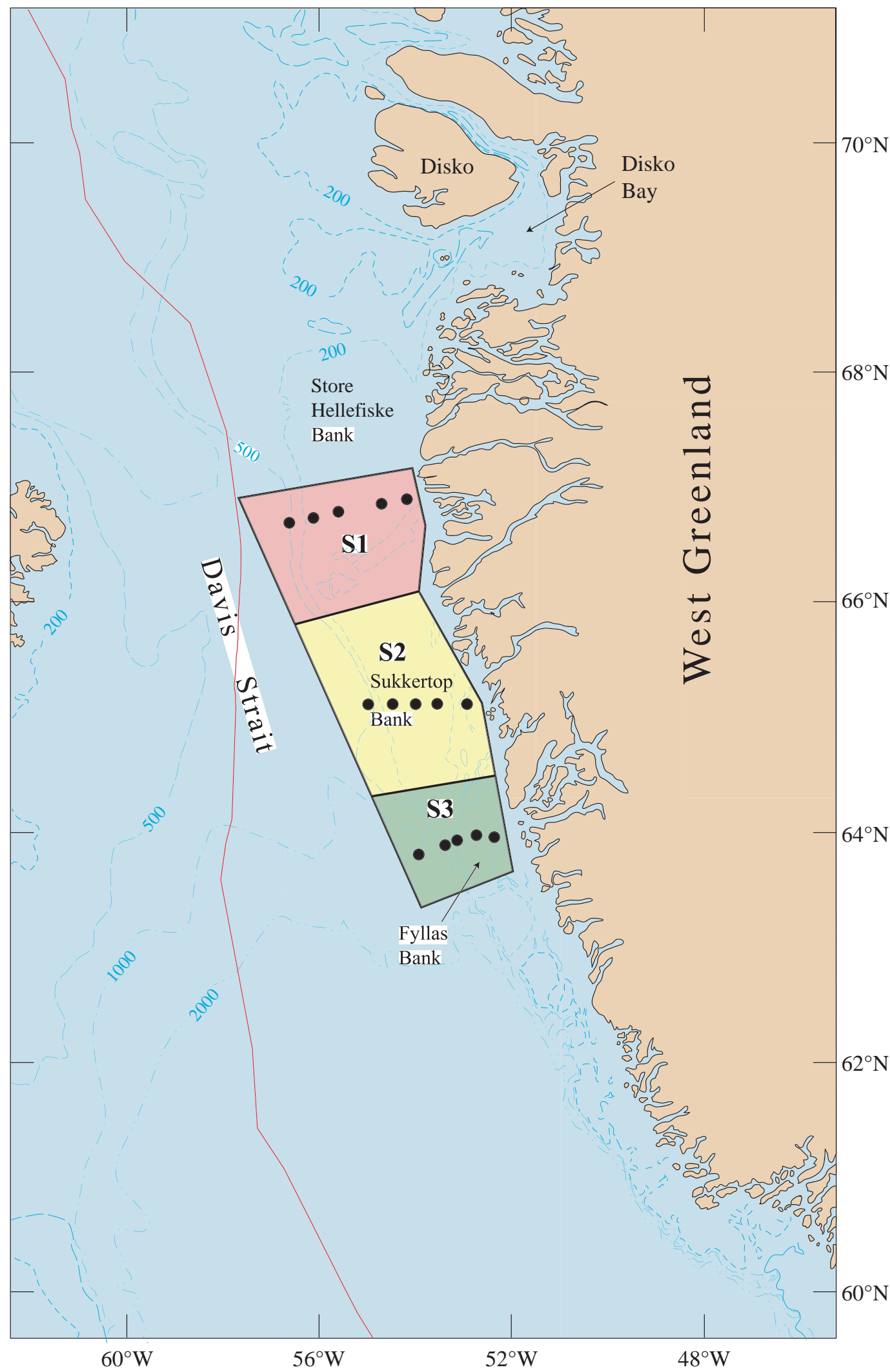

Fig. 2. Map showing the major physiographic features off West Greenland and the location of the study area and three sampling sections S1, S2 and S3. Dots are positions of sampling stations. 


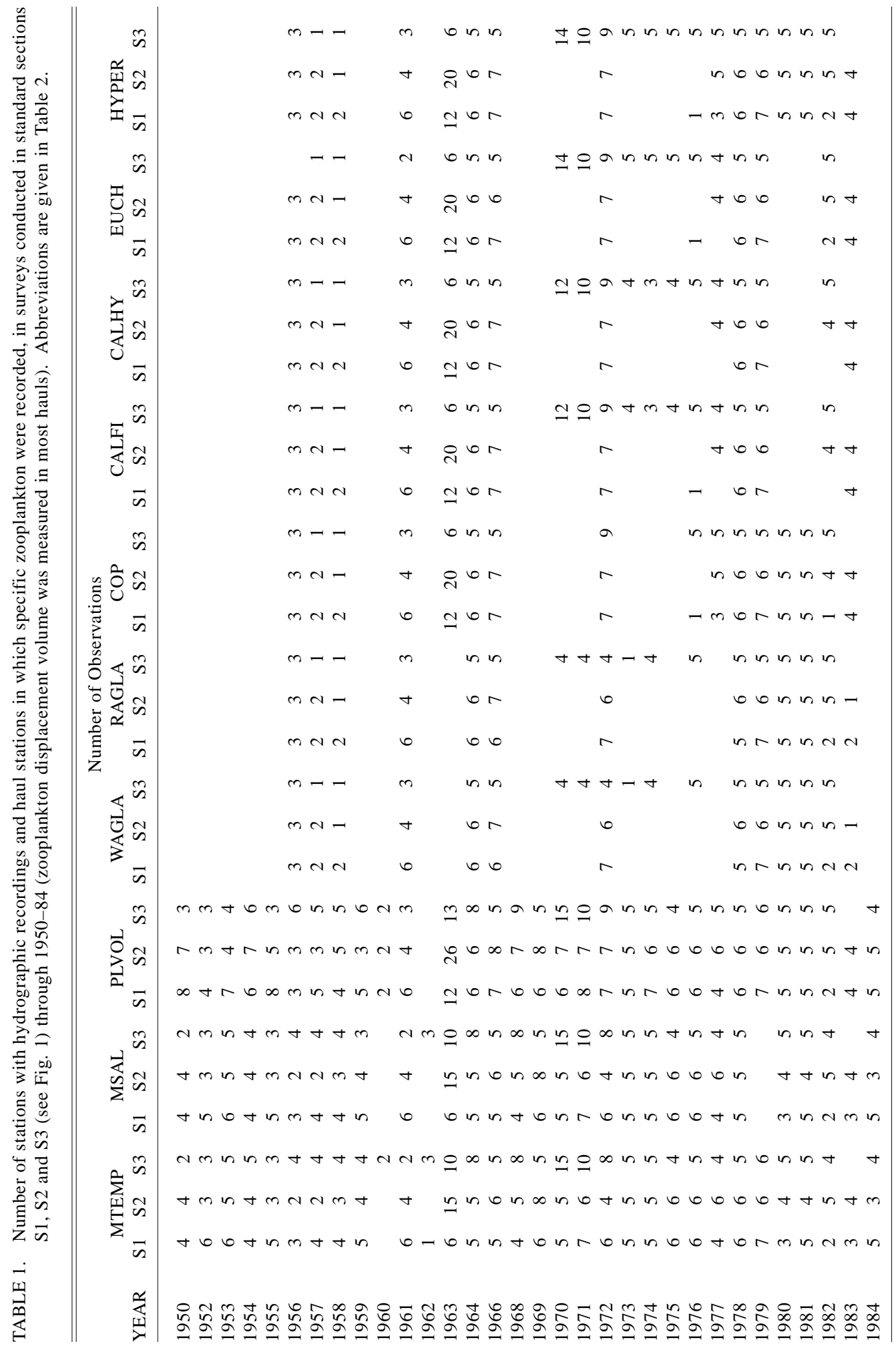




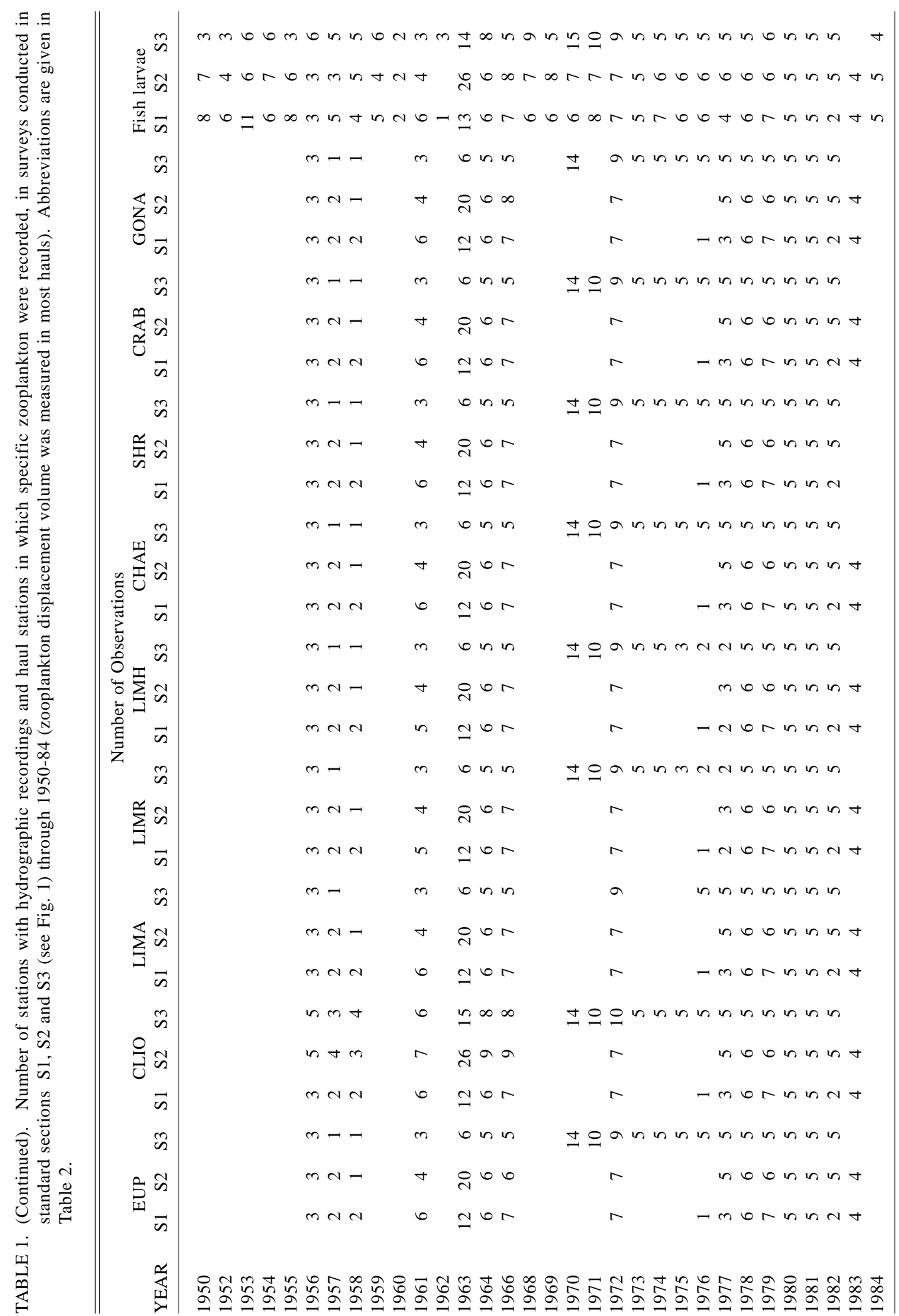


TABLE 2. List of species identified in the West Greenland zooplankton samples. $X$ indicates group or species included in the analyses, abbreviations given in parentheses.

Ctenophora:

Beroe cucumis

Mertensia ovum

Hydromedusae:

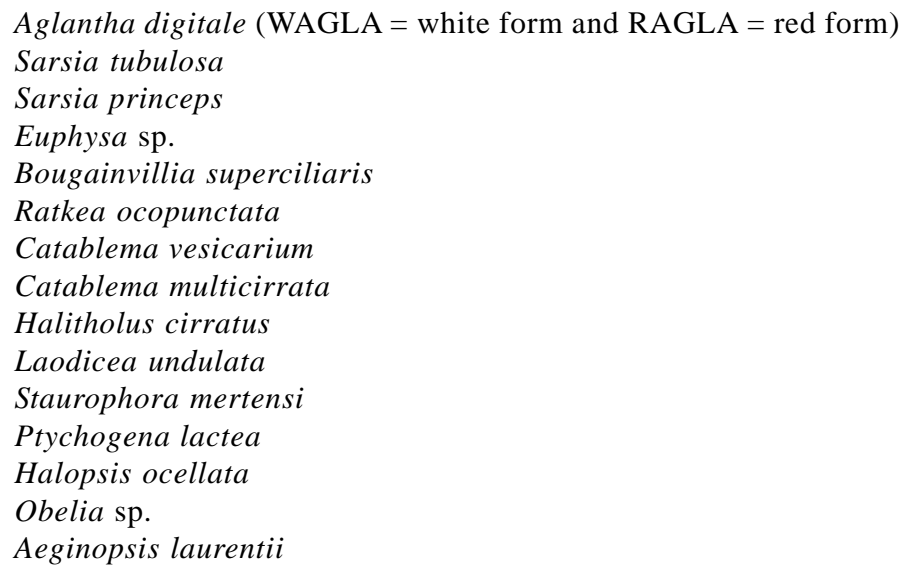

Scyphomedusae: (Discarded, not included in plankton displacement volume)

$$
\begin{aligned}
& \text { Aurelia aurita } \\
& \text { Aurelia limbata } \\
& \text { Cyanea capillata } \\
& \text { Periphylla periphylla }
\end{aligned}
$$

Siphonophora:

Physophora hydrostatica

Dimophyes arctica

Polychaeta:

Tomopteris spp.

Autolytus sp.

Ostracoda:

$$
\begin{aligned}
& \text { Concoecia elegans } \\
& \text { Concoecia obtusata }
\end{aligned}
$$

$\mathrm{X}$ Copepoda (COP):

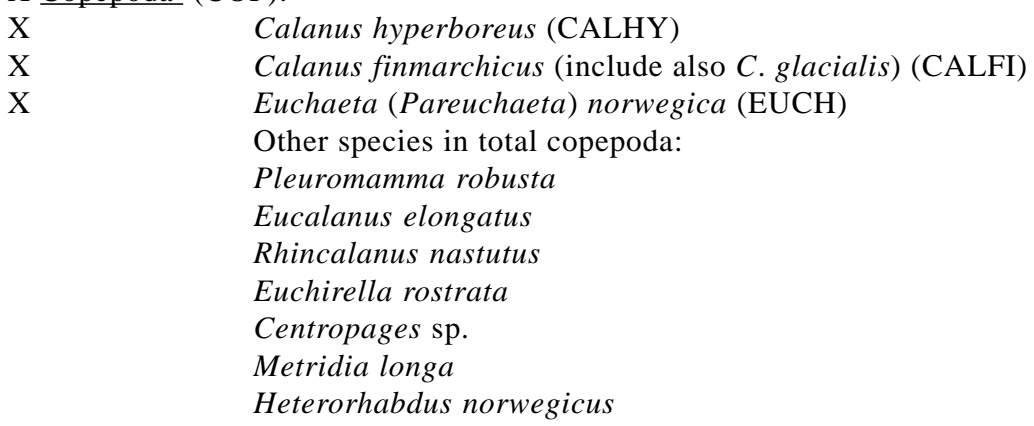

X Hyperiidae (HYPER):

Parathemisto abyssorum Parathemisto gadicaudi

Parathemisto libellula

Hyperoche medusarum

Hyperia galba

Hyperia medusarum 
TABLE 2. (Continued). List of species identified in the West Greenland zooplankton samples. X indicates group or species included in the analyses, abbreviations given in parentheses.

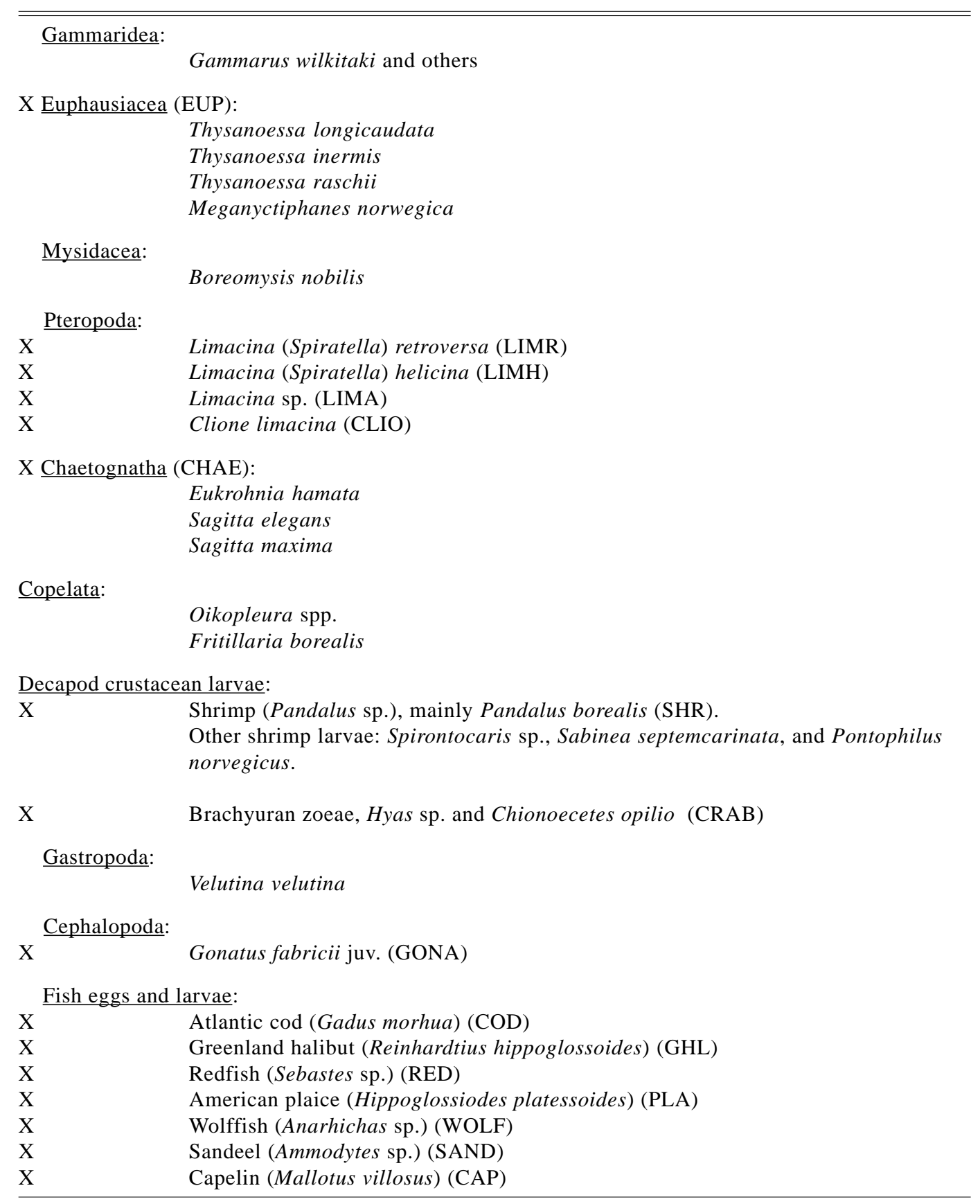

Correlations between temperature, salinity, and abundance indices of different zooplankton taxa were investigated using Spearman rank correlations (SAS CORR procedure; Anon., 1985) using data for individual stations. One-way ANOVA were used to examine residuals and test trends in the abundance of the different zooplankton taxa and covariability with temperature.

\section{Results}

\section{Mean sea temperature and salinity}

Residuals and least squares means of multi-way nonparametric ANOVA showed general trends of higher mean sea temperatures (MTEMP) during 195266, 1977 and 1979, on section 2, at depth to bottom between 200-400 $\mathrm{m}$ and in July (Fig. 3, Table 3). 

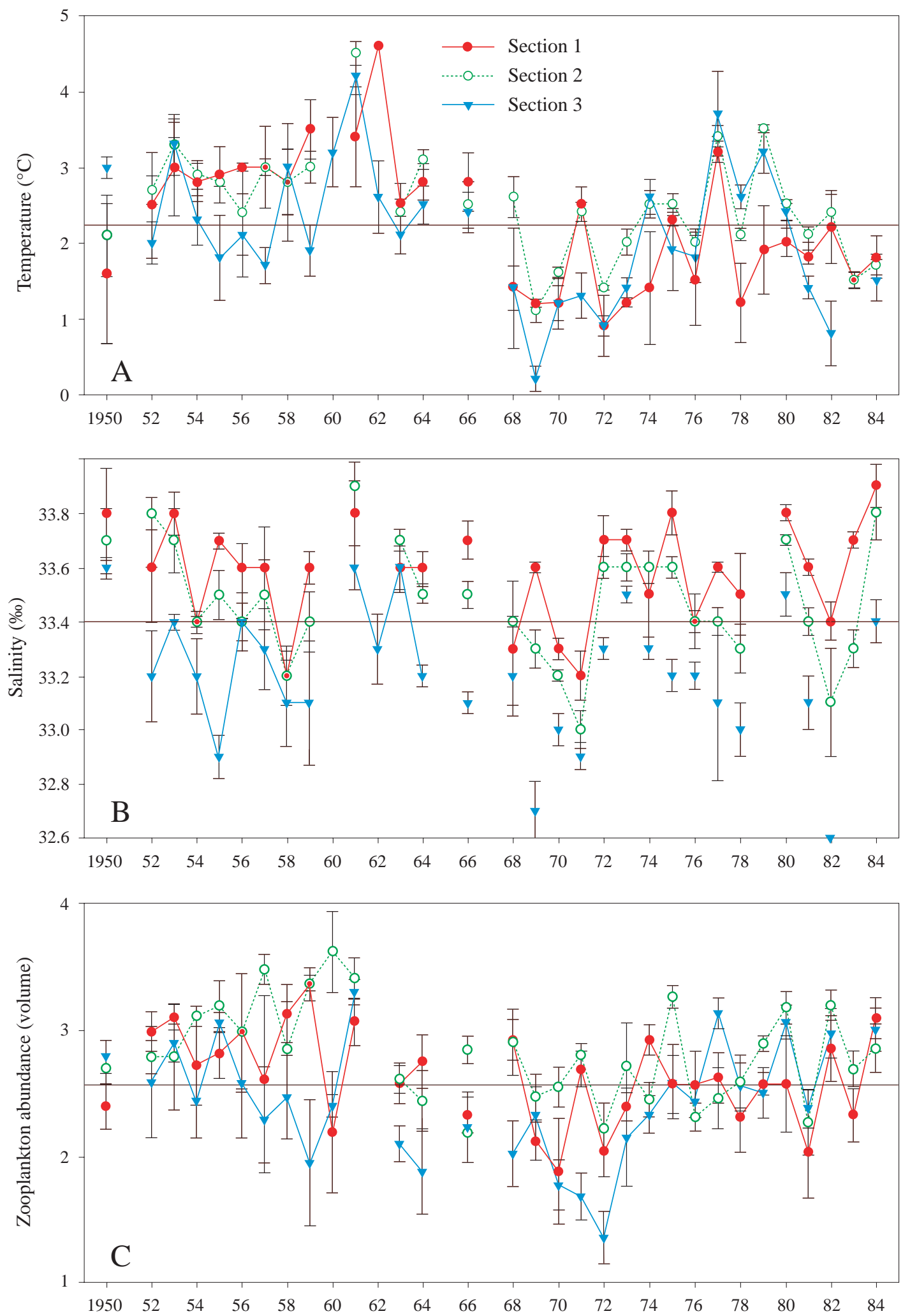

Fig. 3. Mean with standard error (A) sea temperature and (B) salinity of the 10-50 m layer, and (C) zooplankton displacement volume $(\mathrm{ml})[\log 10(x+1)]$ in June-July by year and section (see Appendix 1). Horizontal reference lines indicate long-term mean (1950-84). 
TABLE 3. Results of nonparametric multi-way analysis of variance (ANOVA) of hydrography data and abundance indices of different zooplankton taxa from individual stations. $D F=$ degrees of freedom. $0.00=(\operatorname{Pr}<0.005)$. Abbreviations shown in Table 2.

\begin{tabular}{|c|c|c|c|c|c|c|}
\hline & \multicolumn{6}{|c|}{ Source of variation } \\
\hline & Year & Section & Depth & Month & $\begin{array}{l}\text { Year } \times \\
\text { Section }\end{array}$ & $\begin{array}{l}\text { Year } \times \\
\text { Month }\end{array}$ \\
\hline Dependent variable=MTEMP & & & Total $D F=454$ & & $e=0.75$ & \\
\hline$D F$ & 31 & 2 & 10 & 1 & 57 & 13 \\
\hline$F$ Value & 12.41 & 8.55 & 9.32 & 50.34 & 1.95 & 2.04 \\
\hline $\operatorname{Pr}>F$ & 0.00 & 0.00 & 0.00 & 0.00 & 0.00 & 0.02 \\
\hline Dependent variable $=$ MSAL & & & Total $D F=427$ & & $e=0.78$ & \\
\hline$D F$ & 29 & 2 & 10 & 1 & 54 & 10 \\
\hline$F$ Value & 13.52 & 157.81 & 8.61 & 17.51 & 1.84 & 1.79 \\
\hline $\operatorname{Pr}>F$ & 0.00 & 0.00 & 0.00 & 0.00 & 0.00 & 0.06 \\
\hline Dependent variable $=$ PLVOL & & & Total $D F=531$ & & $e=0.66$ & \\
\hline$D F$ & 31 & 2 & 10 & 1 & 58 & 13 \\
\hline$F$ Value & 5.6 & 13.9 & 13.06 & 62.17 & 1.8 & 2.59 \\
\hline $\operatorname{Pr}>F$ & 0.00 & 0.00 & 0.00 & 0.00 & 0.00 & 0.00 \\
\hline Dependent variable $=$ AGLA & & & Total $D F=270$ & & $e=0.69$ & \\
\hline$D F$ & 20 & 2 & 10 & 1 & 28 & 2 \\
\hline$F$ Value & 10.48 & 11.46 & 8.52 & 2.5 & 0.91 & 1.38 \\
\hline $\operatorname{Pr}>F$ & 0.00 & 0.00 & 0.00 & 0.12 & 0.60 & 0.26 \\
\hline Dependent variable $=\mathrm{COP}$ & & & Total $D F=268$ & & $e=0.58$ & \\
\hline$D F$ & 20 & 2 & 10 & 1 & 28 & 2 \\
\hline$F$ Value & 5.78 & 2.57 & 4.84 & 2.95 & 2.27 & 0.14 \\
\hline $\operatorname{Pr}>F$ & 0.00 & 0.08 & 0.00 & 0.09 & 0.00 & 0.87 \\
\hline Dependent variable $=$ CALFI & & & Total $D F=226$ & & $e=0.56$ & \\
\hline$D F$ & 18 & 2 & 10 & 1 & 22 & 2 \\
\hline$F$ Value & 4.95 & 7.42 & 3.64 & 1.47 & 1.73 & 0.28 \\
\hline $\operatorname{Pr}>F$ & 0.00 & 0.00 & 0.00 & 0.23 & 0.03 & 0.76 \\
\hline Dependent variable $=\mathrm{CALHY}$ & & & Total $D F=226$ & & $e=0.60$ & \\
\hline$D F$ & 18 & 2 & 10 & 1 & 22 & 2 \\
\hline$F$ Value & 7.39 & 5.14 & 3.28 & 2.73 & 0.78 & 0.42 \\
\hline $\operatorname{Pr}>F$ & 0.00 & 0.01 & 0.00 & 0.10 & 0.75 & 0.66 \\
\hline Dependent variable $=\mathrm{EUCH}$ & & & Total $D F=230$ & & $=0.54$ & \\
\hline$D F$ & 18 & 2 & 10 & 1 & 22 & 2 \\
\hline$F$ Value & 4.18 & 0.77 & 5.19 & 1.02 & 2.51 & 0.86 \\
\hline $\operatorname{Pr}>F$ & 0.00 & 0.47 & 0.00 & 0.31 & 0.00 & 0.43 \\
\hline Dependent variable $=$ HYPER & & & Total $D F=270$ & & $e=0.50$ & \\
\hline$D F$ & 20 & 2 & 10 & 1 & 28 & 2 \\
\hline$F$ Value & 4.18 & 0.5 & 5.74 & 0.59 & 2.5 & 0.66 \\
\hline $\operatorname{Pr}>F$ & 0.00 & 0.61 & 0.00 & 0.44 & 0.00 & 0.52 \\
\hline Dependent variable $=$ EUP & & & Total $D F=269$ & & $e=0.50$ & \\
\hline$D F$ & 20 & 2 & 10 & 1 & 28 & 2 \\
\hline$F$ Value & 3.74 & 1.84 & 5.42 & 0.28 & 1.44 & 0.52 \\
\hline $\operatorname{Pr}>F$ & 0.00 & 0.16 & 0.00 & 0.60 & 0.08 & 0.60 \\
\hline
\end{tabular}


TABLE 3. (Continued). Results of nonparametric multi-way analysis of variance (ANOVA) of hydrography data and abundance indices of different zooplankton taxa from individual stations. $D F=$ degrees of freedom. $0.00=$ $(\operatorname{Pr}<0.005)$. Abbreviations shown in Table 2.

\begin{tabular}{|c|c|c|c|c|c|c|}
\hline \multirow{3}{*}{ Dependent variable=LIMR } & \multicolumn{6}{|c|}{ Source of variation } \\
\hline & Year & Section & Depth & Month & Section & Month \\
\hline & & & Total $D F=257$ & & $=0.65$ & \\
\hline$D F$ & 20 & 2 & 10 & 1 & 27 & 2 \\
\hline$F$ Value & 6.76 & 18.6 & 6.51 & 0.65 & 2.75 & 0.26 \\
\hline $\operatorname{Pr}>F$ & 0.00 & 0.00 & 0.00 & 0.42 & 0.00 & 0.77 \\
\hline Dependent variable $=\mathrm{LIMH}$ & & & Total $D F=258$ & & are $=0.68$ & \\
\hline$D F$ & 20 & 2 & 10 & 1 & 28 & 2 \\
\hline$F$ Value & 8.68 & 11.51 & 5.21 & 2.44 & 3.07 & 0.19 \\
\hline $\operatorname{Pr}>F$ & 0.00 & 0.00 & 0.00 & 0.12 & 0.00 & 0.83 \\
\hline Dependent variable $=$ CLIO & & & Total $D F=270$ & & are $=0.56$ & \\
\hline$D F$ & 20 & 2 & 10 & 1 & 28 & 2 \\
\hline$F$ Value & 5.31 & 0.4 & 2.97 & 8.35 & 2.55 & 3.27 \\
\hline $\operatorname{Pr}>F$ & 0.00 & 0.67 & 0.00 & 0.00 & 0.00 & 0.04 \\
\hline Dependent variable $=\mathrm{CHAE}$ & & & Total $D F=270$ & & $\operatorname{are}=0.53$ & \\
\hline$D F$ & 20 & 2 & 10 & 1 & 28 & 2 \\
\hline$F$ Value & 4.5 & 3.51 & 6.99 & 2.02 & 1.67 & 0.3 \\
\hline $\operatorname{Pr}>F$ & 0.00 & 0.03 & 0.00 & 0.16 & 0.02 & 0.74 \\
\hline Dependent variable $=\mathrm{SHR}$ & & & Total $D F=262$ & & are $=0.46$ & \\
\hline$D F$ & 19 & 2 & 10 & 1 & 27 & 2 \\
\hline$F$ Value & 4.1 & 0.51 & 3.67 & 0.01 & 1.4 & 0.59 \\
\hline $\operatorname{Pr}>F$ & 0.00 & 0.60 & 0.00 & 0.91 & 0.10 & 0.56 \\
\hline Dependent variable $=\mathrm{CRAB}$ & & & Total $D F=270$ & & $\operatorname{are}=0.55$ & \\
\hline$D F$ & 20 & 2 & 10 & 1 & 28 & 2 \\
\hline$F$ Value & 4.58 & 15.18 & 4.04 & 0.77 & 1.55 & 0.04 \\
\hline $\operatorname{Pr}>F$ & 0.00 & 0.00 & 0.00 & 0.38 & 0.04 & 0.96 \\
\hline Dependent variable $=$ GONA & & & Total $D F=261$ & & $\operatorname{are}=0.59$ & \\
\hline$D F$ & 19 & 2 & 10 & 1 & 28 & 1 \\
\hline$F$ Value & 4.53 & 7.15 & 11.67 & 0.01 & 1.59 & 0 \\
\hline $\operatorname{Pr}>F$ & 0.00 & 0.00 & 0.00 & 0.92 & 0.04 & 0.95 \\
\hline Dependent variable $=\mathrm{COD}$ & & & Total $D F=550$ & & are $=0.47$ & \\
\hline$D F$ & 31 & 2 & 10 & 1 & 59 & 15 \\
\hline$F$ Value & 4.49 & 11.9 & 1.61 & 5.06 & 1.69 & 2.17 \\
\hline $\operatorname{Pr}>F$ & 0.00 & 0.00 & 0.10 & 0.03 & 0.00 & 0.01 \\
\hline Dependent variable $=\mathrm{GHL}$ & & & Total $D F=550$ & & $\operatorname{are}=0.57$ & \\
\hline$D F$ & 31 & 2 & 10 & 1 & 59 & 15 \\
\hline$F$ Value & 2.78 & 69.08 & 12.04 & 12.41 & 1.74 & 1.68 \\
\hline $\operatorname{Pr}>F$ & 0.00 & 0.00 & 0.00 & 0.00 & 0.00 & 0.05 \\
\hline Dependent variable $=$ RED & & & Total $D F=550$ & & $\operatorname{are}=0.38$ & \\
\hline$D F$ & 31 & 2 & 10 & 1 & 59 & 15 \\
\hline$F$ Value & 2.78 & 1.54 & 1.15 & 4.4 & 1.5 & 2.65 \\
\hline $\operatorname{Pr}>F$ & 0.00 & 0.22 & 0.32 & 0.04 & 0.01 & 0.00 \\
\hline Dependent variable $=$ PLA & & & Total $D F=550$ & & $\operatorname{are}=0.52$ & \\
\hline$D F$ & 31 & 2 & 10 & 1 & 59 & 15 \\
\hline$F$ Value & 3.28 & 51.23 & 5.36 & 1.3 & 1.67 & 1.12 \\
\hline $\operatorname{Pr}>F$ & 0.00 & 0.00 & 0.00 & 0.26 & 0.00 & 0.34 \\
\hline
\end{tabular}


TABLE 3. (Continued). Results of nonparametric multi-way analysis of variance (ANOVA) of hydrography data and abundance indices of different zooplankton taxa from individual stations. $D F=$ degrees of freedom. $0.00=(\operatorname{Pr}<0.005)$. Abbreviations shown in Table 2 .

\begin{tabular}{|c|c|c|c|c|c|c|}
\hline & \multicolumn{6}{|c|}{ Source of variation } \\
\hline & Year & Section & Depth & Month & $\begin{array}{l}\text { Year } \times \\
\text { Section }\end{array}$ & $\begin{array}{l}\text { Year } \times \\
\text { Month }\end{array}$ \\
\hline Dependent variable $=\mathrm{WOLF}$ & & & $D F=550$ & & are $=0.37$ & \\
\hline$D F$ & 31 & 2 & 10 & 1 & 59 & 15 \\
\hline$F$ Value & 1.64 & 12.02 & 2.82 & 2.45 & 1.28 & 0.95 \\
\hline $\operatorname{Pr}>F$ & 0.02 & 0.00 & 0.00 & 0.12 & 0.09 & 0.50 \\
\hline Dependent variable $=$ SAND & & & $D F=549$ & & are $=0.57$ & \\
\hline$D F$ & 31 & 2 & 10 & 1 & 59 & 15 \\
\hline$F$ Value & 7.68 & 13.22 & 7.37 & 4.71 & 1.41 & 2.55 \\
\hline $\operatorname{Pr}>F$ & 0.00 & 0.00 & 0.00 & 0.03 & 0.03 & 0.00 \\
\hline
\end{tabular}

Effects of year and month explained most of the variation in mean temperature. The investigated interactions were also significant but explained minor parts of the variation (Table 3). Mean salinity (MSAL) was significantly lower during 1969-71 and 1982, from section 1 to 3 (north to south) and in July. Section and month explained most of the variation in mean salinity; interactions between year and month were not significant (Table 3).

One-way ANOVA and examination of the pattern of the residuals showed a significant decreasing trend in the mean sea temperature over the period 1950-84 $\left(r^{2}=0.14, p<0.005, n=91\right)$. There was no significant trend in the salinity over the period.

\section{Zooplankton displacement volume}

Zooplankton displacement volume (PLVOL) showed decreasing trends from 1961 to 1972 (Fig. 3). PLVOL were generally higher on section 2, with increasing depth to bottom and in July. Sampling month explained most of the variations (Table 3). Distribution maps of zooplankton displacement volumes sampled in the years 1957 (warm year), 1963 (the year of the international NORWESTLANT survey - an average year for temperature) and 1982 (cold year) illustrate general trends in the data (Fig. 4). The highest densities of zooplankton were generally observed offshore in the Davis Strait, but in 1982 high densities of zooplankton were sampled inshore in the Disko Bay area (Fig. 4). Zooplankton displacement volume showed positive correlations with mean temperature and depth to bottom (Table 4).

\section{Indices of invertebrate abundance}

Aglantha digitale, including a white (WAGLA) and a red (RAGLA) form, showed a decreasing trend during the 1960s and an increasing trend from the early-1970s onwards (Fig. 5). Sampling section explained most of the variation and $A$. digitale showed a trend of higher abundance on section 2 (Table 3). Distribution maps of abundance indices of A. digitale in 1957, 1964 and 1982 illustrate trends in the data (Fig. 6). Aglantha digitale were generally more abundant in the deeper parts of Davis Strait, however, in 1982 high densities of the red form was sampled inshore in Disko Bay area (Fig. 6). The white form was positively correlated with temperature, whereas the red form was negatively correlated with temperature (Table 4).

Copepods (COP), Calanus finmarchicus (CALFI) and $C$. hyperboreus (CALHY) abundance indices showed decreasing trends during the 1960s, and copepods and $C$. hyperboreus increase again from 1977 onwards (Fig. 5). C. finmarchicus and C. hyperboreus showed trends of being more abundant on section 3 and 2, respectively. Highest abundances of $C$. finmarchicus and C. hyperboreus were observed in the Davis Strait and in Disko Bay with a trend of $C$. hyperboreus being more abundant than $C$. finmarchicus in Southwest Greenland (Fig. 7 and 8). The abundance of $C$. finmarchicus and $C$. hyperboreus were correlated $(r=0.57, p<0.005, n=227)$ and the abundance of both species showed correlations with the abundance of e.g. Pandalus shrimp larvae, juvenile squids (Gonatus fabricii), and larval fish of American 

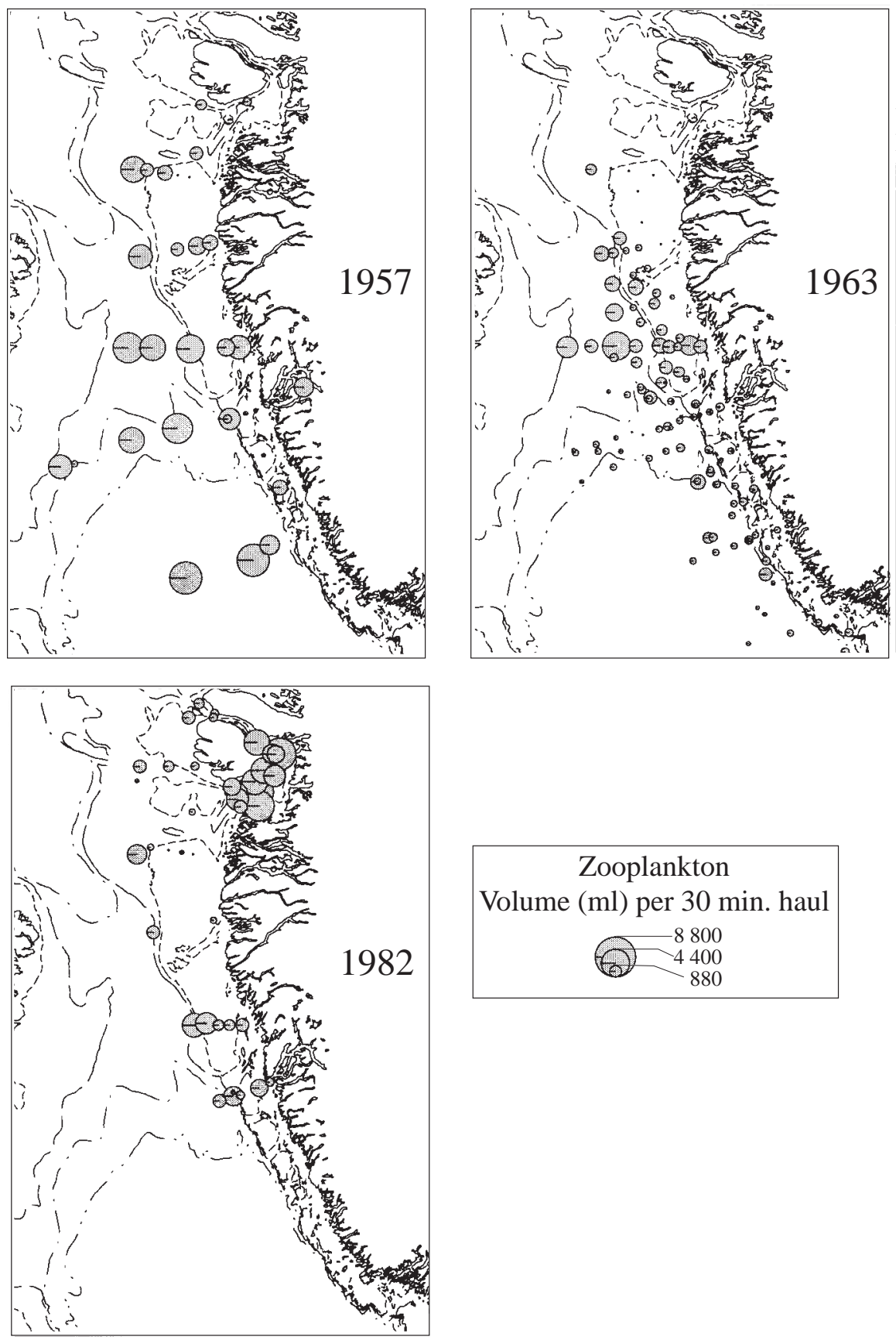

Fig. 4. Zooplankton displacement volume (ml) per $30 \mathrm{~min}$. haul; all samples in JuneJuly 1957, 1963 and 1982. Dot diameter is graduated by square root of the displacement volume.

plaice, and Greenland halibut (Table 4). The abundance of $C$. finmarchicus and $C$. hyperboreus showed no correlations with temperature or salinity (Table 4).

Euchaeta norwegica (EUCH) showed trends of being most abundant on section 2 and over deep water (above 500 m) (Fig. 9). Euchaeta norwegica showed relatively high abundance in the mid-1970s where the abundance of $C$. finmarchicus and C. hyperboreus were nil (Fig. 5). Euchaeta norwegica abundance was positively correlated with several zooplankton taxa e.g. C. finmarchicus $(r=0.52, p<0.005, n=222)$; but not with temperature or salinity (Table 4 ). 


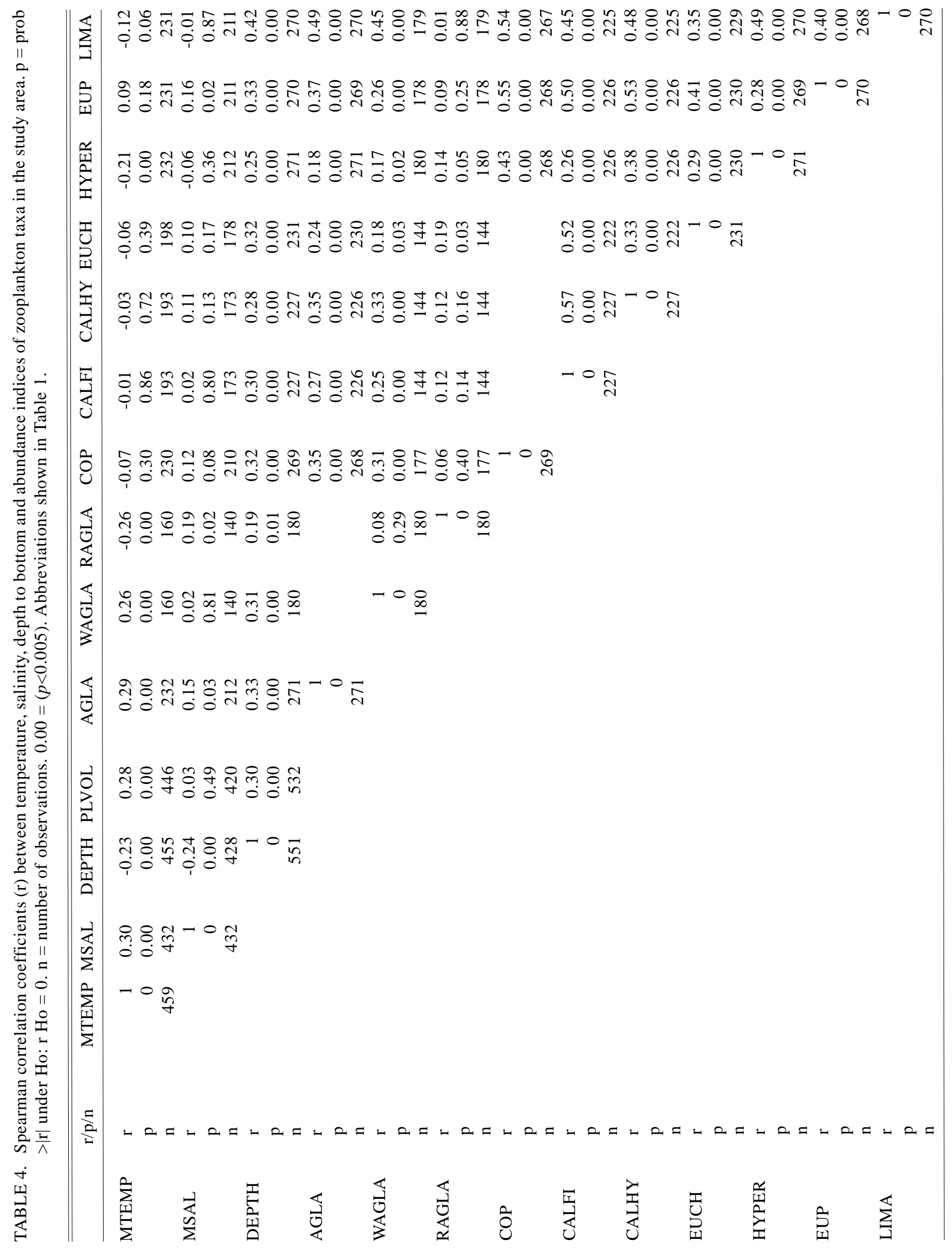




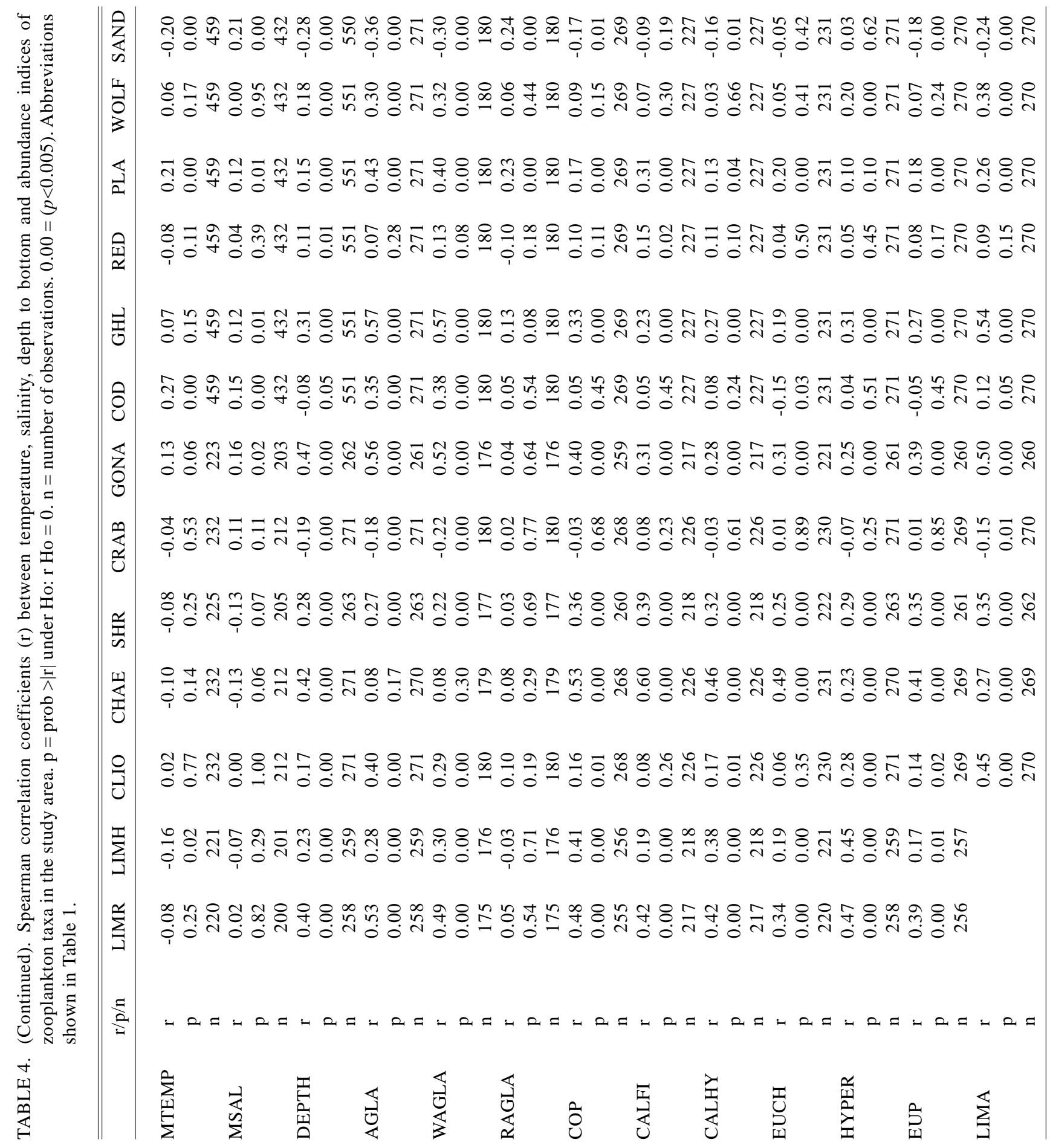




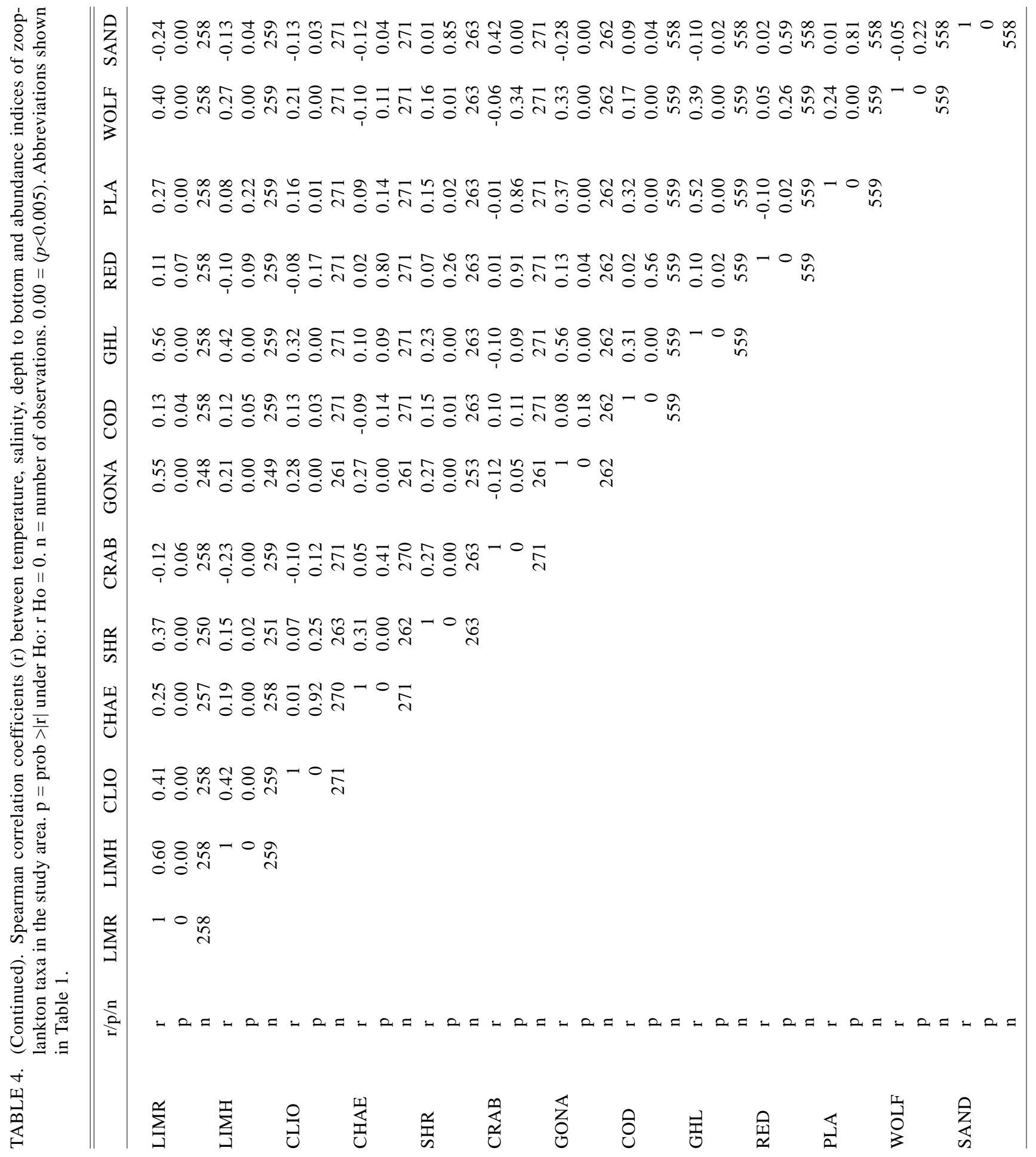



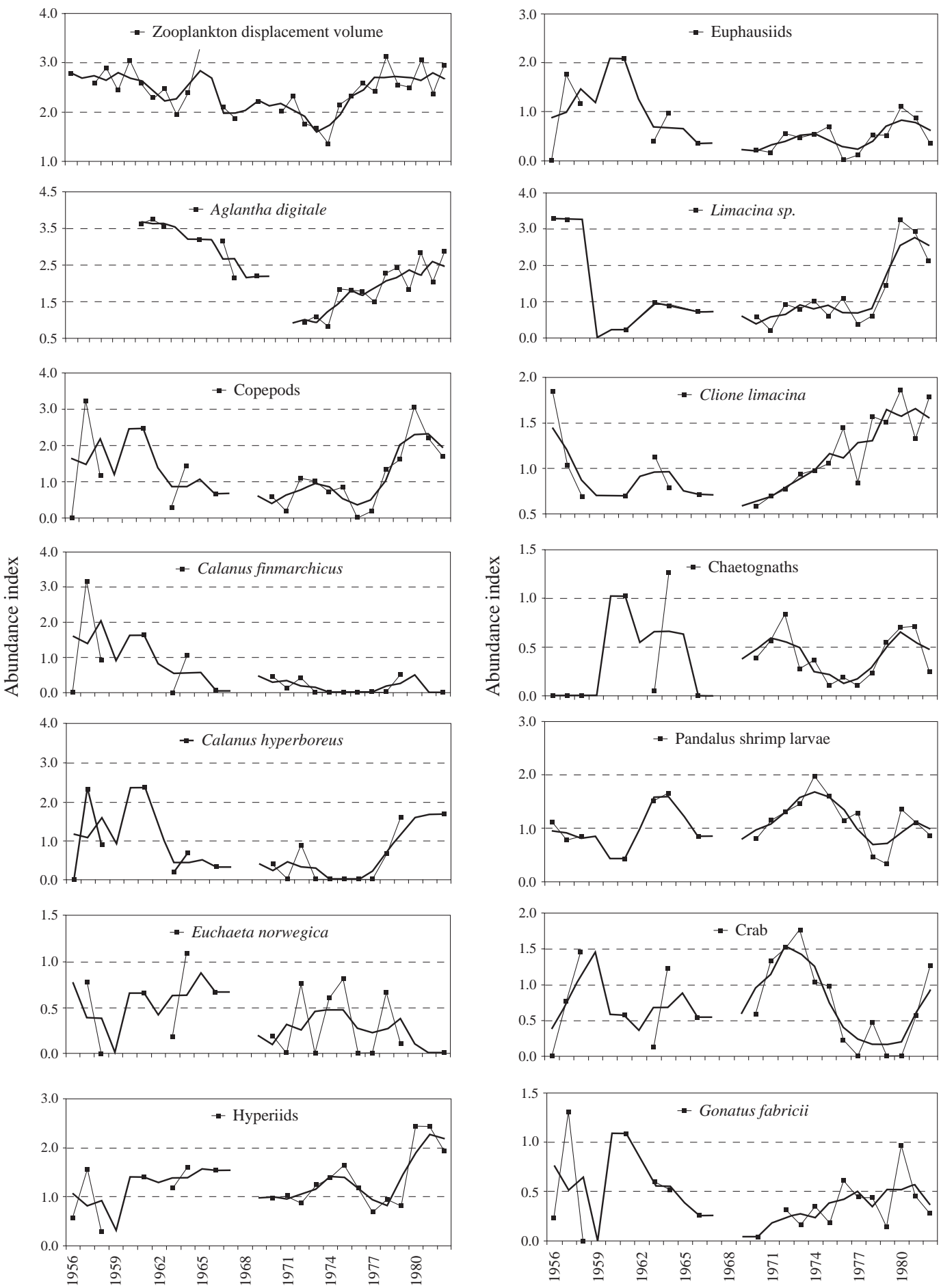

Fig. 5. Indices of invertebrate abundance. Mean of logarithmic transformed data $[\log 10(x+1)]$ from the Fylla Bank section (S3) (see Appendix 2). Trends were smoothed by taking 3-year running averages (heavy solid line).

Hyperiids (HYPER) were more abundant in 1980, 1981 and 1982, over deep water in Davis Strait and in
Disko Bay (Fig. 5, and Fig. 10). The abundance of hyperiids were positively correlated with several 

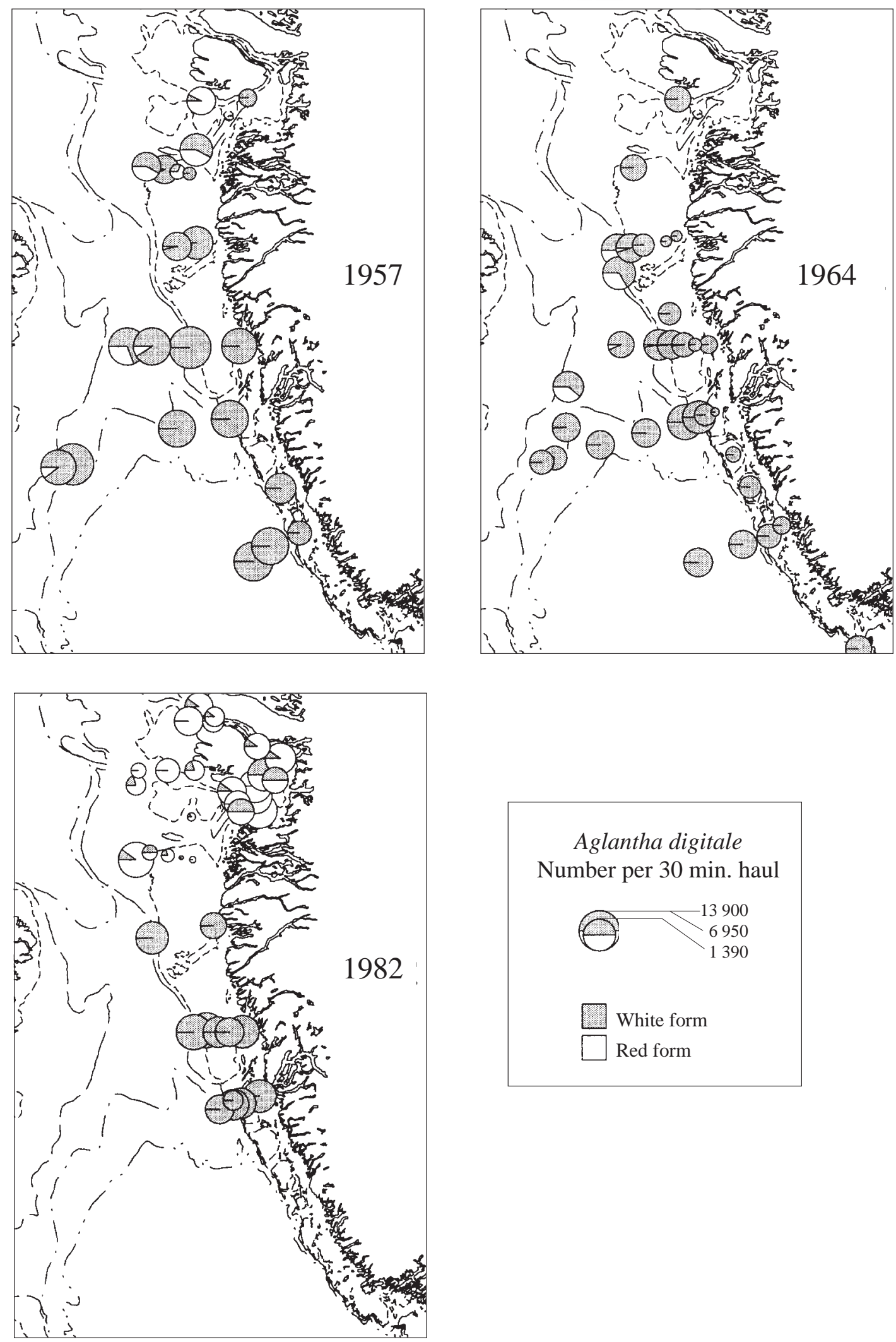

Fig. 6. Number of Aglantha digitale (white (WAGLA) and red (RAGLA) form) per 30 min. haul; all samples in June-July 1957, 1964 and 1982. Dot diameter is graduated by log (number of Aglantha digitale). 1964 used for comparison instead of 1963 as there was no sorting in red and white in 1963. 


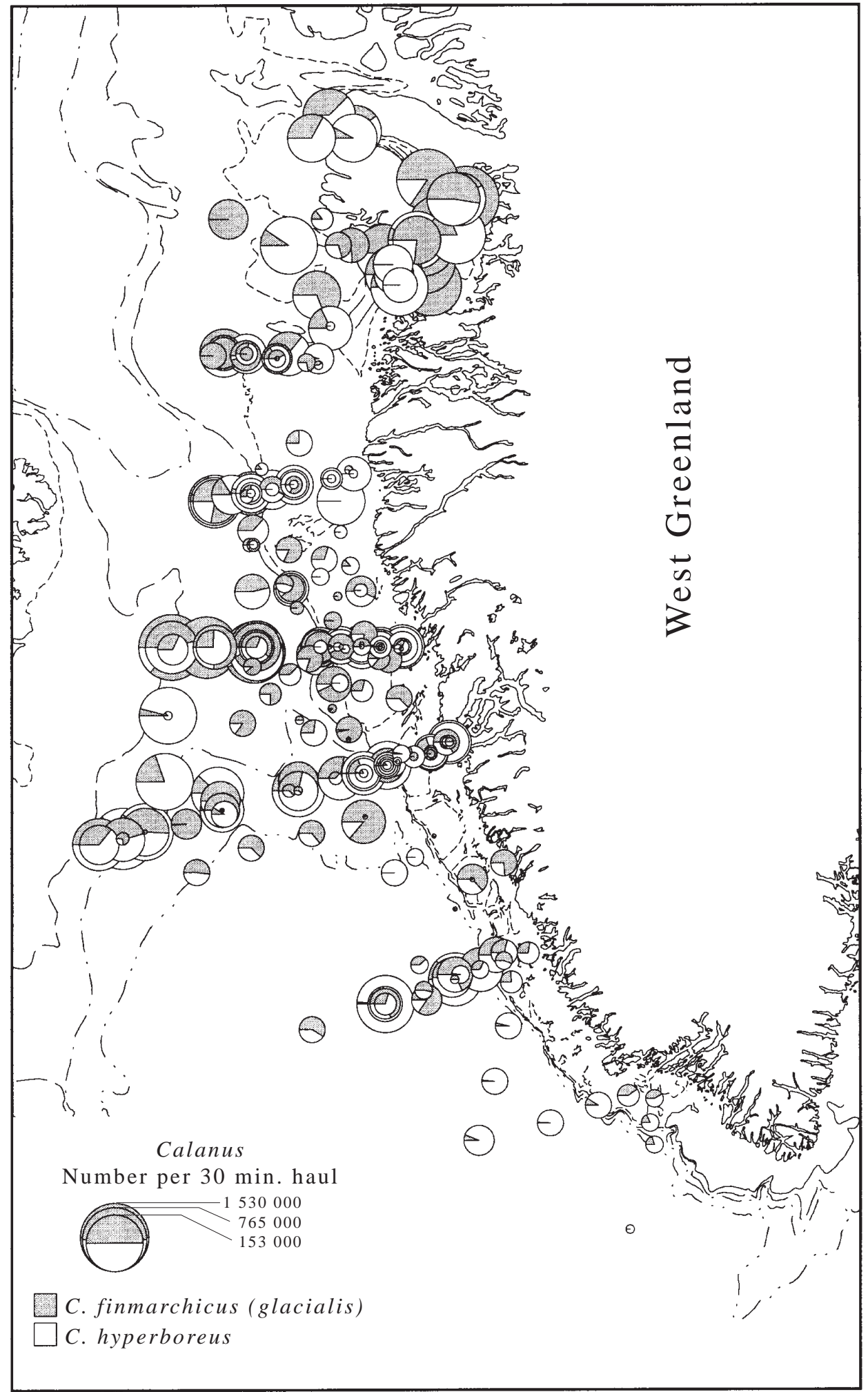

Fig. 7. Number of Calanus (C. finmarchicus (glacialis) (CALFI) and C. hyperboreus (CALHY)) per $30 \mathrm{~min}$. haul; all samples in June-July 1956-83. Dot diameter is graduated by $\log$ (number of Calanus). 

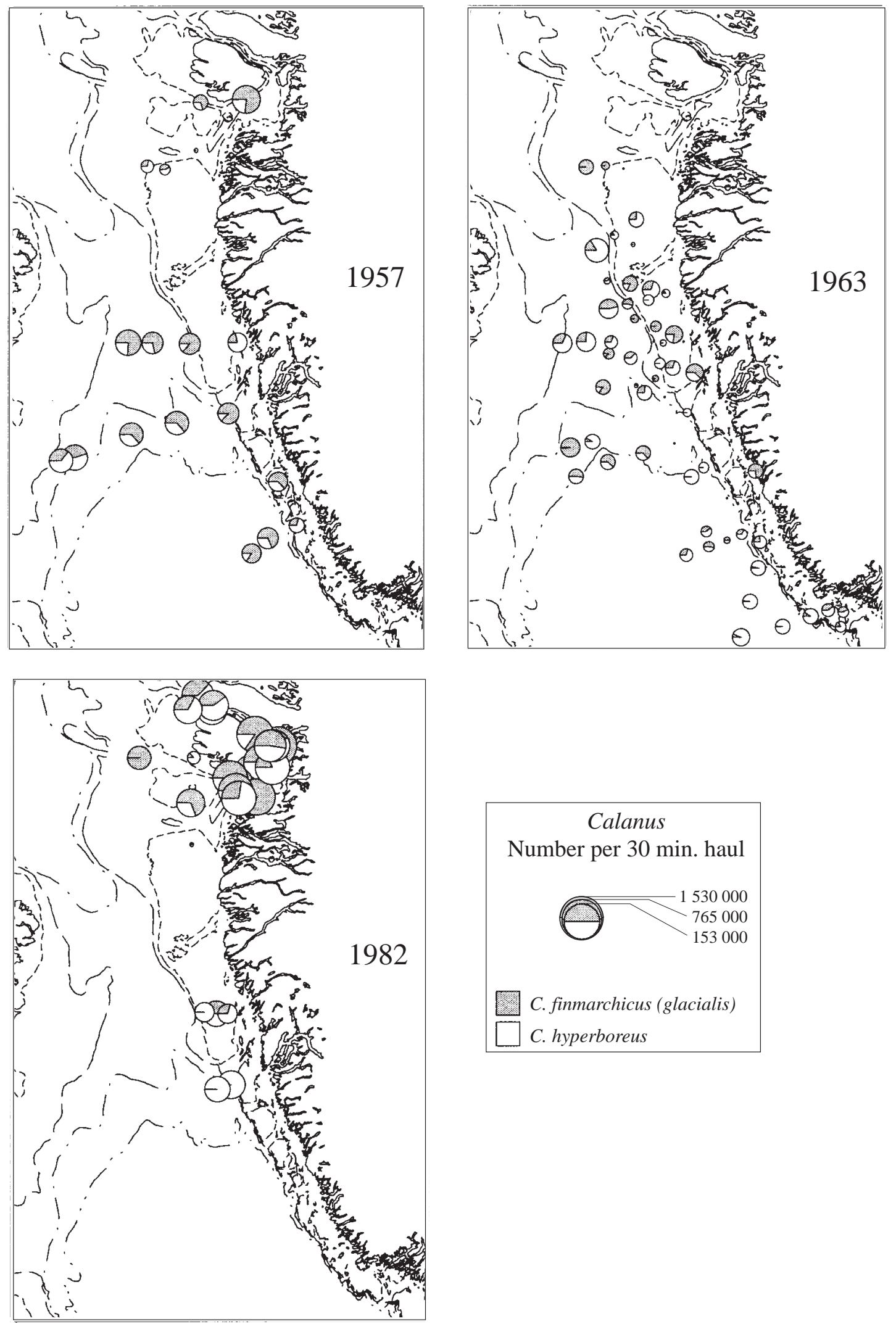

Fig. 8. Number of Calanus (C. finmarchicus (glacialis) (CALFI) and C. hyperboreus (CALHY)) per 30 min. haul; all samples in June-July 1957, 1963 and 1982. Dot diameter is graduated by log (number of Calanus). 

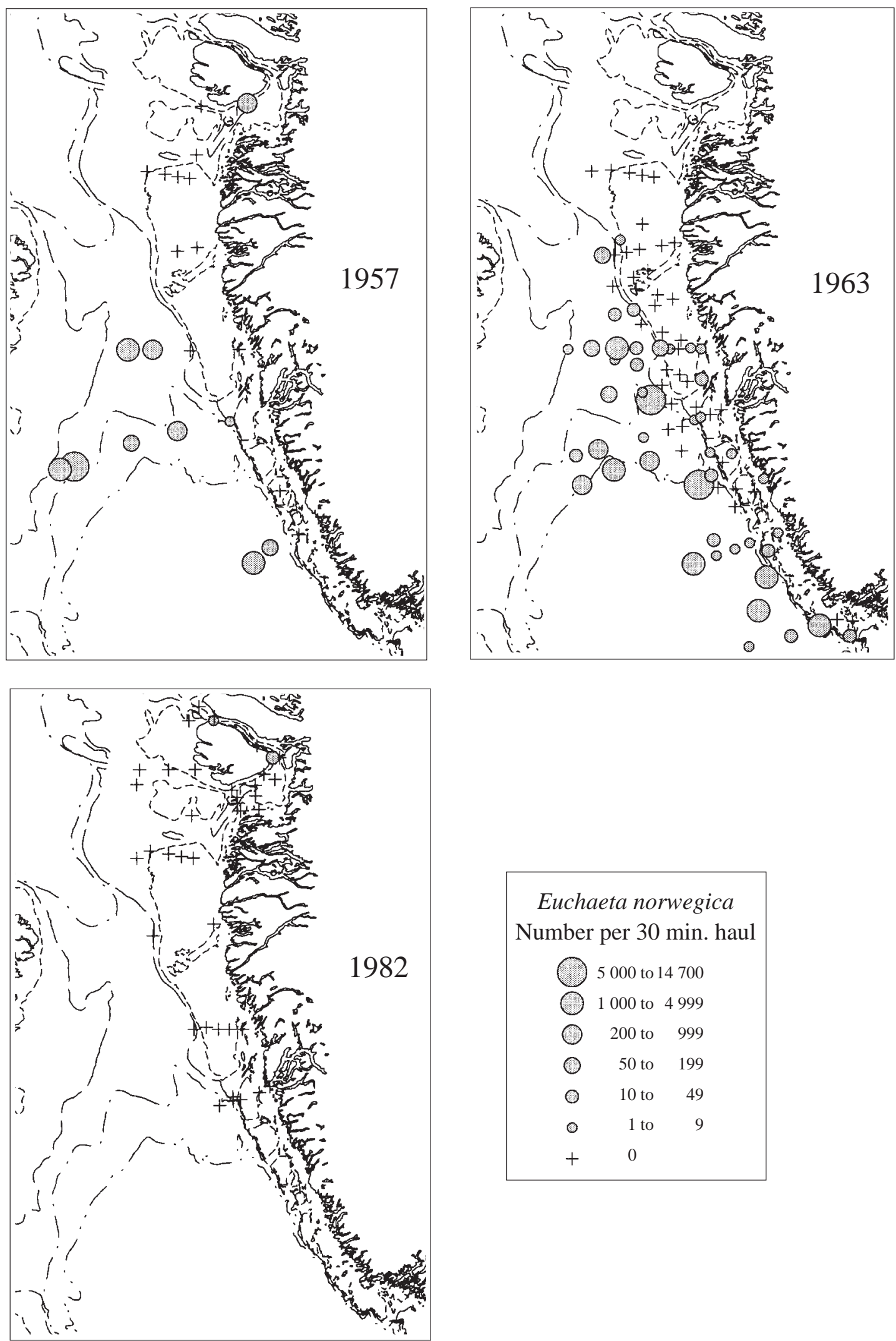

Euchaeta norwegica

Number per 30 min. haul

(O) 5000 to 14700

1000 to 4999

- 200 to 999

- 50 to 199

- 10 to 49

- 1 to 9

$+\quad 0$

Fig. 9. Number of Euchaeta norwegica (EUCH) per 30 min. haul; all samples in June-July 1957, 1963 and 1982. 


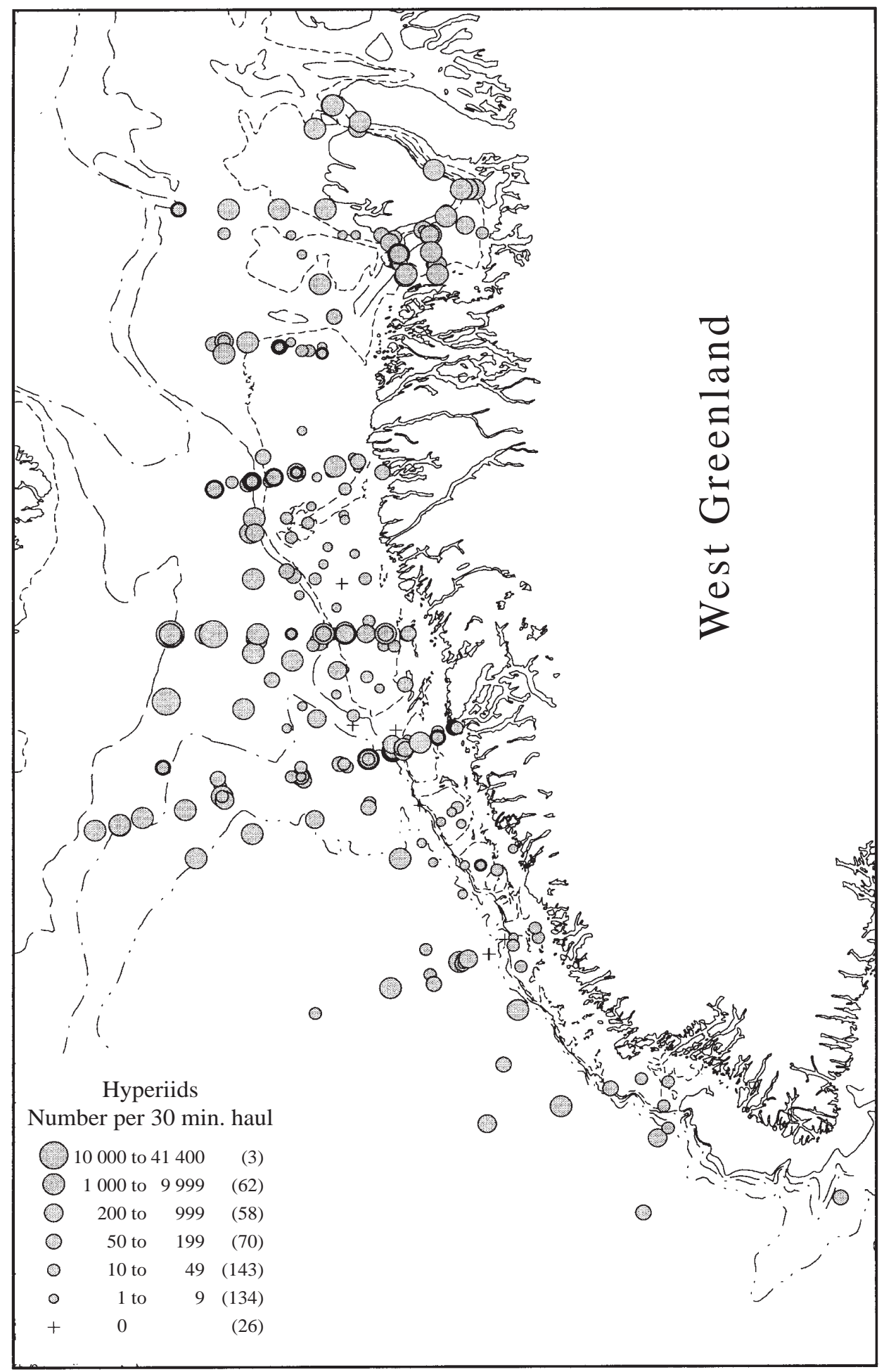

Fig. 10. Number of hyperiids (HYPER) per $30 \mathrm{~min}$. haul; all samples in June-July 1956-83. Frequency of occurrence in parentheses. 
zooplankton taxa e.g. Limacina sp., C. hyperboreus, Greenland halibut larvae and were negatively correlated with temperature (Table 4).

Euphausiid (EUP) abundance showed decreasing trend during the 1960s (Fig. 5). Euphausiids were most abundant over deep water (Fig. 11). The abundance of euphausiids was most highly correlated with copepods, chaetognaths, Limacina sp. (Table 4). Euphausiid abundance was correlated with salinity, but not with temperature (Table 4).

Limacina sp. (LIMA) and Clione limacina (CLIO) showed similar decreasing trends from the late-1950s to 1970 and increasing trends thereafter (Fig. 5). Limacina retroversa (LIMR) and L. helicina (LIMH) both showed significantly higher abundance on section 2. Although significant, there were no clear trends with depth to bottom. However, abundance indices of both species showed generally highest abundances over deep water, and L. retroversa show a more southerly distribution than L. helicina (Fig. 12). Limacina retroversa and L. helicina abundances were correlated and the abundance of both species were correlated with the abundance of e.g. Greenland halibut larvae, copepods, juvenile squids (Gonatus fabricii), and hyperiids (Table 4). Abundance of L. retroversa showed no correlation with temperature or salinity, but abundance of L. helicina was negatively correlated with temperature (Table 4). Clione limacina was generally more abundant in July and sampling month explained most of the variation (Table 3). Although the effect of depth to bottom were significant there were no trend in abundance with depth to bottom (Table 3, Fig. 13). Clione limacina abundance showed highest correlations with abundance of Limacina helicina and L. retroversa (Table 4). Abundance of $C$. limacina showed no correlation with temperature or salinity.

For chaetognaths (CHAE), depth to bottom and section explained most of the variation in the abundance indices (Table 3). Chaetognaths were generally most abundant on section 2. Although significant, trends with depth to bottom were not clear. However, high abundances of chaetognaths were observed in the deeper parts of Davis Strait and in Disko Bay (Fig. 14). Chaetognath abundance showed highest correlations with abundance of Calanus finmarchicus and no correlations with temperature or salinity (Table 4).

Shrimp larvae (SHR) were assumed to be primarily Pandalus borealis, although no documentation for this exists (see Pedersen, 1998). Sampling year and depth to bottom explained most of the variation in the abundance (Table 3). Although significant, there was no clear trend in abundance with year (Fig. 5). Shrimp larvae were generally more abundant at depth to bottom above $200 \mathrm{~m}$ and showed high abundances mainly over the West Greenland shelf and in the Disko Bay area (Fig. 15). Shrimp larvae abundance correlated most highly with copepods and Greenland halibut larvae (Table 4). Shrimp larvae abundance showed no correlation with temperature or salinity.

Crab larvae (Zoea stages) (CRAB) showed trends of being more abundant on section 1 and at depth to bottom below $300 \mathrm{~m}$ revealed from least square means of multi-way nonparametric ANOVA (Table 3). High crab larvae abundance were observed in Disko Bay (Fig. 16). Crab larvae abundance correlated positively with sandeel larvae abundance (Table 4). Crab larvae abundance and temperature or salinity showed no correlation.

Gonatus fabricii (juveniles) (GON) showed trends of being more abundant during the late-1950s and early1960 s, on section 2 and at depth to bottom above 500 m (Fig. 5, Table 3). Gonatus fabricii was abundant in hauls from the southern and deeper parts of the Davis Strait, and seldom in the northern part and in Disko Bay (Fig. 17). Abundance was positively correlated with e.g. Greenland halibut larvae, Calanus finmarchicus, Aglantha digitale, and Limacina retroversa (Table 4). Gonatus fabricii abundance was correlated with salinity but not with temperature (Table 4).

\section{Indices of larval fish abundance}

Atlantic cod larvae (COD) showed trends of being more abundant during 1950-68 and early-1980s, on section 2 and in July (Table 3, Fig. 18). Sampling section explained most of the variation (Table 3 ). There was no significant effect of depth to bottom and Atlantic cod larvae occured in hauls from coastal shelf areas as well as in the deeper parts of the Davis Strait (Fig. 19). Atlantic cod larvae abundance were positively correlated with Aglantha digitale (white form), American plaice larvae, Greenland halibut larvae, temperature and salinity (Table 4).

Greenland halibut larvae (GHL) showed trends of being more abundant on section 2, at depth to bottom above $400 \mathrm{~m}$ and in July (Table 3, Fig. 18). Sampling section explained most of the variation. There was no clear trend over the time period. Greenland halibut 


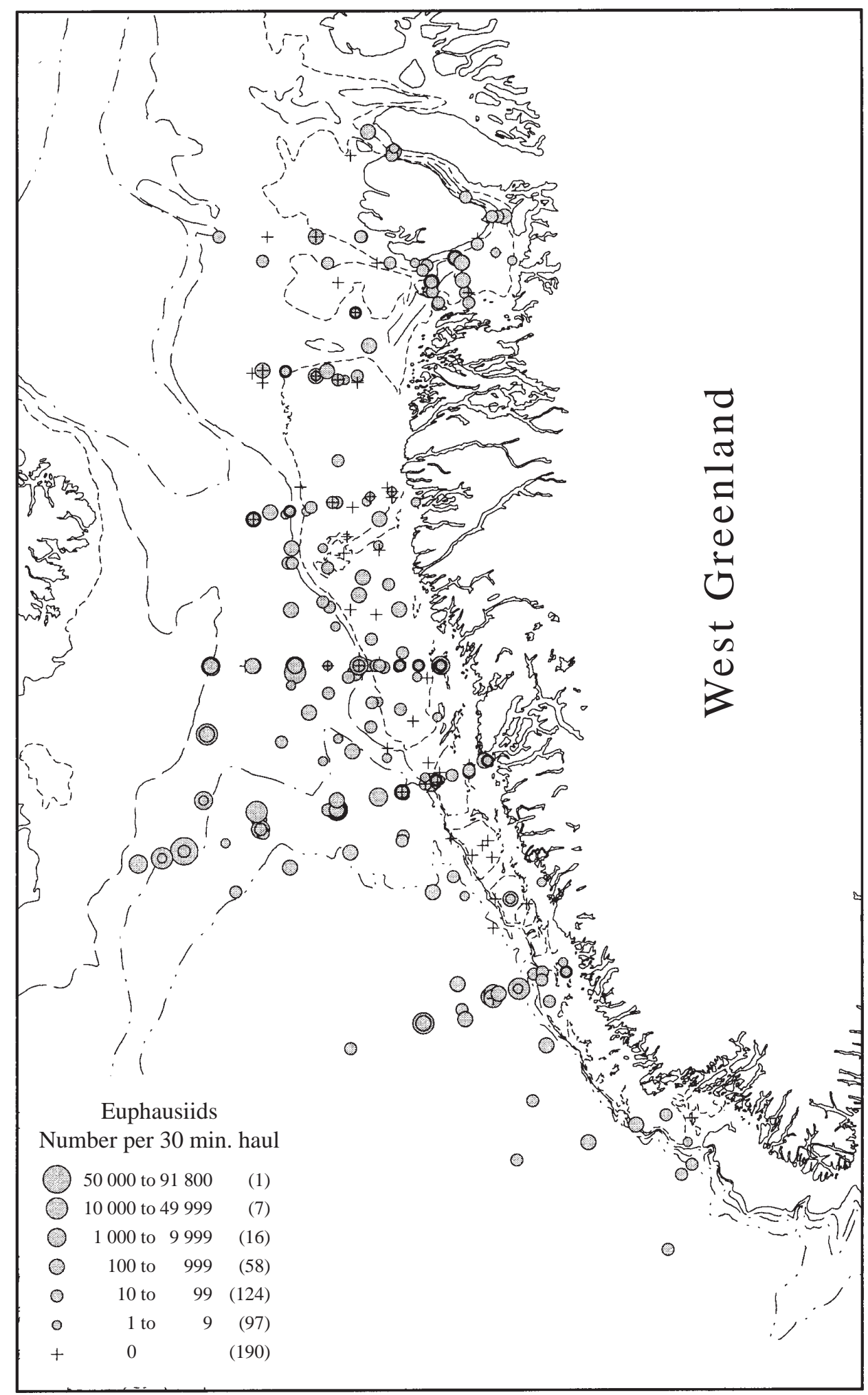

Fig. 11. Number of euphausiids (EUP) per $30 \mathrm{~min}$. haul; all samples in June-July 1956-83. Frequency of occurrence in parentheses. 

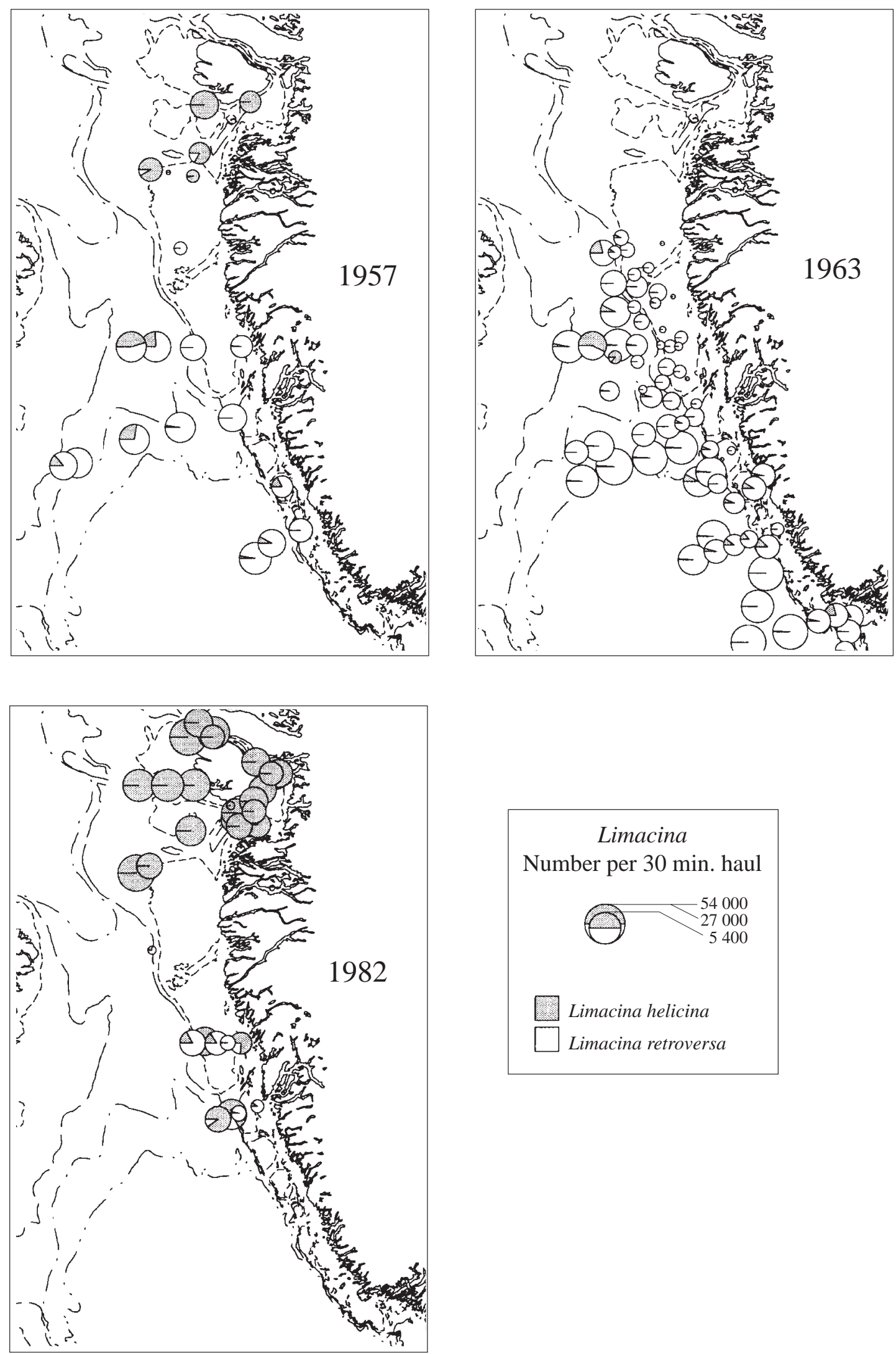

Fig. 12. Number of Limacina (L. helicina (LIMH) and L. retroversa (LIMR)) per $30 \mathrm{~min}$. haul; all samples in June-July 1957, 1963 and 1982. Dot diameter is graduated by log (number of Limacina). 

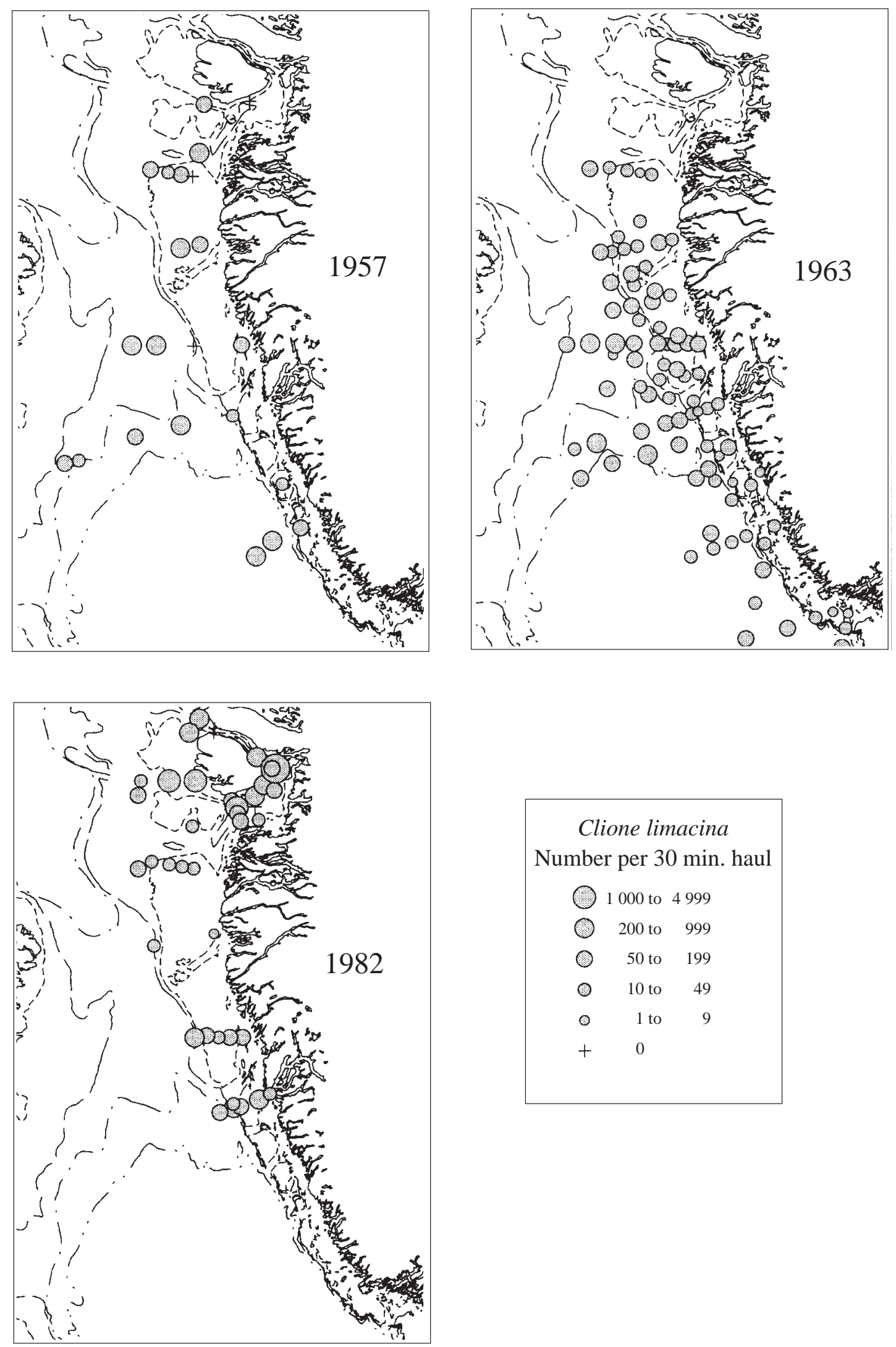

Fig. 13. Number of Clione limacina (CLIO) per 30 min. haul; all samples in June-July 1957, 1963 and 1982. 


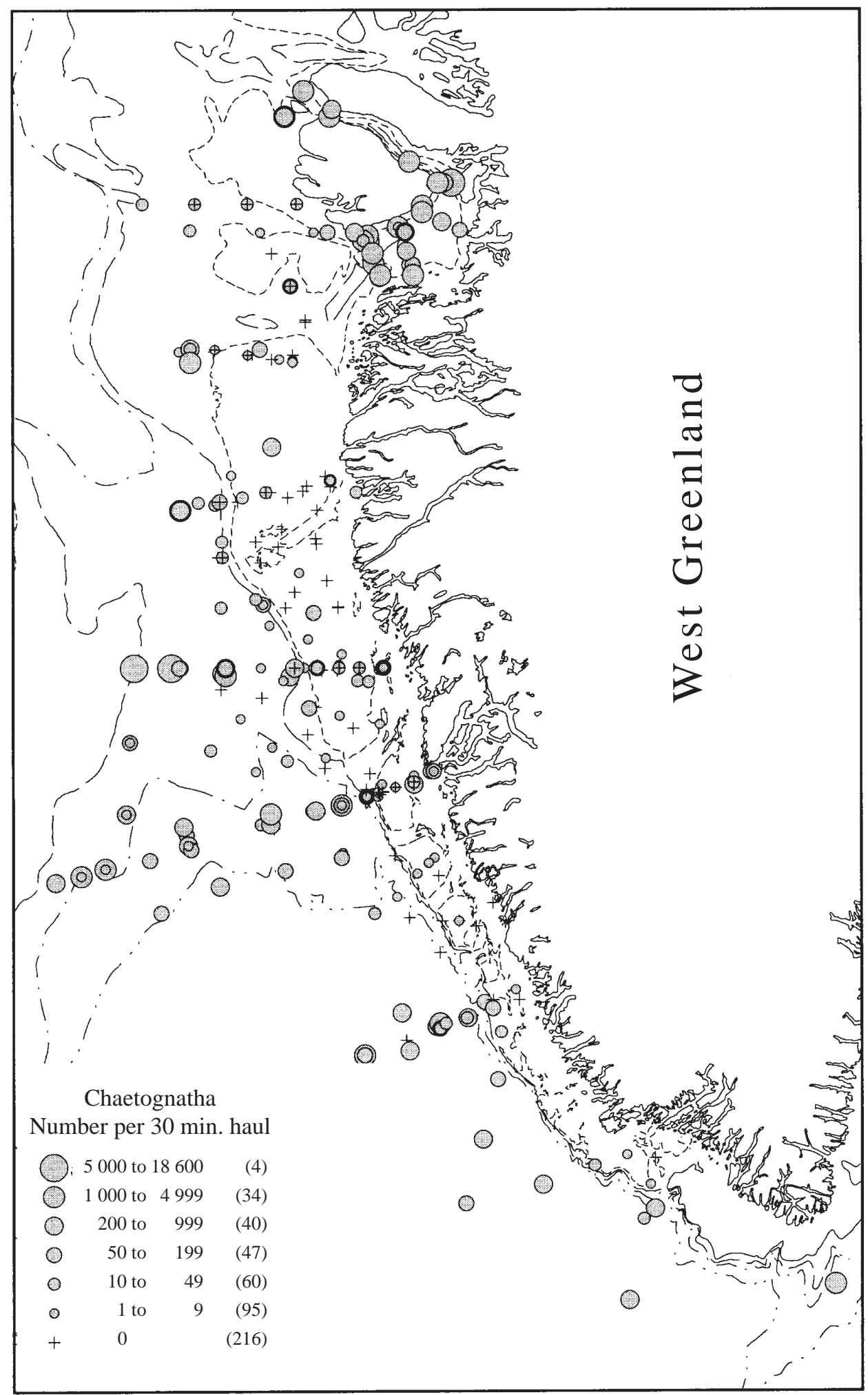

Fig. 14. Number of chaetognaths (CHAE) per $30 \mathrm{~min}$. haul; all samples in June-July 1956-83. Frequency of occurrence in parentheses. 


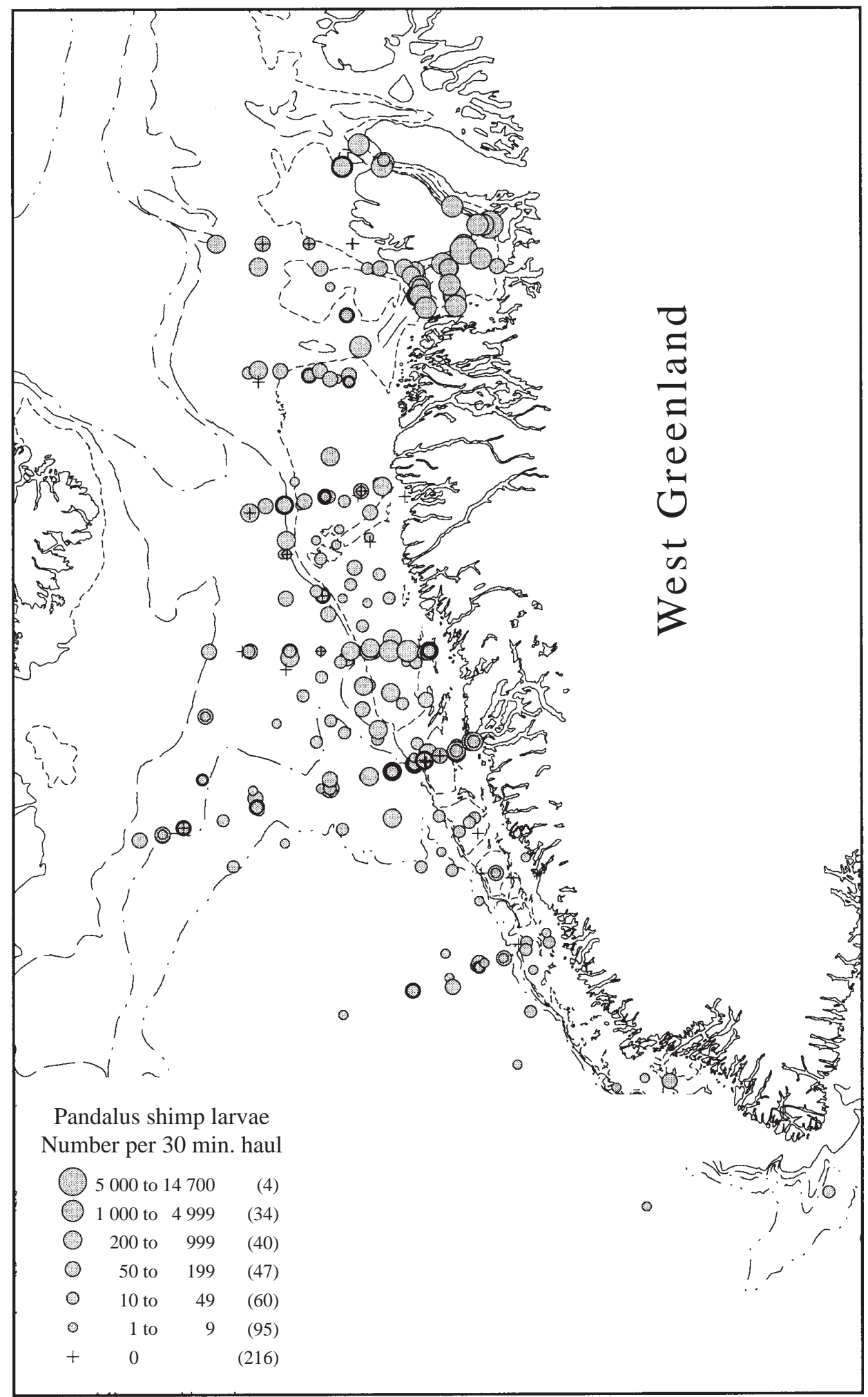

Fig. 15. Number of Pandalus shrimp larvae (mainly P. borealis) (SHR) per $30 \mathrm{~min}$. haul; all samples in June-July 1956-82. Frequency of occurrence in parentheses. 


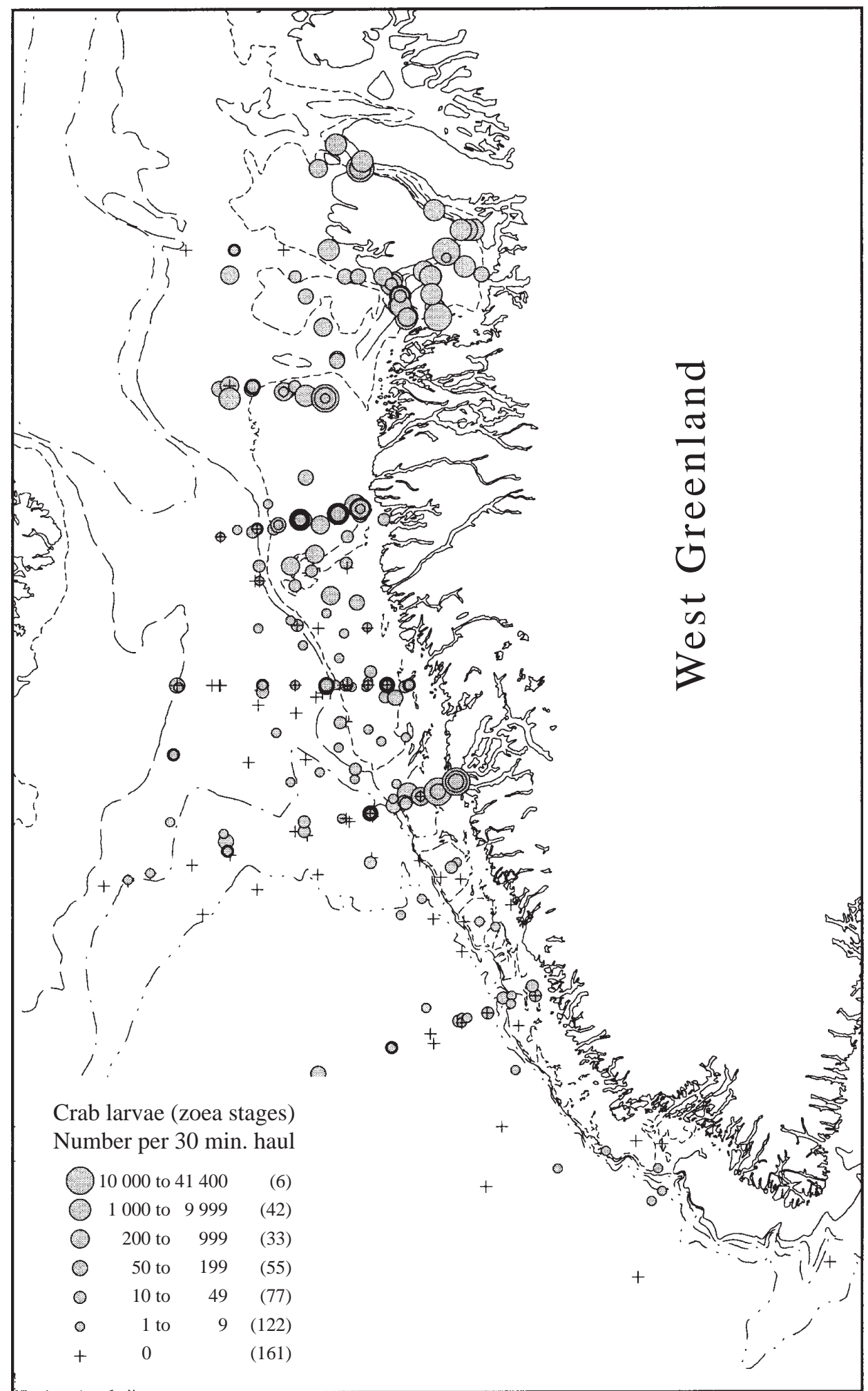

Fig. 16. Number of crab larvae (CRAB) per 30 min. haul; all samples in June-July 1956-83. Frequency of occurrence in parentheses. 


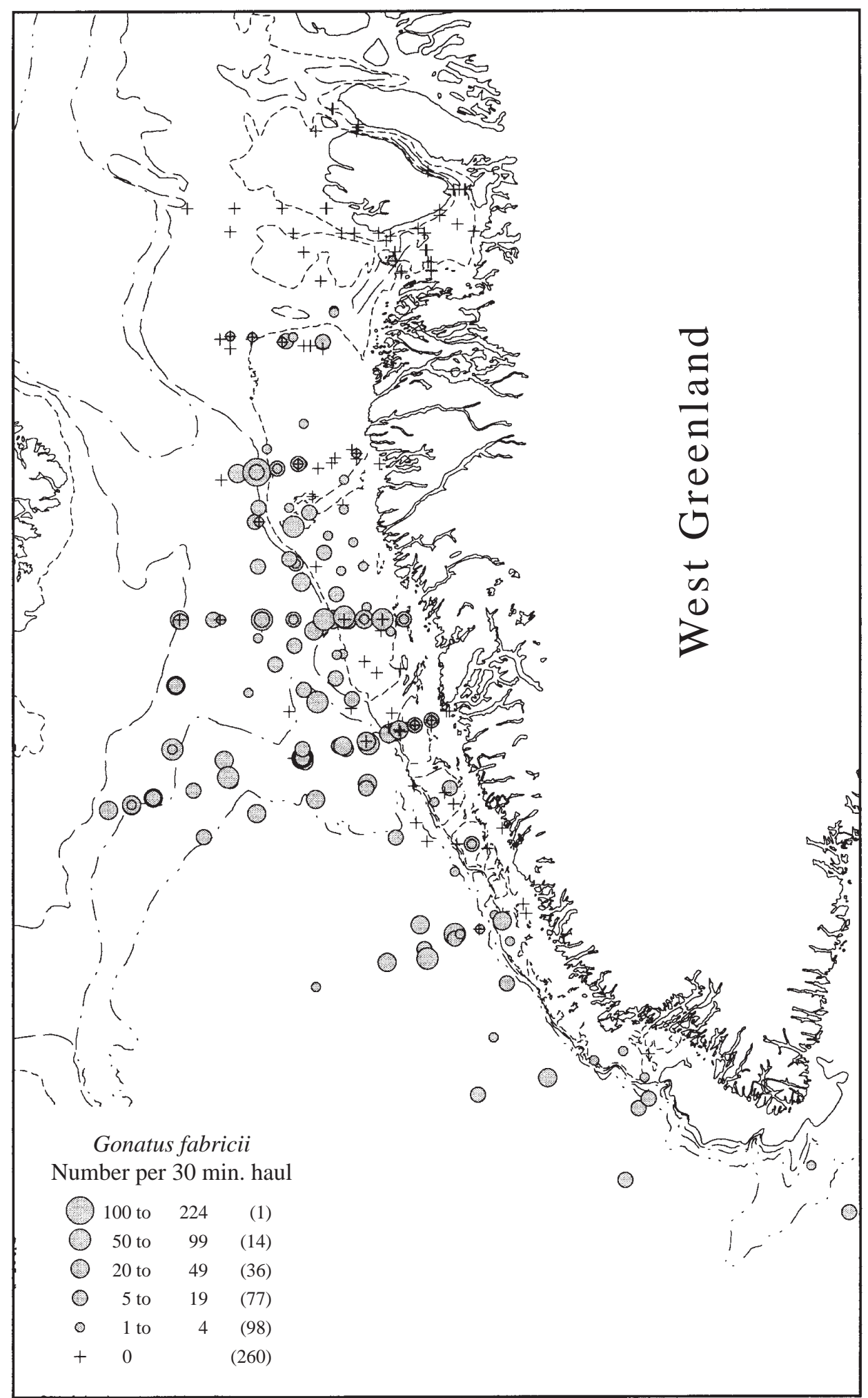

Fig. 17. Number of Gonatus fabricii (GONA) per $30 \mathrm{~min}$. haul; all samples in June-July 1956-83. Frequency of occurrence in parentheses. 

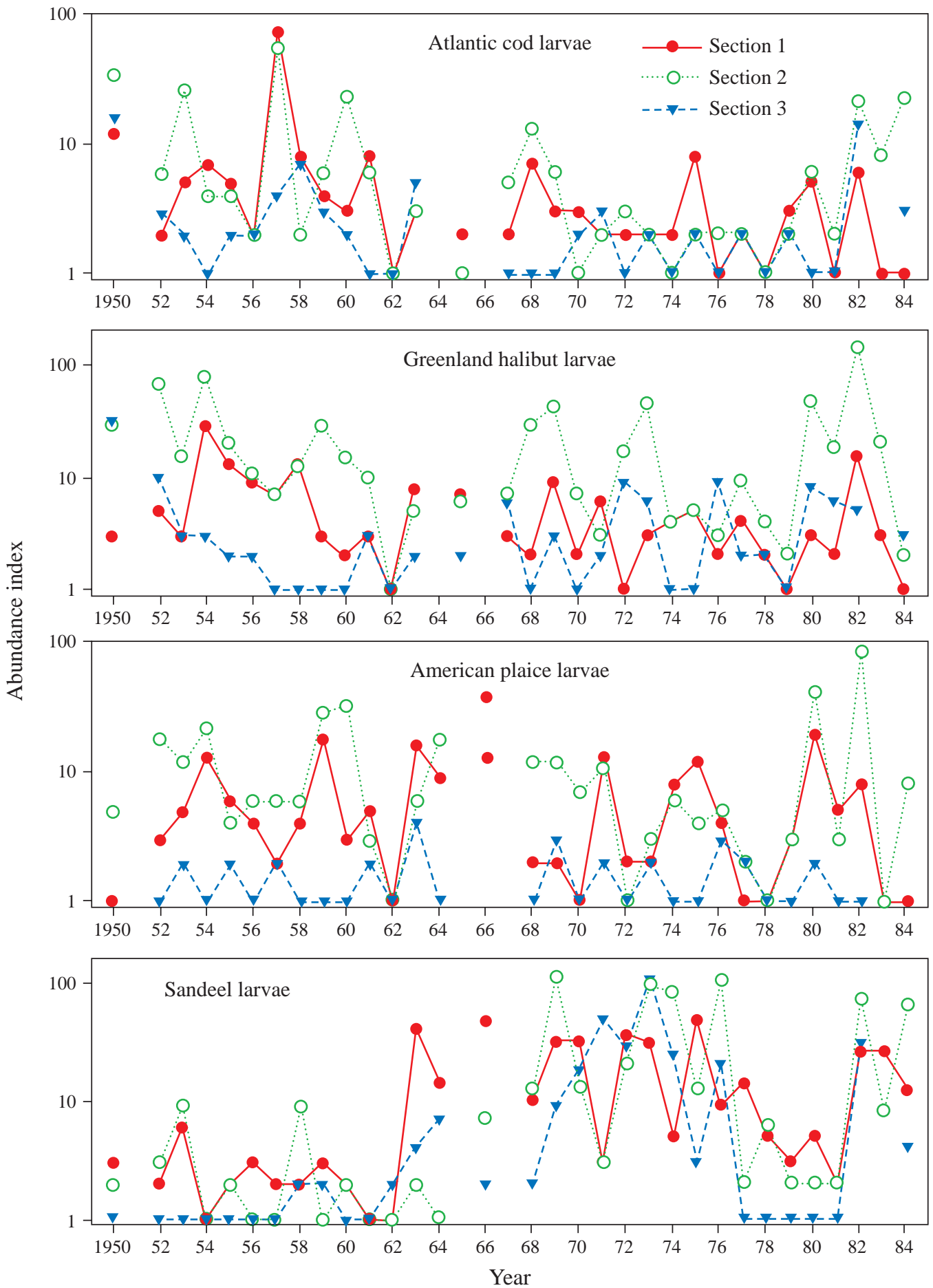

Fig. 18. Mean number of fish larvae per $30 \mathrm{~min}$. haul in June-July in the study area by sampling year and section.

larvae were common also in the deeper parts of the Davis Strait (Fig. 20). Abundance indices were positively correlated with e.g. Aglantha digitale (white form), Limacina retroversa, American plaice, wolffish, cod larvae, and salinity (Table 4).
Redfish larvae (RED) occurrence showed annual variation between year and a trend of being more common in June (Table 3). Due to the infrequent samples of redfish larvae no effects of section or depth were found. Redfish larvae were abundant in samples 


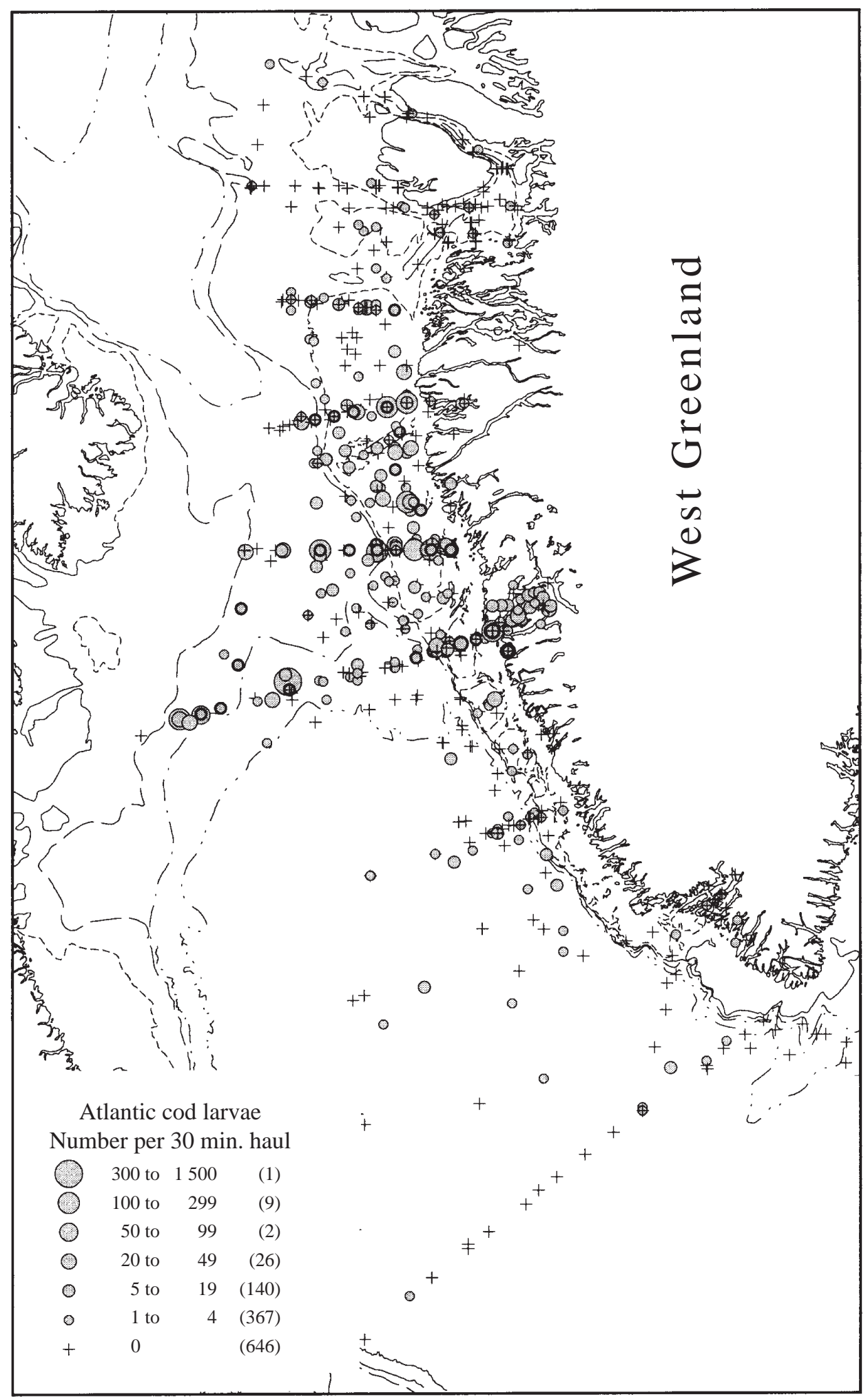

Fig. 19. Number of Atlantic cod larvae (COD) per $30 \mathrm{~min}$. haul; all samples in June-July 1950-84. Frequency of occurrence in parentheses. 


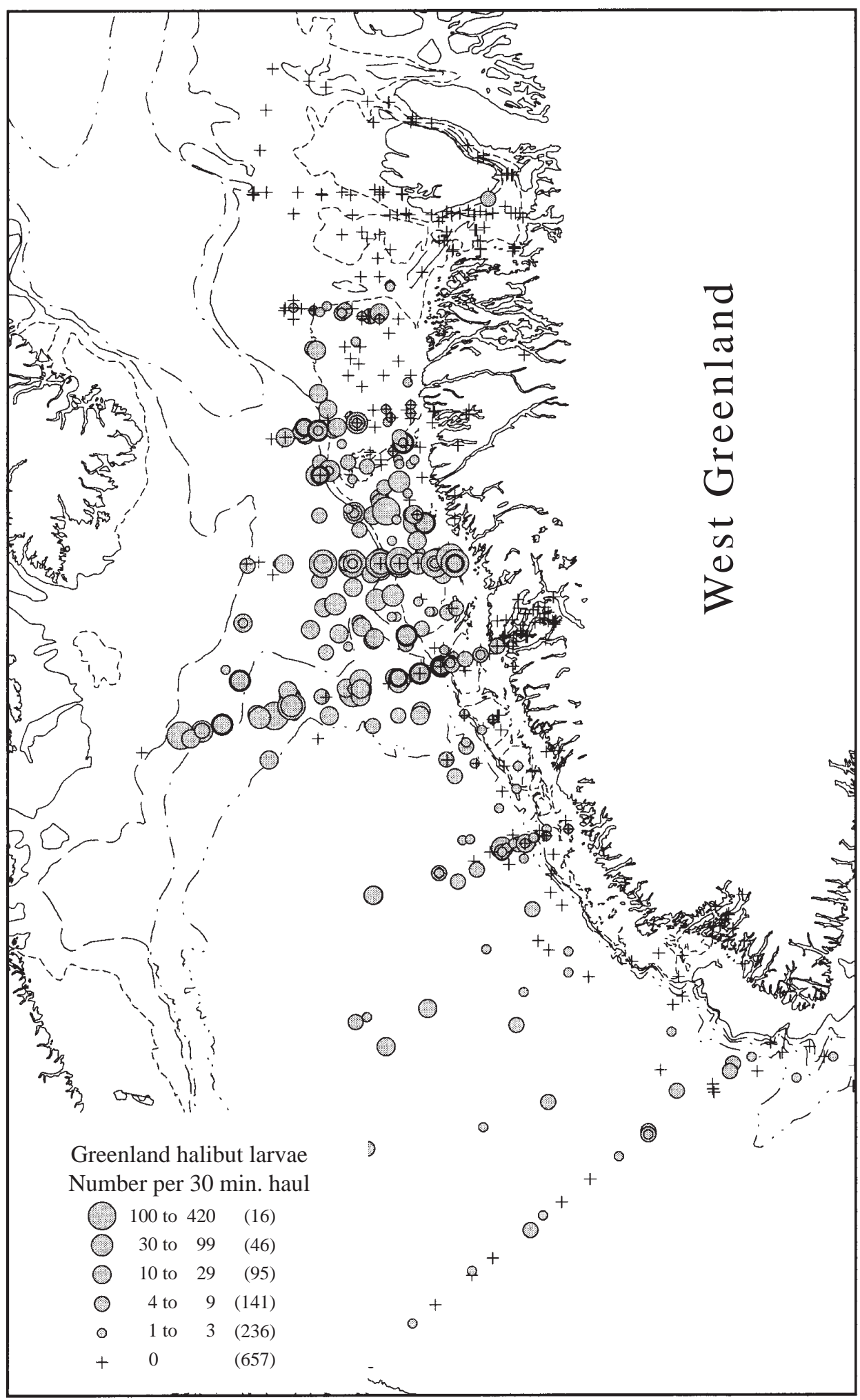

Fig. 20. Number of Greenland halibut larvae (GHL) per $30 \mathrm{~min}$. haul; all samples in JuneJuly $1950-84$. Frequency of occurrence in parentheses. 
from Southwest Greenland and the Labrador Sea (Fig. 21). Occurrence was positively correlated with e.g. Calanus finmarchicus and euphausiids (Table 4). Larval redfish occurrence was not correlated with temperature or salinity.

American plaice larvae (PLA) showed similar trends as Atlantic cod larvae, being more abundant during 1950-68 and early-1980s, on section 2 (Table 3, Fig. 18). Sampling section explained most of the variation. Although the effect of depth to bottom was significant, there was no clear trend in the abundance with depth to bottom. American plaice larvae were most abundant in samples from the shelf areas of the three sampling sections (Fig. 22). Abundance indices were positively correlated with Greenland halibut larvae, cod larvae, Calanus finmarchicus, Aglantha digitale, Gonatus fabricii (juveniles), temperature, and salinity (Table 4).

Wolffish larvae (WOLF) abundance showed a trend of being more common at section 2 (Table 3 ). No effects of sampling month were found. Although the effect of depth to bottom was significant there was no clear trend in the abundance with depth to bottom. Wolffish larvae were most abundant in samples from the shelf areas of the three sampling sections and in the Disko Bay area (Fig. 23). Wolffish larvae abundance indices were positively correlated with Limacina sp., Greenland halibut larvae, and G. fabricii (juveniles) (Table 4). Wolffish larvae abundance indices were not correlated with temperature or salinity.

Sandeel larvae (SAND) showed trends of being more abundant during 1963-76 and 1982-84, on section 1, at depth to bottom below $200 \mathrm{~m}$, and in June (Table 3, Fig. 18). Sampling section explained most of the variation. Sandeel larvae were most abundant in samples in the shelf areas of the three sampling sections and in the Disko Bay area (Fig. 24). Abundance was positively correlated with crab larvae and Aglantha digitale (red form), but negatively correlated with most other zooplankton taxa (Table 4). Sandeel larvae were negatively correlated with temperature (Table 4).

\section{Discussion}

\section{Long-term relationship between hydrography and zooplankton}

The hydrographical data from the study area from 1950 to 1984 showed generally higher mean temperatures during 1950-68 compared with the period
1969-84. The latter period was more variable with unusual low temperatures and salinities from 1969 to 1971 and again from 1982 to 1984 (Fig. 3). While the cold period 1969-71 was explained by increased flow intensity of the East Greenland Polar Current, the cold period 1982-84 was explained mainly by inflow of extremely cold air masses from Canada which caused a cooling of the water masses (Rosenørn et. al., MS 1985; Buch, MS 1998).

The zooplankton displacement volume and most of the zooplankton taxa analysed showed higher abundance indices in the generally warmer period 1950-68. Only a few taxa such as hyperiids, the pteropod Limacina helicina, and sandeel were more abundant in the more variable and colder period after 1968. Correlations with temperature and salinity differed among zooplankton taxa e.g. American plaice larvae were positively related and sandeel larvae negatively related to temperature (Fig. 25). Of all correlations with temperature, zooplankton displacement volume (PLVOL) showed the highest positive correlation $(r=0.28, p<0.005, n=446)$.

Several aspects of sampling design and biological processes weaken the ability to detect and describe relationships between hydrographical characteristics and zooplankton in this study. These include: 1) low numbers of sampling stations, 2) oblique and depth integrated hauls in the upper $50 \mathrm{~m}$, which resulted in coarse spatial and temporal resolution of the samples with respect to hydrographical fronts and zooplankton distributions, 3) prey-predator interactions, if predators were very effectively grazing their prey.

Zooplankton displacement volume and most of the taxa investigated showed significantly higher abundance in section 2. Hyperiids, Clione limacina and shrimp larvae were exceptions, showing no effect of sampling section. Calanus finmarchicus was more abundant in the less saline section 3, whereas crab and sandeel larvae were more abundant in the more saline section 1. Crab and sandeel larvae were most common in the relatively shallow coastal areas over Store Hellefiske Bank. However, most zooplankton taxa were more abundant in the oceanic areas than in coastal areas. The differences in distributions and abundances are due to differences between the taxa in geographic origin, timing of their life cycle and development (Bainbridge and Corlett 1968; Pavshtiks, 1968, 1972; Smidt, 1979). For Pandalus shrimp larvae Pedersen (1998) found larger developmental stages over Lille Hellefiske Bank (section 2) than further north, 


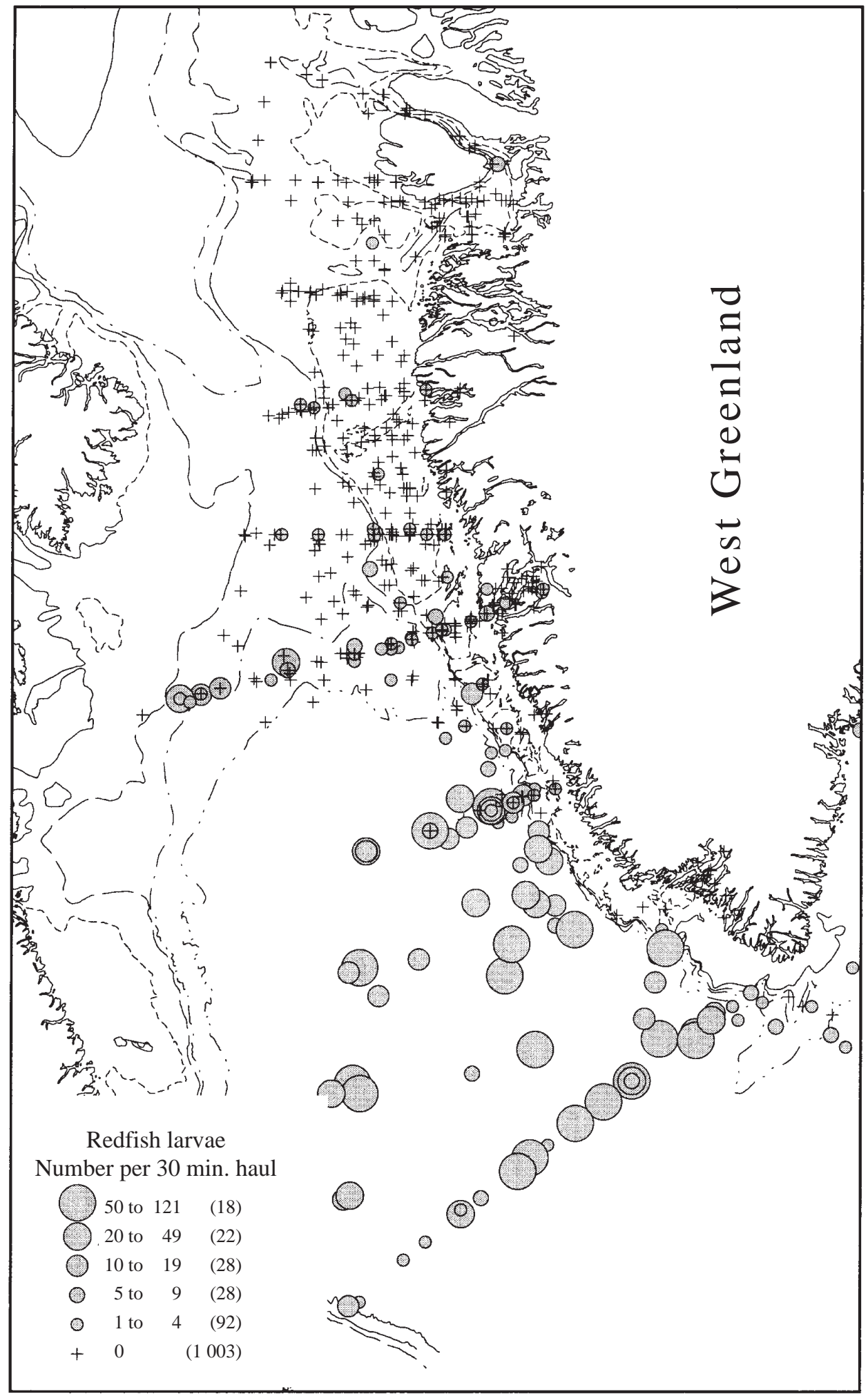

Fig. 21. Number of redfish larvae (RED) per 30 min. haul; all samples in June-July 1950-84. Frequency of occurrence in parentheses. 


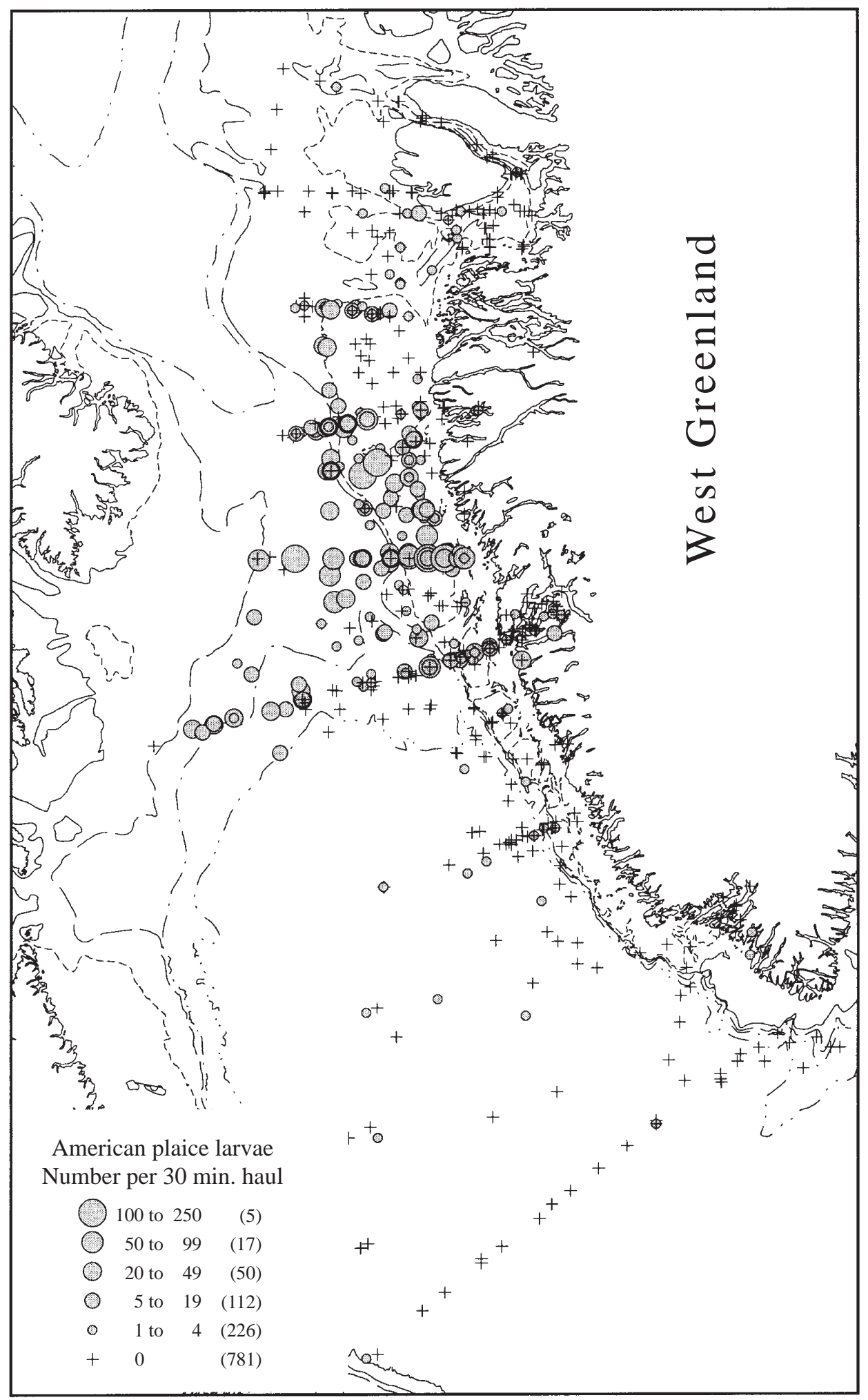

Fig. 22. Number of American plaice larvae (PLA) per $30 \mathrm{~min}$. haul; all samples in June-July 1950-84. Frequency of occurrence in parentheses. 


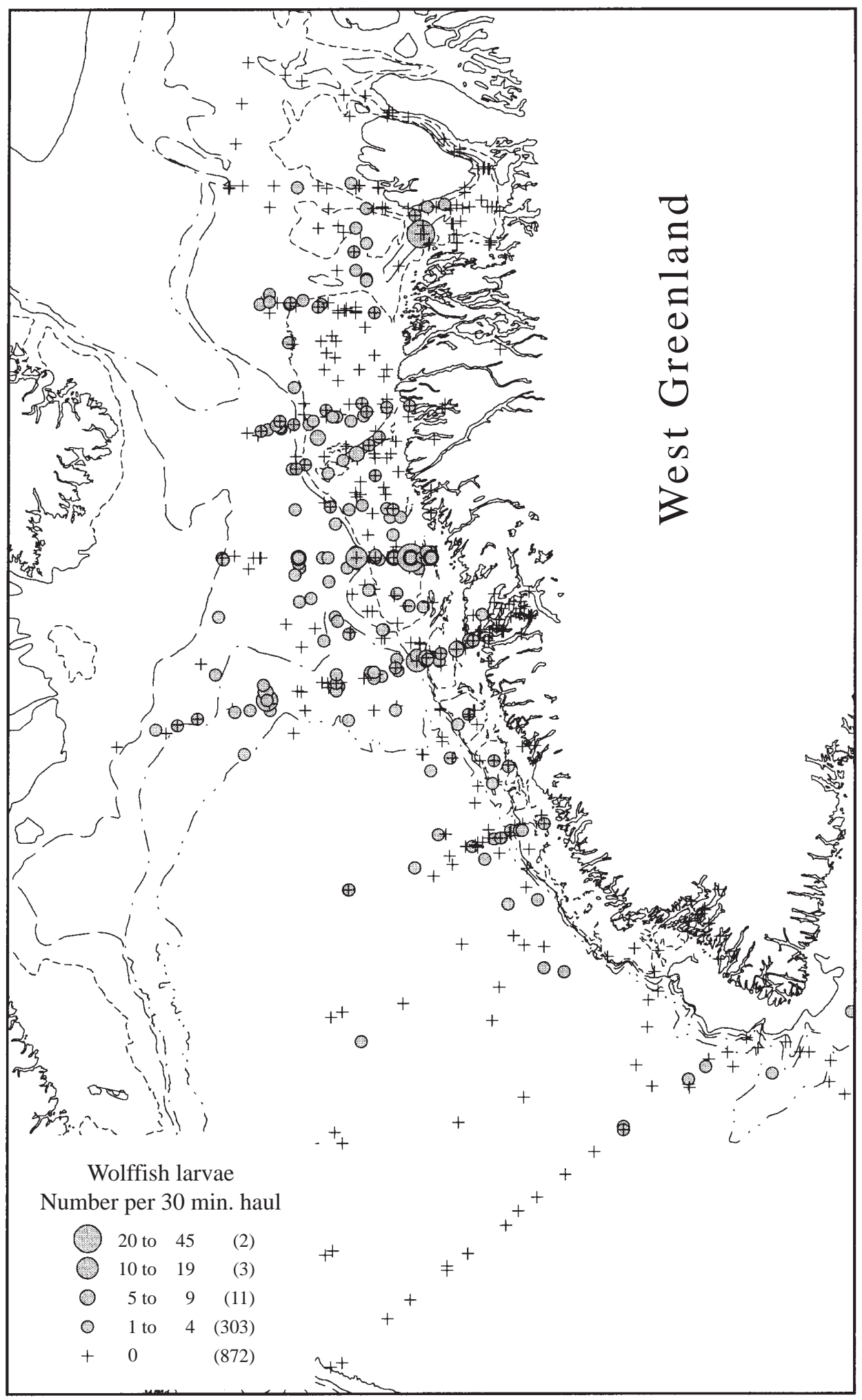

Fig. 23. Number of wolffish larvae (WOLF) per $30 \mathrm{~min}$. haul; all samples in June-July 1950-84. Frequency of occurrence in parentheses. 


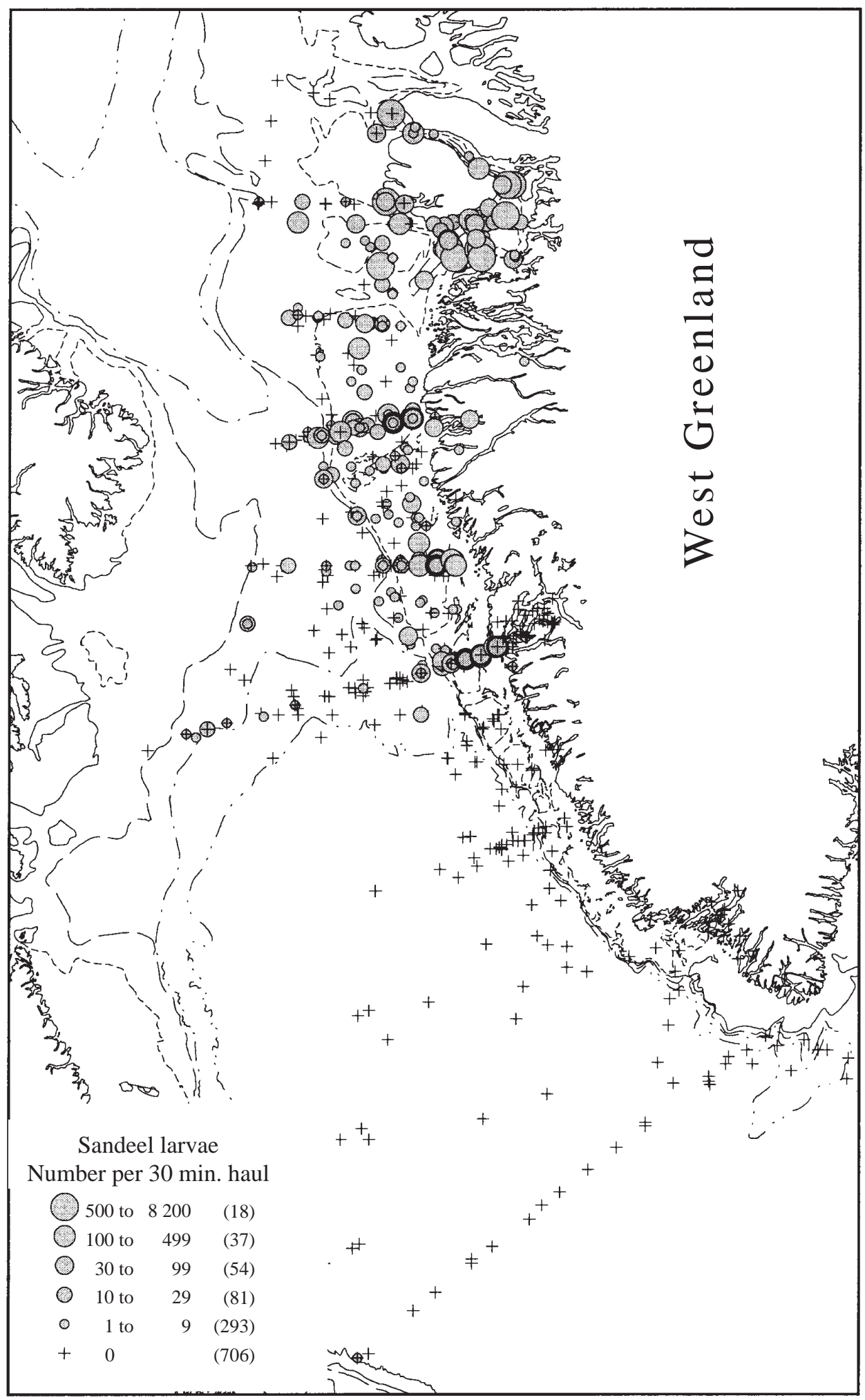

Fig. 24. Number of sandeel larvae (SAND) per $30 \mathrm{~min}$. haul; all samples in June-July 195084. Frequency of occurrence in parentheses. 


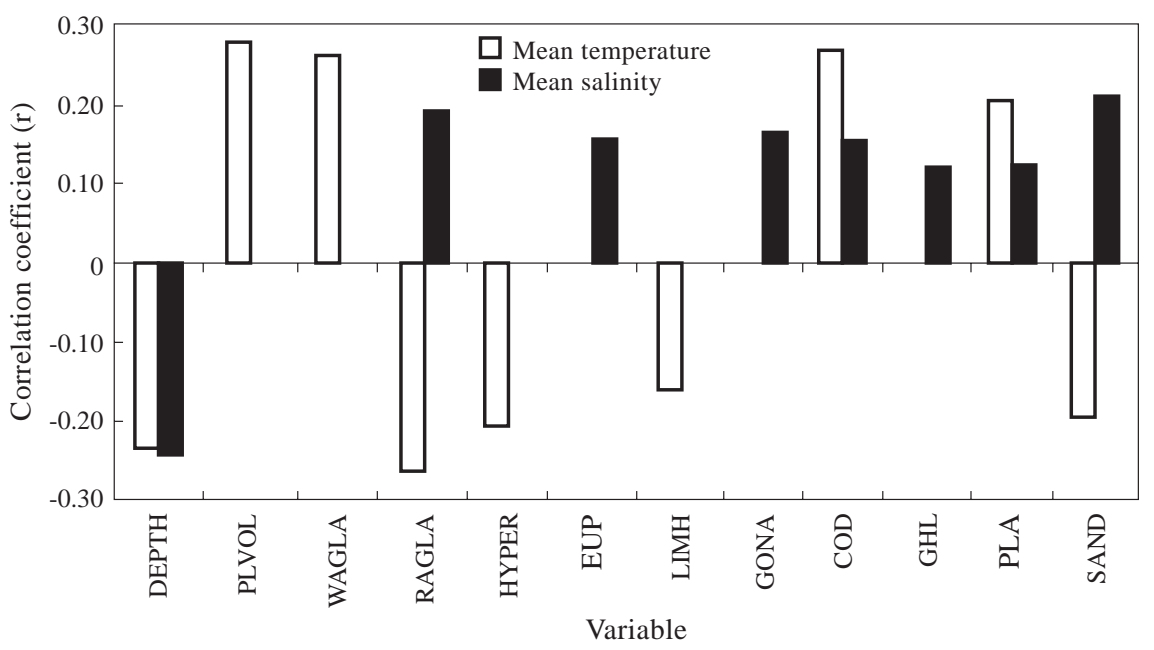

Fig. 25. Significant $(p<0.05)$ correlations $(r)$ between zooplankton abundance indices and mean temperature and salinity. All data included (Table 1 and 4).

suggesting a delay in hatching and development from south to north, related to the later warming and onset of primary and secondary production from south to north.

Seasonal and inter-annual variability in the hydrographic conditions in the Davis Strait influence the composition of the zooplankton and the timing of its development (Pavshtiks, 1968, 1972). However, by sampling the same stations on a particular section at approximately the same time each year and calculating the average density for that section one should get a measure of each years conditions and the most marked annual changes taking place (Astthórsson et al., 1983). Therefore the variable trends of both temperature and indices of zooplankton abundance presented in this study may be indicative of general trends in the overall zooplankton productivity and food for higher trophic level species e.g. Atlantic cod. This is consistent with reduced weight-at-age and recruitment of the West Greenland offshore cod stock during cold periods after 1968 (Brander, 1995; Riget and Engelstoft, 1998; Buch et al., 1994).

Decreasing trends in plankton abundance and especially in Calanus finmarchicus were observed in northern Icelandic waters between the periods 195864 to 1965-71 (Astthórsson et al., 1983, Stefansson and Jakobsson, 1989). According to Astthórsson et al. (1983) a reduced influx of Atlantic water to the areas north of Iceland probably delayed the onset of the spring primary production and thus the zooplankton production. The hydrographic conditions probably also delayed and reduced the plankton production in West Greenland during cold periods, e.g. from 1969 to1971 and between 1982 and 1984. However, effects of these cold periods on the abundance indices of zooplankton and fish larvae in this study were minor, in fact the abundance indices of most zooplankton taxa including fish larvae were exceptionally high in 1982 (Fig. 18). Only the time-series for sandeel larvae showed markedly higher larvae abundance indices from 1969 to 1976 (Fig. 18). Possible explanations for this include 1) direct effects of oceanographic conditions on sandeel larval growth and survival, and 2) increased sandeel stock due to a reduction in the abundance of predators such as Atlantic cod.

\section{Warm and cold water indicators}

In this study, abundance indices of Aglantha digitale white form, Atlantic cod and American plaice larvae were positively correlated with temperature, whereas Aglantha digitale red form, hyperiids, Limacina helicina and sandeel larvae were negatively correlated with temperature (Fig. 25). No other zooplankton taxa were significantly correlated with temperature (Table 4). The white form of Aglantha occurs almost everywhere in the Davis Strait, but in decreasing numbers with colder water, and it is replaced by the red form in arctic waters (Bainbridge and Corlett, 1968). According to Pavshtiks (1972) boreal species (Calanus finmarchicus, Euchaeta norwegica, Limacina retroversa) and Arctic forms ( $C$. hyperboreus, C. glacialis, Metridia longa, Limacina helicina) occur in the Davis Strait zooplankton during the greater part of the year. Arctic forms enter the Davis Strait with the cold Baffin Land Current (Labrador Current), and with the East Greenland Current (Fig. 1). The boreal species occur throughout the strait together 
with the cold water forms from the Arctic; they overwinter in the deep part of the strait (Pavshtiks, 1972). Limacina retroversa is a warm-water species found only off southern West Greenland whereas Limacina helicina is a cold water species found further to the north and with similar distribution as another cold water species, the gastropod Clione limacina (Smidt, 1979). Our findings agree with these patterns.

C. finmarchicus (glacialis) was positively correlated with $C$. hyperboreus (Table 4) indicating mixing between relatively warm and cold water. C. finmarchicus and C. glacialis were difficult to identify to species, therefore, the C. finmarchicus data may include some $C$. glacialis. According to Pavshtiks (1972) C. finmarchicus and C. glacialis form the bulk of the Davis Strait zooplankton during the greater part of the year and it is assumed that several populations of Calanus exist and spawn in this area. However, the most abundant $C$. finmarchicus population is brought into the Davis Strait with the Irminger Current (Atlantic water) during spring (Pavshtiks, 1972). Spawning of C. finmarchicus takes place from May to July both in the Atlantic water of the Irminger current and in the West Greenland coastal waters whereas $C$. glacialis is correlated with cold water in the Baffin Land Current and spawns in the coastal waters of Canada (Pavshtiks, 1972). Therefore, the C. finmarchicus data from the study area (section 1-3) of this paper were assumed to include only a low number or no $C$. glacialis.

\section{Linking zooplankton with recruitment of fish}

Of the large number of relationships between fish and zooplankton, the most important is that linking zooplankton with recruitment of fish (Cushing, 1995b). Recruitment success for fish and shellfish larvae depends on mainly two controlling biological processes - predation and food availability (the right food in sufficient amount at the right time) (Cushing, 1995a and b). In this study, the abundance indices of most fish larvae were positively correlated to each other (exceptions were sandeel and redfish larvae). This could indicate aggregation of fish larvae in locations of higher larval food production, growth rate and survival. However, the abundance indices of fish larvae were correlated to abundance indices of both potential prey and predators. Greenland halibut larvae showed positive correlations with white form Aglantha digitale, Limacina sp., small squids (Gonatus fabricii), American plaice larvae, wolffish larvae, Clione limacina, hyperiids, cod larvae, C. hyperboreus, and others (Table 4). Hence, larval fish, their prey and predators tend to aggregate.
An assessment of the possible intensity of predation on fish larvae is difficult since little is known of the relative importance of the various carnivorous species as predators of young fish (Bainbridge and Corlett, 1968). A common carnivorous species in the North Atlantic is Clione limacina but this gastropod may be a selective feeder on Limacina (Spiratella). Our results support this hypothesis because Clione limacina was positively correlated with Limacina retroversa and L. helicina. Little information on feeding ecology of fish larvae exists from West Greenland. However, in a study of the stomach contents of wolffish larvae collected from West Greenland in July 1980, 1981, and 1982 the principal fish prey of wolffish larvae were found to be sandeel larvae, followed by wolffish, cod and American plaice larvae (Alfonso Guzmán, Universidad de Los Lagos, Puerto Mont, Chile, unpublished). Cannibalism by larvae may thus be a population regulating mechanism in wolffish and probably in other fish species such as Atlantic cod and redfish. Predation on fish larvae (including cannibalism) may be avoided during good food conditions. However, larval fish will be vulnerable to predators if fish larvae co-occur with other organisms (e.g. medusae, chaetognaths) that compete for the same basic food. This latter predator group would be responsible for diminishing the food supply for fish larvae and consequently fish larvae may remain small and vulnerable to predators. As indicated by this study, the potential fish predators (e.g. Aglanta, chaetognaths) were generally more abundant in oceanic areas over deep water (depth to bottom more than $300 \mathrm{~m}$ ) than in coastal areas (less than $300 \mathrm{~m}$ ). Hence, fish larvae e.g. Atlantic cod, American plaice and sandeel larvae drifting northwards over the West Greenland fishing banks may be less exposed to predation than larvae drifting westwards over deep water in the Davis Strait.

Calanus finmarchicus is the most important food organism for both redfish and cod larvae (Bainbridge and McKay, 1968) and may be crucial for larvae survival. However, it has not been established whether inter-annual variability in fish stock recruitment depends directly upon variations of Calanus productivity (Miller, 1995). In this study, the abundance indices of Greenland halibut, American plaice and redfish larvae were significantly correlated with abundance indices of $C$. finmarchicus, whereas abundance indices of cod larvae were not (Table 4). Bainbridge and McKay (1968) found that cod larvae off West Greenland feed almost entirely on nauplii and copepodites of $C$. finmarchicus, which are not caught by the $1 \mathrm{~mm}$ mesh stramin net used for sampling. This may explain why we found no association for cod. 
Year-class strength (as number at age 3) of Atlantic cod off West Greenland has been positively correlated with mean sea temperature (surface to $45 \mathrm{~m}$ over Fylla Bank in June) during the larval phase (Hermann et al., 1965; Hansen and Buch, 1986). Thus lower and more variable temperatures in West Greenland waters after 1968 may have contributed to decreased recruitment of the Atlantic cod stock. Year-class strength (at age 3 ) positively correlated with abundance indices of cod larvae (Hansen and Buch, 1986). In this study abundance indices of cod larvae were positively correlated with temperature. Cod eggs and larvae normally concentrate in the upper water layers and they are therefore exposed to relatively large temperature variations. In comparison eggs and larvae of American plaice are more deeply distributed and thus better protected against low temperatures. This may partly explain why the cod stock is more vulnerable to low temperatures than the American plaice stock in Greenland waters (Smidt, 1979).

In addition to direct effects of temperature on development time and survival of cod eggs and larvae, temperature can have indirect effects by altering the timing between first feeding and availability of food (Bainbridge and McKay, 1968; Cushing, 1990; Munk, 1997). Increased growth rates of cod larvae during warm years may increase survival if vulnerability to predation is size dependent. This may partly explain the relationship between water temperatures at West Greenland and year-class strength of the West Greenland cod stock.

Estimating the strength of new year-classes of fish and shellfish based on larval abundance is difficult due to the many variables affecting larval survival. Sea temperature, drift of larvae by surface currents, and stability of the water masses (hydrographic fronts) are important oceanographic factors affecting recruitment to harvestable fish and shellfish stocks (e.g. Taggart et al., 1989; Franks, 1992; Buch et al., 1994; Nilssen et al., 1994; Aadlandsvik and Sundby, 1994; Sundby et al., 1994; Stein and Lloret, 1995; Munk et al., 1995; Pedersen, 1998). In 1982, the relatively high mean number of Atlantic cod larvae caught in the stramin net hauls on the West Greenland sampling sections 13 indicated a good prospect for a large cod recruitment (Fig. 18), however, the 1982 year-class became poor. It has been assumed that the failure of the 1982 yearclass mainly was caused by the extremely low winter temperatures in West Greenland during 1982-84 (Rosenørn et. al., MS 1985). The failure of the 1982 year-class of Atlantic cod and the general inability to relate catches of larvae to subsequent recruitment were the main reasons for terminating the time-series of zooplankton collections off West Greenland in 1985.

There is a need for better understanding of the dynamics between environmental conditions and variability in the fisheries resources in West Greenland waters. Progress in understanding recruitment success of fish and shellfish requires process oriented studies of zooplankton, ichthyoplankton, hydrography, and climate. Multivariate models which include variables like ocean temperature, seasonal timing of larval food production, spawning stock biomass, larval drift, species interactions (cannibalism), for each individual species in focus should prove to increase the ability to predict recruitment for fish and shellfish.

\section{Acknowledgements}

We acknowledge the many people involved over the years at the Danish and Greenland Institutes for Fisheries Research under the leadership of K. Vagn Hansen (1952-62) and E.L.B. Smidt (1963-85), especially E. Rosendahl Nielsen. Thanks to Director Klaus Nygaard (Greenland Institute of Natural Resources) for support and to the ICES Secretariat, Rasmus Nielsen and Karen L. Nielsen for help with the hydrographic data. Special thanks to Associate Editor Anne Richards for constructive comments and substantial rewording to improve the manuscript. During part of the work with this paper the Commission of Scientific Research in Greenland and Danish National Research Council project no. 9803018 funded the first author.

\section{References}

AADLANDSVIK, B., and SUNDBY, S. 1994. Modelling the transport of cod larvae from the Lofoten area. In: Cod and Climate Change, J. Jakobsson, O.S. Astthorsson, R.J.H. Beverton, B. Bjoernsson, N. Daan, K.T. Frank, J. Meincke, B. Rothschild, S. Sundby, and S. Tilseth (eds.). Proceedings of a Symposium held in Reykjavik, 23-27 August 1993. ICES Mar. Sci. Sym., 198: $379-392$.

AEBISCHER, N. J., J. C. COULSON, and J. M. COLEBROOK. 1990. Parallel long-term trends across four marine trophic levels and weather. Nature, 347, no. 6295: 753-755.

ANDERSON, P. J., and J. F. PIATT. 1999. Community reorganization in the Gulf of Alaska following ocean climate regime shift. Mar. Ecol. Prog. Ser, 189: 117123.

ANON. 1985. SAS User's Guide: Statistics Version 5. Edition. SAS Institute Inc., Raleigh, North Carolina 1985.

MS 1998a. Report of the North-western Working 
Group. ICES C.M. Doc., ACFM:19, 350 p. MS 1998b. Third ICES/GLOBEC BackwardFacing Workshop Ocean Climate of the NW Atlantic during the 1960s and 1970s and Consequences for Gadoid Populations. Oceanography Committee ICES C.M. Doc., C:9, 89 p.

ASTTHÓRSSON, O. S., I. HALLGRÍMSSON, and G. S. JÓNSSON. 1983. Variations in zooplankton densities in Icelandic waters in spring during the years 19611982. Rit Fiskideildar, 7(2): 73-113.

BAINBRIDGE, V., and J. CORLETT. 1968. The zooplankton of the NORWESTLANT surveys. ICNAF Spec. Publ., 7(I): 101-122.

BAINBRIDGE, V., and B. J. MCKAY. 1968. The feeding of cod and redfish larvae. ICNAF Spec. Publ., 7(I): 187217.

BRANDER, K. M. 1995. The effect of temperature on growth of Atlantic cod (Gadus morhua L.). ICES J. Mar. Sci., 52: 1-10.

BUCH, E. MS 1990. A monograph on the physical environment of Greenland waters. Greenland Fisheries Research Institute Report, $405 \mathrm{p}$.

BUCH, E. MS 1998. Oceanographic conditions in West Greenland waters 1981-1997. Danish Meteorological Institute, Lyngbyvej 100, 2100 Copenhagen $\emptyset$. Report, $29 \mathrm{p}$.

BUCH, E., S. AA. HORSTED, and H. HOVGAARD. 1994. Fluctuations in the occurrence of cod in Greenland waters and their possible causes. In: Cod and Climate Change, J. Jakobsson, O.S. Astthorsson, R.J.H. Beverton, B. Bjoernsson, N. Daan, K. T. Frank, J. Meincke, B. Rothschild, S. Sundby, and S. Tilseth (eds.). Proceedings of a Symposium held in Reykjavik, 23-27 August 1993. ICES Mar. Sci. Symp., 198: 158-174.

CUSHING, D. H. 1990. Plankton production and year-class strength in fish populations: an update of the match/ mismatch hypothesis. Advances in Marine Biology, 26: 249-293.

1995a. Population production and regulation in the sea: A Fisheries perspective. Cambridge University Press. 354 p.

1995b. The long-term relationship between zooplankton and fish. ICES J. Mar. Sci., 52: 611-626.

FRANKS, P. J. S. 1992. Sink or swim: Accumulation of biomass at fronts. Mar. Ecol. Prog. Ser., 82(1): 1-12.

HACHEY, H. B., F. HERMANN, and W. B. BAILEY. 1954. The waters of the ICNAF Convention Area. ICNAF Ann. Proc., 4: 67-102.

HANSEN, H., and E. BUCH. 1986. Prediction of year-class strength of Atlantic cod (Gadus morhua) off West Greenland. NAFO Sci. Coun. Studies, 10: 7-11.

HERMANN, F., HANSEN, P. M., and S. AA. HORSTED. 1965. The effect of temperature and currents on the distribution and survival of cod larvae at West Greenland. ICNAF Spec. Publ., 6: 389-395.

HURRELL, J. W. 1995. Decadal Trends in the North Atlantic Oscillation: Regional Temperatures and Precipitation. Science., 269: 676-679.

ICNAF. 1968. NORWESTLANT Surveys - Text (Part I),
Atlas (Part II), Physical and Chemical Oceanographic Data (Part III), Biological Data (Part IV). ICNAF Spec. Publ., 7, Parts 1-4.

MACKAS, D. L., R. GOLDBLATT, AND A. G. LEWIS. 1998. Interdecadal variation in developmental timing of Neocalanus plumchrus populations at Ocean Station $\mathrm{P}$ in the subarctic NorthPacific. Can. J. Fish. Aquat. Sci. 55: 1878-1893.

MILLER, C. 1995. TransAtlantic Studies of Calanus (TASC) Working Group. U.S. GLOBEC NEWS No. 8 - March 1995.

MUNK, P. 1997. Prey size spectra and prey availability of larval and small juvenile cod. J. Fish. Biol., 51(A): 340351

MUNK, P., P. O. LARSSON, D. DANIELSEN, and E. MOKSNESS. 1995. Larval and small juvenile cod (Gadus morhua) concentrated in the highly productive areas of a shelf break front. Mar. Ecol. Prog. Ser., 125: 21-30.

NILSSEN, E. M., T. PEDERSEN, C. C. E. HOPKINS, K. THYHOLT, and J. G. POPE. 1994. Recruitment variability and growth of the Northeast Arctic cod: influence of physical environment, demography, and predator-prey energetics. In: Cod and Climate Change, J. Jakobsson, O.S. Astthorsson, R.J.H. Beverton, B. Bjoernsson, N. Daan, K.T. Frank, J. Meincke, B. Rothschild, S. Sundby, and S. Tilseth (eds.). Proceedings of a Symposium held in Reykjavik, 23-27 August 1993. ICES Mar. Sci. Symp., 198: 449-470.

NAFO 1995. Statistical Bulletin, Supplementary Issue, Fishery Statistics for 1960-90, 156 p.

1998. NAFO Scientific Council Reports 1997, $274 \mathrm{p}$.

PAVSHTIKS, E. A. 1968. The influence of currents upon seasonal fluctations in the plankton of the Davis Strait. Sarsia, 34: 383-392.

1972. Biological seasons in the zooplankton of Davis Strait. Akad. Nauk. SSSR, Zool. Inst., Explor. Mar. Fauna. 12(20): 200-247. Israel Prog. Sci. Transl., Jerusalem 1975.

PEDERSEN, S. A. 1998. Distribution and lipid composition of Pandalus shrimp larvae in relation to hydrography in West Greenland waters. J. Northwest Atl. Fish. Sci., 24: 39-60.

RIGET, F., and J. ENGELSTOFT. 1998. Size-at-age of Cod (Gadus morhua) off West Greenland, 1952-92. NAFO Sci. Coun. Studies, 31: 1-12.

ROSENØRN, S., J. FABRICIUS, E. BUCH, and S. AA. HORSTED. MS 1985. Record-hard winters at West Greenland. NAFO SCR Doc., No. 61, Serial No. N1011. $17 \mathrm{p}$.

SMIDT, E. L. B. 1971. Summary report of the ICNAF NORWESTLANT surveys, 1963. ICNAF Redbook, Part III: 275-295.

1979. Annual cycles of primary production and of zooplankton at Southwest Greenland. Meddelelser om Grønland, Bioscience, No. 1.53 p.

STEFÁNSON, U., and J. JAKOBSSON. 1989. Oceanographical variations in the Iceland Sea and their impact 
on biological conditions - a brief review. In: Proceedings of the sixth conference of the comite arctique international 13-15 May 1985, Louis Rey and Vera Alexander. E.J. Brill (ed.). Leiden, New York, København, Köln, 427-455.

STEIN, M. 1998. Integrating Fisheries Observations with Environmental Data - Towards a Better Understanding of the Conditions for Fish in the Sea. J. Northw. Atl. Fish. Sci., 23: 143-156.

STEIN, M., and J. LLORET. 1995. Stability of water masses - impact on cod recruitment off West Greenland. Fish. Ocean., 4(3): 230-237.

STEIN, M., and V. A. BOROVKOV. 1997. Climatic variability of deep waters off Greenland and in the Labrador Sea. NAFO Sci. Coun. Studies, 30: 27-39.

SUNDBY, S., ELLERTSEN, B. and FOSSUM, P. 1994. Encounter rates between first-feeding cod larvae and their prey during moderate to strong turbulent mixing. In: Cod and Climate Change, J. Jakobsson, O.S.
Astthorsson, R.J.H. Beverton, B. Bjoernsson, N. Daan, K.T. Frank, J. Meincke, B. Rothschild, S. Sundby, and S. Tilseth (eds.). Proceedings of a Symposium held in Reykjavik, 23-27 August 1993. ICES Mar. Sci. Symp., 198: $398-405$.

SVERDRUP, H. U., M. W. JOHNSON, and R. H. FLEMING. 1946. The oceans - their physics, chemistry, and general biology. New York. Prentice-Hall, Inc., 1060 p.

TAGGART, C. T., K. F. DRINKWATER, K. T. FRANK, J. MCRUER, and P. LAROUCHE. 1989. Larval fish, zooplankton community structure, and physical dynamics at tidal front. In: Early Life History of Fish, Blaxter, J.H.S., Gamble, J.C., Westernhagen, H. von (eds). 3. ICES Symp. on the Early Life History of Fish, Bergen (Norway), 3-5 Oct 1988. Rapp. p. v. Reun. CIEM., 191: 184-194.

WANNACOTT, R. J., and T. H. WANNACOTT. 1985. Introductory Statistics, Fourth Edition. John Wiley \& Sons. 649 p. 
Appendix 1. Arithmetic mean with 1 standard error (SE) of sea temperature (MTEMP) and salinity (MSAL) by year and section. $\mathrm{N}=$ number of samples.

\begin{tabular}{|c|c|c|c|c|c|c|c|c|c|}
\hline \multirow[b]{2}{*}{ Year } & \multicolumn{3}{|c|}{ Section 1} & \multicolumn{3}{|c|}{ Section 2} & \multicolumn{3}{|c|}{ Section 3} \\
\hline & $\mathrm{N}$ & Mean & SE & $\mathrm{N}$ & Mean & SE & $\mathrm{N}$ & Mean & $\mathrm{SE}$ \\
\hline \multicolumn{10}{|c|}{ МТЕМР } \\
\hline 1950 & 4 & 1.64 & 0.92 & 4 & 2.06 & 0.54 & 2 & 2.99 & 0.14 \\
\hline 1952 & 6 & 2.45 & 0.70 & 3 & 2.70 & 0.19 & 3 & 2.03 & 0.28 \\
\hline 1953 & 6 & 3.00 & 0.64 & 5 & 3.25 & 0.30 & 5 & 3.26 & 0.40 \\
\hline 1954 & 4 & 2.82 & 0.25 & 4 & 2.89 & 0.19 & 5 & 2.32 & 0.33 \\
\hline 1955 & 5 & 2.95 & 0.37 & 3 & 2.79 & 0.05 & 3 & 1.80 & 0.56 \\
\hline 1956 & 3 & 2.96 & 0.05 & 2 & 2.37 & 0.56 & 4 & 2.08 & 0.55 \\
\hline 1957 & 4 & 3.05 & 0.54 & 2 & 2.96 & 0.11 & 4 & 1.68 & 0.24 \\
\hline 1958 & 4 & 2.81 & 0.78 & 3 & 2.82 & 0.43 & 4 & 3.03 & 0.25 \\
\hline 1959 & 5 & 3.51 & 0.39 & 4 & 3.00 & 0.21 & 4 & 1.90 & 0.34 \\
\hline 1960 & & & & & & & 2 & 3.17 & 0.46 \\
\hline 1961 & 6 & 3.42 & 0.66 & 4 & 4.46 & 0.16 & 2 & 4.20 & 0.25 \\
\hline 1962 & 1 & 4.56 & & & & & 3 & 2.58 & 0.48 \\
\hline 1963 & 6 & 2.50 & 0.28 & 15 & 2.42 & 0.17 & 10 & 2.10 & 0.25 \\
\hline 1964 & 5 & 2.84 & 0.24 & 5 & 3.12 & 0.13 & 8 & 2.53 & 0.25 \\
\hline 1966 & 5 & 2.78 & 0.39 & 6 & 2.47 & 0.31 & 5 & 2.40 & 0.27 \\
\hline 1968 & 4 & 1.45 & 0.79 & 5 & 2.61 & 0.27 & 8 & 1.45 & 0.29 \\
\hline 1969 & 6 & 1.17 & 0.05 & 8 & 1.10 & 0.15 & 5 & 0.21 & 0.17 \\
\hline 1970 & 5 & 1.15 & 0.34 & 5 & 1.61 & 0.08 & 15 & 1.17 & 0.23 \\
\hline 1971 & 7 & 2.48 & 0.23 & 6 & 2.38 & 0.13 & 10 & 1.35 & 0.30 \\
\hline 1972 & 6 & 0.91 & 0.40 & 4 & 1.35 & 0.03 & 8 & 0.92 & 0.13 \\
\hline 1973 & 5 & 1.23 & 0.05 & 5 & 1.97 & 0.17 & 5 & 1.43 & 0.13 \\
\hline 1974 & 5 & 1.40 & 0.74 & 5 & 2.54 & 0.18 & 5 & 2.58 & 0.23 \\
\hline 1975 & 6 & 2.27 & 0.09 & 6 & 2.47 & 0.15 & 4 & 1.85 & 0.54 \\
\hline 1976 & 6 & 1.52 & 0.59 & 6 & 2.01 & 0.18 & 5 & 1.82 & 0.33 \\
\hline 1977 & 4 & 3.16 & 0.14 & 6 & 3.42 & 0.14 & 4 & 3.74 & 0.56 \\
\hline 1978 & 6 & 1.17 & 0.52 & 6 & 2.10 & 0.08 & 5 & 2.60 & 0.15 \\
\hline 1979 & 7 & 1.94 & 0.58 & 6 & 3.51 & 0.05 & 6 & 3.16 & 0.28 \\
\hline 1980 & 3 & 2.04 & 0.19 & 4 & 2.49 & 0.06 & 5 & 2.41 & 0.11 \\
\hline 1981 & 5 & 1.79 & 0.09 & 4 & 2.10 & 0.10 & 5 & 1.45 & 0.15 \\
\hline 1982 & 2 & 2.18 & 0.48 & 5 & 2.43 & 0.23 & 4 & 0.76 & 0.43 \\
\hline 1983 & 3 & 1.54 & 0.10 & 4 & 1.47 & 0.12 & & & \\
\hline 1984 & 5 & 1.82 & 0.28 & 3 & 1.71 & 0.14 & 4 & 1.51 & 0.27 \\
\hline \multicolumn{10}{|c|}{ MSAL } \\
\hline 1950 & 4 & 33.81 & 0.17 & 4 & 33.65 & 0.12 & 2 & 33.61 & 0.04 \\
\hline 1952 & 5 & 33.57 & 0.20 & 3 & 33.75 & 0.06 & 3 & 33.24 & 0.17 \\
\hline 1953 & 6 & 33.79 & 0.08 & 5 & 33.69 & 0.12 & 5 & 33.37 & 0.03 \\
\hline 1954 & 4 & 33.45 & 0.04 & 4 & 33.44 & 0.02 & 4 & 33.18 & 0.14 \\
\hline 1955 & 5 & 33.68 & 0.03 & 3 & 33.51 & 0.09 & 3 & 32.87 & 0.08 \\
\hline 1956 & 3 & 33.63 & 0.09 & 2 & 33.42 & 0.07 & 4 & 33.36 & 0.11 \\
\hline 1957 & 4 & 33.57 & 0.15 & 2 & 33.49 & 0.13 & 4 & 33.30 & 0.15 \\
\hline 1958 & 4 & 33.18 & 0.11 & 3 & 33.20 & 0.09 & 4 & 33.07 & 0.16 \\
\hline 1959 & 5 & 33.57 & 0.06 & 4 & 33.44 & 0.11 & 3 & 33.09 & 0.23 \\
\hline 1961 & 6 & 33.83 & 0.12 & 4 & 33.91 & 0.09 & 2 & 33.55 & 0.08 \\
\hline 1962 & & & & & & & 3 & 33.26 & 0.13 \\
\hline 1963 & 6 & 33.59 & 0.08 & 15 & 33.66 & 0.04 & 10 & 33.64 & 0.09 \\
\hline 1964 & 5 & 33.59 & 0.06 & 5 & 33.51 & 0.03 & 8 & 33.16 & 0.04 \\
\hline 1966 & 5 & 33.66 & 0.07 & 6 & 33.50 & 0.05 & 5 & 33.11 & 0.04 \\
\hline 1968 & 4 & 33.32 & 0.25 & 5 & 33.36 & 0.02 & 8 & 33.16 & 0.11 \\
\hline 1969 & 6 & 33.59 & 0.02 & 8 & 33.30 & 0.07 & 5 & 32.69 & 0.11 \\
\hline 1970 & 5 & 33.30 & 0.04 & 5 & 33.16 & 0.02 & 15 & 33.00 & 0.06 \\
\hline
\end{tabular}


Appendix 1. (Continued). Arithmetic mean with 1 standard error (SE) of sea temperature (MTEMP) and salinity (MSAL) by year and section. $\mathrm{N}=$ number of samples.

\begin{tabular}{|c|c|c|c|c|c|c|c|c|c|}
\hline \multirow[b]{2}{*}{ Year } & \multicolumn{3}{|c|}{ Section 1} & \multicolumn{3}{|c|}{ Section 2} & \multicolumn{3}{|c|}{ Section 3} \\
\hline & $\mathrm{N}$ & Mean & SE & $\mathrm{N}$ & Mean & $\mathrm{SE}$ & $\mathrm{N}$ & Mean & SE \\
\hline \multicolumn{10}{|c|}{ MSAL (cont'd) } \\
\hline 1971 & 7 & 33.24 & 0.09 & 6 & 33.04 & 0.07 & 10 & 32.87 & 0.05 \\
\hline 1972 & 6 & 33.75 & 0.09 & 4 & 33.56 & 0.04 & 8 & 33.33 & 0.04 \\
\hline 1973 & 5 & 33.74 & 0.04 & 5 & 33.58 & 0.05 & 5 & 33.51 & 0.03 \\
\hline 1974 & 5 & 33.54 & 0.16 & 5 & 33.58 & 0.06 & 5 & 33.32 & 0.04 \\
\hline 1975 & 6 & 33.79 & 0.08 & 6 & 33.60 & 0.04 & 4 & 33.20 & 0.06 \\
\hline 1976 & 6 & 33.45 & 0.10 & 6 & 33.37 & 0.04 & 5 & 33.18 & 0.05 \\
\hline 1977 & 4 & 33.55 & 0.02 & 6 & 33.40 & 0.05 & 4 & 33.10 & 0.29 \\
\hline 1978 & 5 & 33.47 & 0.15 & 5 & 33.31 & 0.09 & 5 & 32.99 & 0.10 \\
\hline 1980 & 3 & 33.83 & 0.03 & 4 & 33.74 & 0.02 & 5 & 33.52 & 0.08 \\
\hline 1981 & 5 & 33.55 & 0.03 & 4 & 33.42 & 0.05 & 5 & 33.07 & 0.10 \\
\hline 1982 & 2 & 33.40 & 0.07 & 5 & 33.12 & 0.20 & 4 & 32.64 & 0.06 \\
\hline 1983 & 3 & 33.69 & 0.03 & 4 & 33.35 & 0.07 & & & \\
\hline 1984 & 5 & 33.91 & 0.08 & 3 & 33.79 & 0.10 & 4 & 33.37 & 0.08 \\
\hline
\end{tabular}


Appendix 2. Mean abundance indices $[\log 10(x+1)]$ with 1 standard error $(\mathrm{SE})$ of different zooplankton taxa by year and section. Abbreviations shown in Table 2. $\mathrm{N}=$ number of stations with zooplankton hauls.

\begin{tabular}{|c|c|c|c|c|c|c|c|c|c|}
\hline \multirow[b]{2}{*}{ Year } & \multicolumn{3}{|c|}{ Section 1} & \multicolumn{3}{|c|}{ Section 2} & \multicolumn{3}{|c|}{ Section 3} \\
\hline & $\mathrm{N}$ & Mean & SE & $\mathrm{N}$ & Mean & SE & $\mathrm{N}$ & Mean & SE \\
\hline \multicolumn{10}{|c|}{ PLVOL } \\
\hline 1950 & 8 & 2.40 & 0.18 & 7 & 2.70 & 0.12 & 3 & 2.79 & 0.13 \\
\hline 1952 & 4 & 2.99 & 0.16 & 3 & 2.79 & 0.13 & 3 & 2.59 & 0.44 \\
\hline 1953 & 7 & 3.10 & 0.10 & 4 & 2.79 & 0.42 & 4 & 2.90 & 0.15 \\
\hline 1954 & 6 & 2.72 & 0.31 & 7 & 3.11 & 0.08 & 6 & 2.44 & 0.29 \\
\hline 1955 & 8 & 2.82 & 0.20 & 5 & 3.19 & 0.20 & 3 & 3.06 & 0.08 \\
\hline 1956 & 3 & 2.98 & 0.47 & 3 & 2.99 & 0.45 & 6 & 2.58 & 0.43 \\
\hline 1957 & 5 & 2.61 & 0.66 & 3 & 3.48 & 0.12 & 5 & 2.29 & 0.42 \\
\hline 1958 & 4 & 3.13 & 0.23 & 5 & 2.85 & 0.37 & 5 & 2.47 & 0.33 \\
\hline 1959 & 5 & 3.36 & 0.13 & 3 & 3.37 & 0.06 & 6 & 1.95 & 0.50 \\
\hline 1960 & 2 & 2.19 & 0.48 & 2 & 3.62 & 0.32 & 2 & 2.40 & 0.09 \\
\hline 1961 & 6 & 3.07 & 0.19 & 4 & 3.41 & 0.16 & 3 & 3.30 & 0.10 \\
\hline 1963 & 12 & 2.58 & 0.16 & 26 & 2.61 & 0.11 & 13 & 2.10 & 0.14 \\
\hline 1964 & 6 & 2.75 & 0.21 & 6 & 2.44 & 0.24 & 8 & 1.88 & 0.34 \\
\hline 1966 & 7 & 2.33 & 0.14 & 8 & 2.84 & 0.11 & 5 & 2.23 & 0.28 \\
\hline 1968 & 6 & 2.92 & 0.16 & 7 & 2.90 & 0.26 & 9 & 2.02 & 0.26 \\
\hline 1969 & 6 & 2.12 & 0.15 & 8 & 2.47 & 0.18 & 5 & 2.33 & 0.22 \\
\hline 1970 & 6 & 1.88 & 0.42 & 7 & 2.55 & 0.16 & 15 & 1.77 & 0.20 \\
\hline 1971 & 8 & 2.69 & 0.14 & 7 & 2.80 & 0.09 & 10 & 1.68 & 0.19 \\
\hline 1972 & 7 & 2.04 & 0.20 & 7 & 2.22 & 0.20 & 9 & 1.35 & 0.21 \\
\hline 1973 & 5 & 2.39 & 0.11 & 5 & 2.71 & 0.34 & 5 & 2.15 & 0.39 \\
\hline 1974 & 7 & 2.92 & 0.12 & 6 & 2.45 & 0.14 & 5 & 2.33 & 0.15 \\
\hline 1975 & 6 & 2.57 & 0.23 & 6 & 3.26 & 0.09 & 4 & 2.59 & 0.29 \\
\hline 1976 & 6 & 2.56 & 0.27 & 6 & 2.31 & 0.11 & 5 & 2.43 & 0.12 \\
\hline 1977 & 4 & 2.62 & 0.20 & 6 & 2.46 & 0.24 & 5 & 3.13 & 0.12 \\
\hline 1978 & 6 & 2.31 & 0.28 & 6 & 2.59 & 0.21 & 5 & 2.55 & 0.19 \\
\hline 1979 & 7 & 2.57 & 0.09 & 6 & 2.89 & 0.06 & 6 & 2.50 & 0.20 \\
\hline 1980 & 5 & 2.57 & 0.38 & 5 & 3.17 & 0.13 & 5 & 3.06 & 0.13 \\
\hline 1981 & 5 & 2.03 & 0.37 & 5 & 2.27 & 0.26 & 5 & 2.37 & 0.15 \\
\hline 1982 & 2 & 2.85 & 0.26 & 5 & 3.19 & 0.12 & 5 & 2.97 & 0.20 \\
\hline 1983 & 4 & 2.32 & 0.21 & 4 & 2.69 & 0.14 & & & \\
\hline 1984 & 5 & 3.09 & 0.16 & 5 & 2.85 & 0.19 & 4 & 3.00 & 0.17 \\
\hline \multicolumn{10}{|c|}{ AGLA } \\
\hline 1956 & 3 & 2.87 & 0.44 & 3 & 3.15 & 0.47 & 3 & 3.62 & 0.15 \\
\hline 1957 & 2 & 3.01 & 0.17 & 2 & 3.70 & 0.30 & 1 & 3.74 & \\
\hline 1958 & 2 & 3.08 & 0.80 & 1 & 3.74 & & 1 & 3.53 & \\
\hline 1961 & 6 & 3.10 & 0.26 & 4 & 3.68 & 0.11 & 3 & 3.20 & 0.18 \\
\hline 1963 & 12 & 3.04 & 0.20 & 20 & 3.12 & 0.07 & 6 & 3.17 & 0.18 \\
\hline 1964 & 6 & 2.27 & 0.43 & 6 & 2.28 & 0.27 & 5 & 2.13 & 0.59 \\
\hline 1966 & 7 & 1.72 & 0.42 & 7 & 2.79 & 0.18 & 5 & 2.18 & 0.33 \\
\hline 1970 & & & & & & & 14 & 0.91 & 0.27 \\
\hline 1971 & & & & & & & 10 & 1.08 & 0.27 \\
\hline 1972 & 7 & 1.69 & 0.36 & 7 & 2.03 & 0.47 & 9 & 0.79 & 0.37 \\
\hline 1973 & & & & & & & 5 & 1.82 & 0.58 \\
\hline 1974 & & & & & & & 5 & 1.79 & 0.29 \\
\hline 1975 & & & & & & & 5 & 1.76 & 0.36 \\
\hline 1976 & 1 & 0.60 & & & & & 5 & 1.47 & 0.13 \\
\hline 1977 & 3 & 1.36 & 0.68 & 5 & 1.93 & 0.35 & 5 & 2.26 & 0.21 \\
\hline 1978 & 6 & 1.42 & 0.49 & 6 & 2.21 & 0.32 & 5 & 2.41 & 0.21 \\
\hline
\end{tabular}


Appendix 2. (Continued). Mean abundance indices $[\log 10(x+1)]$ with 1 standard error (SE) of different zooplankton taxa by year and section. Abbreviations shown in Table $2 . \mathrm{N}=$ number of stations with zooplankton hauls.

\begin{tabular}{|c|c|c|c|c|c|c|c|c|c|}
\hline \multirow[b]{2}{*}{ Year } & \multicolumn{3}{|c|}{ Section 1} & \multicolumn{3}{|c|}{ Section 2} & \multicolumn{3}{|c|}{ Section 3} \\
\hline & $\mathrm{N}$ & Mean & SE & $\mathrm{N}$ & Mean & SE & $\mathrm{N}$ & Mean & SE \\
\hline \multicolumn{10}{|c|}{ AGLA (Continued) } \\
\hline 1979 & 7 & 1.61 & 0.46 & 6 & 2.51 & 0.17 & 5 & 1.80 & 0.46 \\
\hline 1980 & 5 & 2.10 & 0.62 & 5 & 3.13 & 0.12 & 5 & 2.84 & 0.20 \\
\hline 1981 & 5 & 1.60 & 0.54 & 5 & 2.15 & 0.51 & 5 & 2.00 & 0.30 \\
\hline 1982 & 2 & 2.93 & 0.36 & 5 & 3.25 & 0.11 & 5 & 2.87 & 0.23 \\
\hline 1983 & 4 & 1.36 & 0.13 & 4 & 2.86 & 0.14 & & & \\
\hline \multicolumn{10}{|c|}{ WAGLA } \\
\hline 1956 & 3 & 2.87 & 0.43 & 3 & 3.14 & 0.47 & 3 & 3.62 & 0.15 \\
\hline 1957 & 2 & 3.00 & 0.17 & 2 & 3.72 & 0.32 & 1 & 3.74 & \\
\hline 1958 & 2 & 3.23 & 0.66 & 1 & 3.74 & & 1 & 3.53 & \\
\hline 1961 & 6 & 2.97 & 0.33 & 4 & 3.67 & 0.11 & 3 & 3.20 & 0.18 \\
\hline 1964 & 6 & 2.21 & 0.40 & 6 & 2.27 & 0.27 & 5 & 2.13 & 0.59 \\
\hline 1966 & 6 & 1.95 & 0.34 & 7 & 2.77 & 0.18 & 5 & 2.18 & 0.33 \\
\hline 1970 & & & & & & & 4 & 1.87 & 0.55 \\
\hline 1971 & & & & & & & 4 & 1.45 & 0.26 \\
\hline 1972 & 7 & 1.14 & 0.49 & 6 & 2.29 & 0.44 & 4 & 1.03 & 0.42 \\
\hline 1973 & & & & & & & 1 & 3.12 & \\
\hline 1974 & & & & & & & 4 & 2.02 & 0.23 \\
\hline 1976 & & & & & & & 5 & 1.47 & 0.13 \\
\hline 1978 & 5 & 1.48 & 0.52 & 6 & 2.19 & 0.32 & 5 & 2.41 & 0.21 \\
\hline 1979 & 7 & 1.50 & 0.44 & 6 & 2.51 & 0.17 & 5 & 1.80 & 0.46 \\
\hline 1980 & 5 & 2.09 & 0.62 & 5 & 3.12 & 0.12 & 5 & 2.84 & 0.20 \\
\hline 1981 & 5 & 1.60 & 0.54 & 5 & 2.15 & 0.51 & 5 & 2.00 & 0.30 \\
\hline 1982 & 2 & 2.93 & 0.36 & 5 & 3.25 & 0.11 & 5 & 2.87 & 0.23 \\
\hline 1983 & 2 & 0.72 & 0.72 & 1 & 3.13 & & & & \\
\hline
\end{tabular}

\begin{tabular}{|c|c|c|c|c|c|c|c|c|c|}
\hline \multicolumn{10}{|c|}{ RAGLA } \\
\hline 1956 & 3 & 0.74 & 0.74 & 3 & 0.65 & 0.65 & 3 & 0 & \\
\hline 1957 & 2 & 0.73 & 0.73 & 2 & 0 & & 1 & 0 & \\
\hline 1958 & 2 & 0 & & 1 & 0 & & 1 & 0 & \\
\hline 1961 & 6 & 0.66 & 0.44 & 4 & 0.53 & 0.53 & 3 & 0 & \\
\hline 1964 & 6 & 1.20 & 0.57 & 6 & 0.54 & 0.26 & 5 & 0 & \\
\hline 1966 & 6 & 1.04 & 0.47 & 7 & 0.77 & 0.38 & 5 & 0.19 & 0.19 \\
\hline 1970 & & & & & & & 4 & 0.25 & 0.25 \\
\hline 1971 & & & & & & & 4 & 0 & \\
\hline 1972 & 7 & 1.38 & 0.24 & 6 & 0.98 & 0.27 & 4 & 0 & \\
\hline 1973 & & & & & & & 1 & 0 & \\
\hline 1974 & & & & & & & 4 & 0 & \\
\hline 1976 & & & & & & & 5 & 0 & \\
\hline 1978 & 5 & 1.32 & 0.46 & 6 & 0.88 & 0.33 & 5 & 0 & \\
\hline 1979 & 7 & 0.59 & 0.35 & 6 & 0 & & 5 & 0 & \\
\hline 1980 & 5 & 0.66 & 0.32 & 5 & 0.25 & 0.25 & 5 & 0 & \\
\hline 1981 & 5 & 0.25 & 0.19 & 5 & 0.06 & 0.06 & 5 & 0.14 & 0.14 \\
\hline 1982 & 2 & 1.01 & 0.31 & 5 & 0 & & 5 & 0 & \\
\hline 1983 & 2 & 1.36 & 0.08 & 1 & 1.18 & & & & \\
\hline \multicolumn{10}{|c|}{ COP } \\
\hline 1956 & 3 & 0.52 & 0.52 & 3 & 2.92 & 0.59 & 3 & 0 & \\
\hline 1957 & 2 & 0.15 & 0.15 & 2 & 3.09 & 0.12 & 1 & 3.24 & \\
\hline
\end{tabular}


Appendix 2. (Continued). Mean abundance indices $[\log 10(x+1)]$ with 1 standard error (SE) of different zooplankton taxa by year and section. Abbreviations shown in Table 2. $\mathrm{N}=$ number of stations with zooplankton hauls.

\begin{tabular}{|c|c|c|c|c|c|c|c|c|c|}
\hline \multirow[b]{2}{*}{ Year } & \multicolumn{3}{|c|}{ Section 1} & \multicolumn{3}{|c|}{ Section 2} & \multicolumn{3}{|c|}{ Section 3} \\
\hline & $\mathrm{N}$ & Mean & SE & $\mathrm{N}$ & Mean & $\mathrm{SE}$ & $\mathrm{N}$ & Mean & SE \\
\hline \multicolumn{10}{|c|}{ COP (Continued) } \\
\hline 1958 & 2 & 4 & 0.54 & 1 & 2.92 & & 1 & 1.18 & \\
\hline 1961 & 6 & 2.55 & 0.71 & 4 & 2.23 & 0.64 & 3 & 2.46 & 0.18 \\
\hline 1963 & 12 & 1.27 & 0.33 & 20 & 1.47 & 0.16 & 6 & 0.3 & 0.22 \\
\hline 1964 & 6 & 2.35 & 0.4 & 6 & 1.68 & 0.29 & 5 & 1.42 & 0.61 \\
\hline 1966 & 7 & 0.29 & 0.25 & 7 & 0.91 & 0.51 & 5 & 0.67 & 0.67 \\
\hline 1970 & & & & & & & 14 & 0.6 & 0.25 \\
\hline 1971 & & & & & & & 10 & 0.18 & 0.12 \\
\hline 1972 & 7 & 1.47 & 0.72 & 7 & 2.24 & 0.52 & 9 & 1.09 & 0.45 \\
\hline 1973 & & & & & & & 5 & 1.01 & 0.48 \\
\hline 1974 & & & & & & & 5 & 0.71 & 0.6 \\
\hline 1975 & & & & & & & 5 & 0.84 & 0.84 \\
\hline 1976 & 1 & 0 & & & & & 5 & 0 & \\
\hline 1977 & 3 & 0.44 & 0.24 & 5 & 0.28 & 0.28 & 5 & 0.17 & 0.17 \\
\hline 1978 & 6 & 0.87 & 0.48 & 6 & 1.13 & 0.41 & 5 & 1.33 & 0.63 \\
\hline 1979 & 7 & 1.87 & 0.63 & 6 & 2.49 & 0.41 & 5 & 1.6 & 0.65 \\
\hline 1980 & 5 & 0.19 & 0.19 & 5 & 2.49 & 0.44 & 5 & 3.05 & 0.36 \\
\hline 1981 & 5 & 0.94 & 0.6 & 5 & 0 & & 5 & 2.18 & 0.55 \\
\hline 1982 & 1 & 2.55 & & 4 & 2.53 & 0.87 & 5 & 1.68 & 0.97 \\
\hline 1983 & 4 & 3.20 & 0.34 & 4 & 3.30 & 0.14 & & & \\
\hline
\end{tabular}

\section{CALFI}

\begin{tabular}{|c|c|c|c|c|c|c|c|c|c|}
\hline 1956 & 3 & 0.33 & 0.33 & 3 & 2.46 & 0.21 & 3 & 0 & \\
\hline 1957 & 2 & 0 & & 2 & 2.73 & 0.43 & 1 & 3.17 & \\
\hline 1958 & 2 & 2.99 & 0.91 & 1 & 2.43 & & 1 & 0.90 & \\
\hline 1961 & 6 & 0.91 & 0.70 & 4 & 0.58 & 0.58 & 3 & 1.63 & 0.2 \\
\hline 1963 & 12 & 0.67 & 0.28 & 20 & 0.83 & 0.19 & 6 & 0 & 0 \\
\hline 1964 & 6 & 1.51 & 0.41 & 6 & 1.60 & 0.30 & 5 & 1.10 & 0.55 \\
\hline 1966 & 7 & 0.10 & 0.10 & 7 & 0.47 & 0.38 & 5 & 0.06 & 0.06 \\
\hline 1970 & & & & & & & 12 & 0.46 & 0.24 \\
\hline 1971 & & & & & & & 10 & 0.13 & 0.1 \\
\hline 1972 & 7 & 1.29 & 0.72 & 7 & 2.02 & 0.51 & 9 & 0.41 & 0.24 \\
\hline 1973 & & & & & & & 4 & 0 & \\
\hline 1974 & & & & & & & 3 & 0 & \\
\hline 1975 & & & & & & & 4 & 0 & \\
\hline 1976 & 1 & 0 & & 4 & 0 & & 5 & 0 & \\
\hline 1977 & & & & & & & 4 & 0 & \\
\hline 1978 & 6 & 0 & & 6 & 0.17 & 0.12 & 5 & 0 & \\
\hline 1979 & 7 & 0.54 & 0.44 & 6 & 0.73 & 0.41 & 5 & 0.50 & 0.32 \\
\hline 1982 & & & & 4 & 1.58 & 0.94 & 5 & 0 & \\
\hline 1983 & 4 & 0 & & 4 & 0 & & & & \\
\hline
\end{tabular}

\section{CALHY}

$\begin{array}{rrrrrrrrrr}1956 & 3 & 0.48 & 0.48 & 3 & 1.92 & 0.69 & 3 & 0 & \\ 1957 & 2 & 0.15 & 0.15 & 2 & 2.61 & 0.25 & 1 & 2.36 & \\ 1958 & 2 & 3.84 & 0.40 & 1 & 2.72 & & 1 & 0.90 & \\ 1961 & 6 & 2.53 & 0.7 & 4 & 2.01 & 0.66 & 3 & 2.38 & 0.18 \\ 1963 & 12 & 0.84 & 0.32 & 20 & 0.98 & 0.18 & 6 & 0.21 & 0.21 \\ 1964 & 6 & 1.33 & 0.44 & 6 & 0.82 & 0.28 & 5 & 0.71 & 0.44\end{array}$


Appendix 2. (Continued). Mean abundance indices $[\log 10(x+1)]$ with 1 standard error (SE) of different zooplankton taxa by year and section. Abbreviations shown in Table 2. $\mathrm{N}=$ number of stations with zooplankton hauls.

\begin{tabular}{|c|c|c|c|c|c|c|c|c|c|}
\hline \multirow[b]{2}{*}{ Year } & \multicolumn{3}{|c|}{ Section 1} & \multicolumn{3}{|c|}{ Section 2} & \multicolumn{3}{|c|}{ Section 3} \\
\hline & $\mathrm{N}$ & Mean & $\mathrm{SE}$ & $\mathrm{N}$ & Mean & SE & $\mathrm{N}$ & Mean & SE \\
\hline \multicolumn{10}{|c|}{ CALHY (Continued) } \\
\hline 1966 & 7 & 0.19 & 0.15 & 7 & 0.37 & 0.37 & 5 & 0.34 & 0.34 \\
\hline 1970 & & & & & & & 12 & 0.40 & 0.27 \\
\hline 1971 & & & & & & & 10 & 0.08 & 0.08 \\
\hline 1972 & 7 & 1.04 & 0.55 & 7 & 1.57 & 0.43 & 9 & 0.90 & 0.36 \\
\hline 1973 & & & & & & & 4 & 0 & \\
\hline 1974 & & & & & & & 3 & 0 & \\
\hline 1975 & & & & & & & 4 & 0 & \\
\hline 1976 & 1 & 0 & & & & & 5 & 0 & \\
\hline 1977 & & & & 4 & 0 & & 4 & 0 & \\
\hline 1978 & 6 & 0.87 & 0.48 & 6 & 1.07 & 0.42 & 5 & 0.67 & 0.42 \\
\hline 1979 & 7 & 1.86 & 0.63 & 6 & 2.48 & 0.41 & 5 & 1.60 & 0.65 \\
\hline 1982 & & & & 4 & 2.40 & 0.81 & 5 & 1.68 & 0.97 \\
\hline 1983 & 4 & 3.20 & 0.34 & 4 & 3.30 & 0.14 & & & \\
\hline
\end{tabular}

\section{EUCH}

$\begin{array}{rrrrrrrrrr}1956 & 3 & 0 & & 3 & 2.23 & 0.88 & & \\ 1957 & 2 & 0 & & 2 & 0 & & 1 & 0.78 \\ 1958 & 2 & 1.54 & 1.54 & 1 & 1.56 & & 1 & 0 & 0.18 \\ 1961 & 6 & 0.49 & 0.49 & 4 & 0.17 & 0.17 & 2 & 0.66 & 0.18 \\ 1963 & 12 & 0.23 & 0.18 & 20 & 0.47 & 0.14 & 6 & 0.18 & 0.11 \\ 1964 & 6 & 2.15 & 0.37 & 6 & 0.10 & 0.06 & 5 & 1.09 & 0.63 \\ 1966 & 7 & 0.27 & 0.23 & 6 & 0.92 & 0.59 & 5 & 0.67 & 0.67 \\ 1970 & & & & & & & 14 & 0.19 & 0.17 \\ 1971 & & & & 7 & 0.40 & 0.28 & 10 & 0 & 0 \\ 1972 & 7 & 1.02 & 0.62 & & & & 5 & 0.76 & 0.44 \\ 1973 & & & & & & & 5 & 0.60 & 0.60 \\ 1974 & & & & & & & 5 & 0.81 & 0.81 \\ 1975 & & & & 4 & 0 & & 5 & 0 & 0 \\ 1976 & 1 & 0 & & 6 & 0 & & 5 & 0.66 & 0.66 \\ 1977 & & & & 6 & 0 & & 5 & 0.10 & 0.10 \\ 1978 & 6 & 0 & & 5 & 0 & & 5 & 0 & \end{array}$

HYPER

$\begin{array}{rrrrrrrrrr}1956 & 3 & 1.24 & 0.50 & 3 & 1.68 & 0.58 & 3 & 0.57 & 0.27 \\ 1957 & 2 & 0.82 & 0.22 & 2 & 0.57 & 0.57 & 1 & 1.57 & \\ 1958 & 2 & 1.82 & 0.78 & 1 & 0 & & 1 & 0.30 & \\ 1961 & 6 & 0.97 & 0.31 & 4 & 0.88 & 0.36 & 3 & 1.41 & 0.11 \\ 1963 & 12 & 1.47 & 0.28 & 20 & 1.04 & 0.19 & 6 & 1.19 & 0.49 \\ 1964 & 6 & 1.58 & 0.39 & 6 & 0.71 & 0.22 & 5 & 1.60 & 0.47 \\ 1966 & 7 & 1.07 & 0.18 & 7 & 0.94 & 0.10 & 5 & 1.54 & 0.42 \\ 1970 & & & & & & & 14 & 0.98 & 0.16 \\ 1971 & & & & & & & 10 & 1.03 & 0.15 \\ 1972 & 7 & 1.13 & 0.27 & & 1.93 & 0.18 & 9 & 0.87 & 0.32 \\ 1973 & & & & & & & 5 & 1.25 & 0.36 \\ 1974 & & & & & & & 5 & 1.37 & 0.38\end{array}$


Appendix 2. (Continued). Mean abundance indices $[\log 10(x+1)]$ with 1 standard error (SE) of different zooplankton taxa by year and section. Abbreviations shown in Table 2. $\mathrm{N}=$ number of stations with zooplankton hauls.

\begin{tabular}{|c|c|c|c|c|c|c|c|c|c|}
\hline \multirow[b]{2}{*}{ Year } & \multicolumn{3}{|c|}{ Section 1} & \multicolumn{3}{|c|}{ Section 2} & \multicolumn{3}{|c|}{ Section 3} \\
\hline & $\mathrm{N}$ & Mean & SE & $\mathrm{N}$ & Mean & SE & $\mathrm{N}$ & Mean & SE \\
\hline \multicolumn{10}{|c|}{ HYPER } \\
\hline 1975 & & & & & & & 5 & 1.64 & 0.56 \\
\hline 1976 & 1 & 1.83 & & & & & 5 & 1.17 & 0.26 \\
\hline 1977 & 3 & 1.13 & 0.51 & 5 & 1.43 & 0.49 & 5 & 0.68 & 0.26 \\
\hline 1978 & 6 & 0.90 & 0.34 & 6 & 0.92 & 0.07 & 5 & 0.94 & 0.35 \\
\hline 1979 & 7 & 1.24 & 0.32 & 6 & 1.54 & 0.37 & 5 & 0.80 & 0.10 \\
\hline 1980 & 5 & 1.37 & 0.15 & 5 & 2.47 & 0.32 & 5 & 2.43 & 0.13 \\
\hline 1981 & 5 & 0.87 & 0.35 & 5 & 2.26 & 0.27 & 5 & 2.43 & 0.17 \\
\hline 1982 & 2 & 1.36 & 0.08 & 5 & 1.70 & 0.38 & 5 & 1.93 & 0.25 \\
\hline 1983 & 4 & 2.49 & 0.24 & 4 & 2.25 & 0.20 & & & \\
\hline \multicolumn{10}{|c|}{ EUP } \\
\hline 1956 & 3 & 0.16 & 0.16 & 3 & 0.91 & 0.59 & 3 & 0 & \\
\hline 1957 & 2 & 0.71 & 0.41 & 2 & 2.12 & 0.06 & 1 & 1.76 & \\
\hline 1958 & 2 & 1.49 & 1.49 & 1 & 0.90 & & 1 & 1.18 & \\
\hline 1961 & 6 & 1.09 & 0.50 & 4 & 1.54 & 0.71 & 3 & 2.08 & 0.67 \\
\hline 1963 & 12 & 0.9 & 0.21 & 20 & 1.15 & 0.13 & 6 & 0.38 & 0.23 \\
\hline 1964 & 6 & 1.28 & 0.44 & 6 & 0.74 & 0.29 & 5 & 0.96 & 0.56 \\
\hline 1966 & 7 & 0.19 & 0.10 & 6 & 0.63 & 0.44 & 5 & 0.34 & 0.34 \\
\hline 1970 & & & & & & & 14 & 0.21 & 0.09 \\
\hline 1971 & & & & & & & 10 & 0.15 & 0.15 \\
\hline 1972 & 7 & 0.45 & 0.27 & 7 & 0.67 & 0.21 & 9 & 0.54 & 0.28 \\
\hline 1973 & & & & & & & 5 & 0.45 & 0.27 \\
\hline 1974 & & & & & & & 5 & 0.52 & 0.32 \\
\hline 1975 & & & & & & & 5 & 0.68 & 0.36 \\
\hline 1976 & 1 & 0 & & & & & 5 & 0 & \\
\hline 1977 & 3 & 0 & & 5 & 0.24 & 0.24 & 5 & 0.10 & 0.10 \\
\hline 1978 & 6 & 0 & & 6 & 0.46 & 0.25 & 5 & 0.51 & 0.51 \\
\hline 1979 & 7 & 0.74 & 0.24 & 6 & 1.63 & 0.4 & 5 & 0.50 & 0.34 \\
\hline 1980 & 5 & 0 & & 5 & 0.25 & 0.25 & 5 & 1.08 & 0.3 \\
\hline 1981 & 5 & 0.39 & 0.19 & 5 & 0.35 & 0.22 & 5 & 0.85 & 0.24 \\
\hline 1982 & 2 & 0.35 & 0.35 & 5 & 0.36 & 0.24 & 5 & 0.33 & 0.26 \\
\hline 1983 & 4 & 0.23 & 0.23 & 4 & 0.82 & 0.09 & & & \\
\hline
\end{tabular}

\section{LIMA}

\begin{tabular}{|c|c|c|c|c|c|c|c|c|c|}
\hline 1956 & 3 & 1.85 & 1.07 & 3 & 3.55 & 0.33 & 3 & 3.29 & 0.79 \\
\hline 1957 & 2 & 0.75 & 0.75 & 2 & 2.82 & 0.27 & 1 & 3.26 & \\
\hline 1958 & 2 & 2.26 & 0.25 & 1 & 3.05 & & & & \\
\hline 1961 & 6 & 0.63 & 0.38 & 4 & 0.51 & 0.29 & 3 & 0.23 & 0.23 \\
\hline 1963 & 12 & 1.41 & 0.31 & 20 & 1.31 & 0.13 & 6 & 0.97 & 0.39 \\
\hline 1964 & 6 & 1.54 & 0.49 & 6 & 1.53 & 0.28 & 5 & 0.86 & 0.30 \\
\hline 1966 & 7 & 0.53 & 0.33 & 7 & 1.59 & 0.29 & 5 & 0.72 & 0.45 \\
\hline 1970 & & & & & & & 14 & 0.57 & 0.17 \\
\hline 1971 & & & & & & & 10 & 0.18 & 0.10 \\
\hline 1972 & 7 & 0.96 & 0.39 & 7 & 2.23 & 0.31 & 9 & 0.91 & 0.33 \\
\hline 1973 & & & & & & & 5 & 0.76 & 0.35 \\
\hline 1974 & & & & & & & 5 & 1.00 & 0.42 \\
\hline 1975 & & & & & & & 5 & 0.58 & 0.43 \\
\hline 1976 & 1 & 0 & & & & & 5 & 1.07 & 0.39 \\
\hline 1977 & 3 & 0.53 & 0.53 & 5 & 0.19 & 0.12 & 5 & 0.34 & 0.17 \\
\hline
\end{tabular}


Appendix 2. (Continued). Mean abundance indices $[\log 10(x+1)]$ with 1 standard error (SE) of different zooplankton taxa by year and section. Abbreviations shown in Table $2 . \mathrm{N}=$ number of stations with zooplankton hauls.

\begin{tabular}{|c|c|c|c|c|c|c|c|c|c|}
\hline \multirow[b]{2}{*}{ Year } & \multicolumn{3}{|c|}{ Section 1} & \multicolumn{3}{|c|}{ Section 2} & \multicolumn{3}{|c|}{ Section 3} \\
\hline & $\mathrm{N}$ & Mean & SE & $\mathrm{N}$ & Mean & SE & $\mathrm{N}$ & Mean & SE \\
\hline \multicolumn{10}{|c|}{ LIMA (Continued) } \\
\hline 1978 & 6 & 0.53 & 0.27 & 6 & 0.57 & 0.37 & 5 & 0.57 & 0.5 \\
\hline 1979 & 7 & 0.67 & 0.33 & 6 & 2.01 & 0.36 & 5 & 1.42 & 0.41 \\
\hline 1980 & 5 & 0.71 & 0.44 & 5 & 3.27 & 0.3 & 5 & 3.21 & 0.15 \\
\hline 1981 & 5 & 0 & & 5 & 2.29 & 0.35 & 5 & 2.91 & 0.15 \\
\hline 1982 & 2 & 0.48 & 0.48 & 5 & 2.67 & 0.26 & 5 & 2.08 & 0.55 \\
\hline 1983 & 4 & 1.64 & 0.63 & 4 & 2.18 & 0.45 & & & \\
\hline
\end{tabular}

\begin{tabular}{|c|c|c|c|c|c|c|c|c|c|}
\hline \multicolumn{10}{|c|}{ LIMR } \\
\hline 1956 & 3 & 1.61 & 1.16 & 3 & 3.51 & 0.33 & 3 & 3.03 & 0.69 \\
\hline 1957 & 2 & 0.75 & 0.75 & 2 & 2.82 & 0.28 & 1 & 3.26 & \\
\hline 1958 & 2 & 1.25 & 1.25 & 1 & 2.85 & & & & \\
\hline 1961 & 5 & 0.25 & 0.16 & 4 & 0.46 & 0.27 & 3 & 0.16 & 0.16 \\
\hline 1963 & 12 & 1.39 & 0.31 & 20 & 1.3 & 0.13 & 6 & 0.96 & 0.39 \\
\hline 1964 & 6 & 1.47 & 0.51 & 6 & 1.53 & 0.28 & 5 & 0.80 & 0.33 \\
\hline 1966 & 7 & 0.44 & 0.34 & 7 & 1.58 & 0.29 & 5 & 0.60 & 0.45 \\
\hline 1970 & & & & & & & 14 & 0.54 & 0.17 \\
\hline 1971 & & & & & & & 10 & 0.11 & 0.08 \\
\hline 1972 & 7 & 0.65 & 0.33 & 7 & 1.84 & 0.21 & 9 & 0.85 & 0.34 \\
\hline 1973 & & & & & & & 5 & 0.76 & 0.35 \\
\hline 1974 & & & & & & & 5 & 1 & 0.42 \\
\hline 1975 & & & & & & & 3 & 0 & \\
\hline 1976 & 1 & 0 & . & & & & 2 & 0 & \\
\hline 1977 & 2 & 0 & & 3 & 0 & & 2 & 0 & \\
\hline 1978 & 6 & 0.43 & 0.22 & 6 & 0.50 & 0.32 & 5 & 0.55 & 0.47 \\
\hline 1979 & 7 & 0.39 & 0.26 & 6 & 1.17 & 0.22 & 5 & 1.22 & 0.39 \\
\hline 1980 & 5 & 0.52 & 0.34 & 5 & 2.62 & 0.18 & 5 & 2.32 & 0.21 \\
\hline 1981 & 5 & 0 & & 5 & 2.08 & 0.37 & 5 & 2.61 & 0.10 \\
\hline 1982 & 2 & 0.42 & 0.42 & 5 & 2.03 & 0.38 & 5 & 1.74 & 0.44 \\
\hline 1983 & 4 & 1.52 & 0.56 & 4 & 1.73 & 0.59 & & & \\
\hline
\end{tabular}

\section{LIMH}

$\begin{array}{rrrrrrrrrr}1956 & 3 & 1.15 & 0.83 & 3 & 1.64 & 0.60 & 3 & 2.86 & 0.95 \\ 1957 & 2 & 0 & & 2 & 0.39 & 0.39 & 1 & 0 & \\ 1958 & 2 & 1.00 & 1.00 & 1 & 2.66 & & 1 & 0 & \\ 1961 & 5 & 0.54 & 0.46 & 4 & 0.17 & 0.17 & 3 & 0 & \\ 1963 & 12 & 0.30 & 0.19 & 20 & 0.06 & 0.05 & 6 & 0.13 & 0.13 \\ 1964 & 6 & 0.52 & 0.37 & 6 & 0.05 & 0.05 & 5 & 0.06 & 0.06 \\ 1966 & 7 & 0.09 & 0.09 & 7 & 0.29 & 0.12 & 5 & 0.17 & 0.17 \\ 1970 & & & & & & & 14 & 0.08 & 0.04 \\ 1971 & & & & & & & 10 & 0.07 & 0.07 \\ 1972 & 7 & 0.66 & 0.35 & & 1.80 & 0.45 & 5 & 0.31 & 0.17 \\ 1973 & & & & & & 5 & 0 & 0 \\ 1974 & & & & & & & 2 & 0 & 0 \\ 1975 & & & & & & & 2 & 0 & \\ 1976 & 1 & 0 & & 3 & 0 & & 5 & 0.39 & 0.39 \\ 1977 & 2 & 0 & & 6 & 0.43 & 0.30 & 5 & 0.66 & 0.46 \\ 1978 & 6 & 0.34 & 0.22 & 6 & 1.89 & 0.42 & 5 & 3.13 & 0.16 \\ 1979 & 7 & 0.28 & 0.28 & 5 & 2.97 & 0.52 & & 5\end{array}$


Appendix 2. (Continued). Mean abundance indices $[\log 10(x+1)]$ with 1 standard error (SE) of different zooplankton taxa by year and section. Abbreviations shown in Table 2. $\mathrm{N}=$ number of stations with zooplankton hauls.

\begin{tabular}{|c|c|c|c|c|c|c|c|c|c|}
\hline \multirow[b]{2}{*}{ Year } & \multicolumn{3}{|c|}{ Section 1} & \multicolumn{3}{|c|}{ Section 2} & \multicolumn{3}{|c|}{ Section 3} \\
\hline & $\mathrm{N}$ & Mean & SE & $\mathrm{N}$ & Mean & SE & $\mathrm{N}$ & Mean & SE \\
\hline \multicolumn{10}{|c|}{ LIMH (Continued) } \\
\hline 1981 & 5 & 0 & & 5 & 1.64 & 0.34 & 5 & 2.46 & 0.30 \\
\hline 1982 & 2 & 0.24 & 0.24 & 5 & 2.04 & 0.48 & 5 & 1.58 & 0.66 \\
\hline 1983 & 4 & 1.17 & 0.68 & 4 & 1.96 & 0.38 & & & \\
\hline \multicolumn{10}{|c|}{ CLIO } \\
\hline 1956 & 3 & 1.41 & 0.43 & 3 & 1.93 & 0.1 & 3 & 1.85 & 0.43 \\
\hline 1957 & 2 & 2.04 & 0.06 & 2 & 0.69 & 0.69 & 1 & 1.04 & \\
\hline 1958 & 2 & 1.54 & 0.37 & 1 & 1.34 & & 1 & 0.70 & \\
\hline 1961 & 6 & 0.82 & 0.28 & 4 & 0.55 & 0.32 & 3 & 0.70 & 0.11 \\
\hline 1963 & 12 & 1.14 & 0.06 & 20 & 1.33 & 0.06 & 6 & 1.13 & 0.18 \\
\hline 1964 & 6 & 1.21 & 0.16 & 6 & 1.05 & 0.11 & 5 & 0.79 & 0.15 \\
\hline 1966 & 7 & 1.33 & 0.28 & 7 & 0.49 & 0.1 & 5 & 0.71 & 0.11 \\
\hline 1970 & & & & & & & 14 & 0.58 & 0.13 \\
\hline 1971 & & & & & & & 10 & 0.69 & 0.21 \\
\hline 1972 & 7 & 1.3 & 0.19 & 7 & 1.15 & 0.14 & 9 & 0.76 & 0.14 \\
\hline 1973 & & & & & & & 5 & 0.94 & 0.13 \\
\hline 1974 & & & & & & & 5 & 0.97 & 0.31 \\
\hline 1975 & & & & & & & 5 & 1.05 & 0.12 \\
\hline 1976 & 1 & 0.48 & & & & & 5 & 1.44 & 0.14 \\
\hline 1977 & 3 & 0.64 & 0.26 & 5 & 0.62 & 0.12 & 5 & 0.83 & 0.23 \\
\hline 1978 & 6 & 1.28 & 0.25 & 6 & 1.19 & 0.23 & 5 & 1.56 & 0.15 \\
\hline 1979 & 7 & 1.10 & 0.13 & 6 & 1.26 & 0.31 & 5 & 1.50 & 0.26 \\
\hline 1980 & 5 & 1.30 & 0.39 & 5 & 2.14 & 0.19 & 5 & 1.86 & 0.18 \\
\hline 1981 & 5 & 1.24 & 0.10 & 5 & 1.60 & 0.20 & 5 & 1.31 & 0.27 \\
\hline 1982 & 2 & 0.94 & 0.34 & 5 & 1.76 & 0.19 & 5 & 1.78 & 0.18 \\
\hline 1983 & 4 & 1.06 & 0.12 & 4 & 1.05 & 0.15 & & & \\
\hline \multicolumn{10}{|c|}{ CHAE } \\
\hline 1956 & 3 & 0 & & 3 & 1.73 & 0.42 & 3 & 0 & \\
\hline 1957 & 2 & 0 & & 2 & 1.15 & 0.19 & 1 & 0 & \\
\hline 1958 & 2 & 1.73 & 1.73 & 1 & 1.49 & & 1 & 0 & \\
\hline 1961 & 6 & 0.61 & 0.50 & 4 & 0.75 & 0.50 & 3 & 1.02 & 0.13 \\
\hline 1963 & 12 & 0.34 & 0.22 & 20 & 0.34 & 0.09 & 6 & 0.05 & 0.05 \\
\hline 1964 & 6 & 0.91 & 0.3 & 6 & 1.82 & 0.19 & 5 & 1.26 & 0.58 \\
\hline 1966 & 7 & 0.17 & 0.17 & 7 & 0.09 & 0.06 & 5 & 0 & \\
\hline 1970 & & & & & & & 14 & 0.38 & 0.17 \\
\hline 1971 & & & & & & & 10 & 0.56 & 0.18 \\
\hline 1972 & 7 & 1 & 0.52 & 7 & 1.18 & 0.34 & 9 & 0.83 & 0.38 \\
\hline 1973 & & & & & & & 5 & 0.27 & 0.2 \\
\hline 1974 & & & & & & & 5 & 0.36 & 0.36 \\
\hline 1975 & & & & & & & 5 & 0.10 & 0.10 \\
\hline 1976 & 1 & 0 & & & & & 5 & 0.19 & 0.12 \\
\hline 1977 & 3 & 0.30 & 0.17 & 5 & 0.56 & 0.26 & 5 & 0.10 & 0.10 \\
\hline 1978 & 6 & 0.10 & 0.10 & 6 & 0.05 & 0.05 & 5 & 0.23 & 0.16 \\
\hline 1979 & 7 & 0.96 & 0.38 & 6 & 0.90 & 0.46 & 5 & 0.54 & 0.33 \\
\hline 1980 & 5 & 0 & & 5 & 0 & & 5 & 0.69 & 0.42 \\
\hline 1981 & 5 & 0.22 & 0.22 & 5 & 0 & & 5 & 0.70 & 0.45 \\
\hline 1982 & 2 & 0 & & 5 & 0 & & 5 & 0.24 & 0.15 \\
\hline 1983 & 4 & 0.08 & 0.08 & 4 & 0.49 & 0.30 & & & \\
\hline
\end{tabular}


Appendix 2. (Continued). Mean abundance indices $[\log 10(x+1)]$ with 1 standard error (SE) of different zooplankton taxa by year and section. Abbreviations shown in Table $2 . \mathrm{N}=$ number of stations with zooplankton hauls.

\begin{tabular}{|c|c|c|c|c|c|c|c|c|c|}
\hline \multirow[b]{2}{*}{ Year } & \multicolumn{3}{|c|}{ Section 1} & \multicolumn{3}{|c|}{ Section 2} & \multicolumn{3}{|c|}{ Section 3} \\
\hline & $\mathrm{N}$ & Mean & SE & $\mathrm{N}$ & Mean & SE & $\mathrm{N}$ & Mean & SE \\
\hline \multicolumn{10}{|c|}{ SHR } \\
\hline 1956 & 3 & 0.52 & 0.52 & 3 & 1.33 & 0.56 & 3 & 1.12 & 0.53 \\
\hline 1957 & 2 & 0.56 & 0.56 & 2 & 2.49 & 0.27 & 1 & 0.78 & \\
\hline 1958 & 2 & 1.68 & 0.06 & 1 & 0.60 & & 1 & 0.85 & \\
\hline 1961 & 6 & 0.95 & 0.36 & 4 & 0.97 & 0.58 & 3 & 0.43 & 0.22 \\
\hline 1963 & 12 & 0.98 & 0.24 & 20 & 1.55 & 0.13 & 6 & 1.51 & 0.19 \\
\hline 1964 & 6 & 1.46 & 0.27 & 6 & 1.06 & 0.24 & 5 & 1.66 & 0.15 \\
\hline 1966 & 7 & 0.46 & 0.15 & 7 & 0.67 & 0.23 & 5 & 0.85 & 0.33 \\
\hline 1970 & & & & & & & 14 & 0.8 & 0.21 \\
\hline 1971 & & & & & & & 10 & 1.15 & 0.35 \\
\hline 1972 & 7 & 1.54 & 0.38 & 7 & 1.98 & 0.28 & 9 & 1.3 & 0.34 \\
\hline 1973 & & & & & & & 5 & 1.45 & 0.3 \\
\hline 1974 & & & & & & & 5 & 1.97 & 0.29 \\
\hline 1975 & & & & & & & 5 & 1.60 & 0.18 \\
\hline 1976 & 1 & 0 & & & & & 5 & 1.14 & 0.37 \\
\hline 1977 & 3 & 1.23 & 0.58 & 5 & 0.77 & 0.36 & 5 & 1.28 & 0.44 \\
\hline 1978 & 6 & 0.13 & 0.09 & 6 & 0.35 & 0.22 & 5 & 0.46 & 0.29 \\
\hline 1979 & 7 & 1.00 & 0.41 & 6 & 0.95 & 0.28 & 5 & 0.32 & 0.23 \\
\hline 1980 & 5 & 0.53 & 0.24 & 5 & 1.17 & 0.30 & 5 & 1.34 & 0.55 \\
\hline 1981 & 5 & 0.46 & 0.23 & 5 & 0.49 & 0.30 & 5 & 1.09 & 0.51 \\
\hline 1982 & 2 & 2.23 & 0.20 & 5 & 2.61 & 0.27 & 5 & 0.85 & 0.30 \\
\hline \multicolumn{10}{|c|}{ CRAB } \\
\hline 1956 & 3 & 1.10 & 0.65 & 3 & 0.93 & 0.51 & 3 & 0 & \\
\hline 1957 & 2 & 1.61 & 0.66 & 2 & 1.35 & 0.39 & 1 & 0.78 & \\
\hline 1958 & 2 & 0 & & 1 & 0 & & 1 & 1.46 & \\
\hline 1961 & 6 & 1.10 & 0.27 & 4 & 0.5 & 0.31 & 3 & 0.58 & 0.29 \\
\hline 1963 & 12 & 1.86 & 0.33 & 20 & 0.8 & 0.15 & 6 & 0.13 & 0.09 \\
\hline 1964 & 6 & 2.16 & 0.45 & 6 & 0.82 & 0.08 & 5 & 1.23 & 0.25 \\
\hline 1966 & 7 & 1.64 & 0.31 & 7 & 0.22 & 0.11 & 5 & 0.55 & 0.4 \\
\hline 1970 & & & & & & & 14 & 0.59 & 0.21 \\
\hline 1971 & & & & & & & 10 & 1.33 & 0.28 \\
\hline 1972 & 7 & 2.14 & 0.51 & 7 & 1.31 & 0.2 & 9 & 1.51 & 0.39 \\
\hline 1973 & & & & & & & 5 & 1.76 & 0.69 \\
\hline 1974 & & & & & & & 5 & 1.04 & 0.32 \\
\hline 1975 & & & & & & & 5 & 0.97 & 0.32 \\
\hline 1976 & 1 & 0 & & & & & 5 & 0.22 & 0.13 \\
\hline 1977 & 3 & 2.04 & 1.02 & 5 & 0 & & 5 & 0 & \\
\hline 1978 & 6 & 0.74 & 0.42 & 6 & 0.27 & 0.13 & 5 & 0.47 & 0.29 \\
\hline 1979 & 7 & 0.91 & 0.51 & 6 & 0.33 & 0.33 & 5 & 0 & \\
\hline 1980 & 5 & 1.06 & 0.47 & 5 & 0.33 & 0.33 & 5 & 0 & \\
\hline 1981 & 5 & 0.54 & 0.37 & 5 & 0 & & 5 & 0.57 & 0.35 \\
\hline 1982 & 2 & 1.38 & 1.38 & 5 & 0.51 & 0.20 & 5 & 1.27 & 0.45 \\
\hline 1983 & 4 & 1.52 & 0.21 & 4 & 0.15 & 0.15 & & & \\
\hline \multicolumn{10}{|c|}{ GONA } \\
\hline 1956 & 3 & 0.44 & 0.44 & 3 & 0.69 & 0.47 & 3 & 0.23 & 0.23 \\
\hline 1957 & 2 & 0.24 & 0.24 & 2 & 0.65 & 0.35 & 1 & 1.32 & \\
\hline 1958 & 2 & 0.52 & 0.52 & 1 & 0.7 & & 1 & 0 & \\
\hline 1961 & 6 & 0.56 & 0.20 & 4 & 0.62 & 0.33 & 3 & 1.10 & 0.20 \\
\hline
\end{tabular}


Appendix 2. (Continued). Mean abundance indices $[\log 10(x+1)]$ with 1 standard error (SE) of different zooplankton taxa by year and section. Abbreviations shown in Table 2. $\mathrm{N}=$ number of stations with zooplankton hauls.

\begin{tabular}{|c|c|c|c|c|c|c|c|c|c|}
\hline \multirow[b]{2}{*}{ Year } & \multicolumn{3}{|c|}{ Section 1} & \multicolumn{3}{|c|}{ Section 2} & \multicolumn{3}{|c|}{ Section 3} \\
\hline & $\mathrm{N}$ & Mean & SE & $\mathrm{N}$ & Mean & SE & $\mathrm{N}$ & Mean & SE \\
\hline \multicolumn{10}{|c|}{ GONA (Continued) } \\
\hline 1963 & 12 & 0.72 & 0.16 & 20 & 0.69 & 0.11 & 6 & 0.60 & 0.32 \\
\hline 1964 & 6 & 0.38 & 0.14 & 6 & 0.9 & 0.23 & 5 & 0.52 & 0.23 \\
\hline 1966 & 7 & 0.16 & 0.12 & 8 & 0.3 & 0.1 & 5 & 0.26 & 0.26 \\
\hline 1970 & & & & & & & 14 & 0.04 & 0.03 \\
\hline 1972 & 7 & 0.04 & 0.04 & 7 & 0.31 & 0.1 & 9 & 0.32 & 0.16 \\
\hline 1973 & & & & & & & 5 & 0.16 & 0.1 \\
\hline 1974 & & & & & & & 5 & 0.35 & 0.21 \\
\hline 1975 & & & & & & & 5 & 0.18 & 0.18 \\
\hline 1976 & 1 & 0 & & & & & 5 & 0.62 & 0.23 \\
\hline 1977 & 3 & 0.16 & 0.16 & 5 & 0.17 & 0.17 & 5 & 0.45 & 0.32 \\
\hline 1978 & 6 & 0.10 & 0.06 & 6 & 0.32 & 0.16 & 5 & 0.44 & 0.27 \\
\hline 1979 & 7 & 0.04 & 0.04 & 6 & 0.21 & 0.10 & 5 & 0.14 & 0.14 \\
\hline 1980 & 5 & 0.47 & 0.47 & 5 & 1.46 & 0.22 & 5 & 0.97 & 0.34 \\
\hline 1981 & 5 & 0 & & 5 & 0.17 & 0.17 & 5 & 0.45 & 0.28 \\
\hline 1982 & 2 & 0.52 & 0.52 & 5 & 0.93 & 0.36 & 5 & 0.28 & 0.28 \\
\hline 1983 & 4 & 0 & & 4 & 0.15 & 0.09 & & & \\
\hline \multicolumn{10}{|c|}{ COD } \\
\hline 1950 & 8 & 0.84 & 0.21 & 7 & 1.05 & 0.28 & 3 & 1.20 & 0.03 \\
\hline 1952 & 6 & 0.20 & 0.13 & 4 & 0.62 & 0.21 & 3 & 0.38 & 0.25 \\
\hline 1953 & 11 & 0.51 & 0.15 & 6 & 0.85 & 0.31 & 6 & 0.18 & 0.11 \\
\hline 1954 & 6 & 0.79 & 0.11 & 7 & 0.57 & 0.09 & 6 & 0.10 & 0.06 \\
\hline 1955 & 8 & 0.62 & 0.12 & 6 & 0.55 & 0.09 & 3 & 0.30 & 0.17 \\
\hline 1956 & 3 & 0.23 & 0.23 & 3 & 0.30 & 0.17 & 6 & 0.31 & 0.1 \\
\hline 1957 & 5 & 1.47 & 0.40 & 3 & 1.45 & 0.34 & 5 & 0.38 & 0.19 \\
\hline 1958 & 4 & 0.69 & 0.26 & 5 & 0.24 & 0.15 & 5 & 0.62 & 0.21 \\
\hline 1959 & 5 & 0.54 & 0.15 & 4 & 0.59 & 0.26 & 6 & 0.38 & 0.14 \\
\hline 1960 & 2 & 0.30 & 0.30 & 2 & 1.29 & 0.25 & 2 & 0.30 & \\
\hline 1961 & 6 & 0.65 & 0.20 & 4 & 0.66 & 0.16 & 3 & 0.10 & 0.10 \\
\hline 1962 & 1 & 0 & & & & & 3 & 0 & \\
\hline 1963 & 13 & 0.33 & 0.09 & 26 & 0.29 & 0.07 & 14 & 0.31 & 0.12 \\
\hline 1964 & 6 & 0.17 & 0.12 & 6 & 0.10 & 0.06 & 8 & 0.18 & 0.14 \\
\hline 1966 & 7 & 0.31 & 0.10 & 8 & 0.64 & 0.09 & 5 & 0.06 & 0.06 \\
\hline 1968 & 6 & 0.64 & 0.22 & 7 & 0.86 & 0.20 & 9 & 0.07 & 0.04 \\
\hline 1969 & 6 & 0.21 & 0.16 & 8 & 0.59 & 0.15 & 5 & 0.12 & 0.07 \\
\hline 1970 & 6 & 0.19 & 0.19 & 7 & 0.09 & 0.06 & 15 & 0.11 & 0.06 \\
\hline 1971 & 8 & 0.16 & 0.08 & 7 & 0.20 & 0.11 & 10 & 0.33 & 0.11 \\
\hline 1972 & 7 & 0.24 & 0.07 & 7 & 0.33 & 0.13 & 9 & 0 & \\
\hline 1973 & 5 & 0.24 & 0.11 & 5 & 0.19 & 0.12 & 5 & 0.22 & 0.13 \\
\hline 1974 & 7 & 0.31 & 0.09 & 6 & 0.10 & 0.06 & 5 & 0.10 & 0.1 \\
\hline 1975 & 6 & 0.84 & 0.10 & 6 & 0.31 & 0.11 & 5 & 0.19 & 0.12 \\
\hline 1976 & 6 & 0.05 & 0.05 & 6 & 0.33 & 0.08 & 5 & 0.10 & 0.10 \\
\hline 1977 & 4 & 0.15 & 0.09 & 6 & 0.13 & 0.09 & 5 & 0.22 & 0.09 \\
\hline 1978 & 6 & 0.08 & 0.08 & 6 & 0.10 & 0.06 & 5 & 0.06 & 0.06 \\
\hline 1979 & 7 & 0.27 & 0.14 & 6 & 0.26 & 0.13 & 6 & 0.15 & 0.07 \\
\hline 1980 & 5 & 0.60 & 0.19 & 5 & 0.52 & 0.24 & 5 & 0.06 & 0.06 \\
\hline 1981 & 5 & 0.06 & 0.06 & 5 & 0.18 & 0.12 & 5 & 0.12 & 0.07 \\
\hline 1982 & 2 & 0.69 & 0.21 & 5 & 1.15 & 0.17 & 5 & 0.92 & 0.2 \\
\hline 1983 & 4 & 0.08 & 0.08 & 4 & 0.72 & 0.26 & & & \\
\hline 1984 & 5 & 0.06 & 0.06 & 5 & 0.62 & 0.36 & 4 & 0.21 & 0.21 \\
\hline
\end{tabular}


Appendix 2. (Continued). Mean abundance indices $[\log 10(x+1)]$ with 1 standard error (SE) of different zooplankton taxa by year and section. Abbreviations shown in Table 2. $\mathrm{N}=$ number of stations with zooplankton hauls.

\begin{tabular}{|c|c|c|c|c|c|c|c|c|c|}
\hline \multirow[b]{2}{*}{ Year } & \multicolumn{3}{|c|}{ Section 1} & \multicolumn{3}{|c|}{ Section 2} & \multicolumn{3}{|c|}{ Section 3} \\
\hline & $\mathrm{N}$ & Mean & SE & $\mathrm{N}$ & Mean & SE & $\mathrm{N}$ & Mean & SE \\
\hline \multicolumn{10}{|c|}{ GHL } \\
\hline 1950 & 8 & 0.30 & 0.11 & 7 & 1.31 & 0.17 & 3 & 1.15 & 0.39 \\
\hline 1952 & 6 & 0.31 & 0.22 & 4 & 1.28 & 0.49 & 3 & 0.71 & 0.39 \\
\hline 1953 & 11 & 0.27 & 0.12 & 6 & 0.61 & 0.31 & 6 & 0.30 & 0.13 \\
\hline 1954 & 6 & 1.00 & 0.31 & 7 & 1.72 & 0.16 & 6 & 0.26 & 0.17 \\
\hline 1955 & 8 & 0.76 & 0.23 & 6 & 0.86 & 0.31 & 3 & 0.16 & 0.16 \\
\hline 1956 & 3 & 0.57 & 0.42 & 3 & 0.65 & 0.44 & 6 & 0.2 & 0.15 \\
\hline 1957 & 5 & 0.50 & 0.26 & 3 & 0.73 & 0.22 & 5 & 0.06 & 0.06 \\
\hline 1958 & 4 & 0.49 & 0.4 & 5 & 0.81 & 0.24 & 5 & 0.06 & 0.06 \\
\hline 1959 & 5 & 0.30 & 0.16 & 4 & 1.10 & 0.30 & 6 & 0 & \\
\hline 1960 & 2 & 0.24 & 0.24 & 2 & 0.87 & 0.57 & 2 & 0 & \\
\hline 1961 & 6 & 0.35 & 0.14 & 4 & 0.65 & 0.32 & 3 & 0.36 & 0.23 \\
\hline 1962 & 1 & 0 & & & & & 3 & 0 & \\
\hline 1963 & 13 & 0.56 & 0.15 & 26 & 0.52 & 0.08 & 14 & 0.24 & 0.09 \\
\hline 1964 & 6 & 0.56 & 0.22 & 6 & 0.56 & 0.21 & 8 & 0.15 & 0.06 \\
\hline 1966 & 7 & 0.31 & 0.13 & 8 & 0.75 & 0.11 & 5 & 0.29 & 0.29 \\
\hline 1968 & 6 & 0.25 & 0.12 & 7 & 1.00 & 0.23 & 9 & 0.05 & 0.05 \\
\hline 1969 & 6 & 0.49 & 0.27 & 8 & 1.18 & 0.27 & 5 & 0.36 & 0.11 \\
\hline 1970 & 6 & 0.17 & 0.12 & 7 & 0.58 & 0.2 & 15 & 0.04 & 0.03 \\
\hline 1971 & 8 & 0.55 & 0.16 & 7 & 0.31 & 0.17 & 10 & 0.14 & 0.09 \\
\hline 1972 & 7 & 0 & & 7 & 0.89 & 0.25 & 9 & 0.31 & 0.20 \\
\hline 1973 & 5 & 0.26 & 0.17 & 5 & 1.36 & 0.27 & 5 & 0.52 & 0.24 \\
\hline 1974 & 7 & 0.35 & 0.18 & 6 & 0.49 & 0.16 & 5 & 0.10 & 0.10 \\
\hline 1975 & 6 & 0.39 & 0.21 & 6 & 0.51 & 0.19 & 5 & 0.06 & 0.06 \\
\hline 1976 & 6 & 0.20 & 0.15 & 6 & 0.45 & 0.07 & 5 & 0.62 & 0.28 \\
\hline 1977 & 4 & 0.39 & 0.22 & 6 & 0.59 & 0.24 & 5 & 0.24 & 0.15 \\
\hline 1978 & 6 & 0.18 & 0.13 & 6 & 0.47 & 0.16 & 5 & 0.28 & 0.12 \\
\hline 1979 & 7 & 0 & & 6 & 0.28 & 0.10 & 6 & 0.05 & 0.05 \\
\hline 1980 & 5 & 0.29 & 0.15 & 5 & 1.30 & 0.27 & 5 & 0.73 & 0.21 \\
\hline 1981 & 5 & 0.31 & 0.13 & 5 & 0.82 & 0.36 & 5 & 0.69 & 0.13 \\
\hline 1982 & 2 & 0.95 & 0.48 & 5 & 1.89 & 0.26 & 5 & 0.52 & 0.22 \\
\hline 1983 & 4 & 0.29 & 0.20 & 4 & 1.21 & 0.18 & & & \\
\hline 1984 & 5 & 0.12 & 0.07 & 5 & 0.25 & 0.16 & 4 & 0.33 & 0.14 \\
\hline \multicolumn{10}{|c|}{ RED } \\
\hline 1950 & 8 & 0 & & 7 & 0 & & 3 & 0.26 & 0.14 \\
\hline 1952 & 6 & 0 & & 4 & 0 & & 3 & 0.20 & 0.20 \\
\hline 1953 & 11 & 0 & & 6 & 0.05 & 0.05 & 6 & 0 & \\
\hline 1954 & 6 & 0 & & 7 & 0 & & 6 & 0 & \\
\hline 1955 & 8 & 0 & & 6 & 0.05 & 0.05 & 3 & 0 & \\
\hline 1956 & 3 & 0 & & 3 & 0 & & 6 & 0 & \\
\hline 1957 & 5 & 0 & & 3 & 0.23 & 0.23 & 5 & 0.06 & 0.06 \\
\hline 1958 & 4 & 0.15 & 0.09 & 5 & 0 & & 5 & 0 & \\
\hline 1959 & 5 & 0 & & 4 & 0 & & 6 & 0 & \\
\hline 1960 & 2 & 0 & & 2 & 0 & & 2 & 0 & \\
\hline 1961 & 6 & 0 & & 4 & 0 & & 3 & 0 & \\
\hline 1962 & 1 & 0 & & & & & 3 & 0 & \\
\hline 1963 & 13 & 0 & & 26 & 0.01 & 0.01 & 14 & 0.08 & 0.06 \\
\hline 1964 & 6 & 0 & & 6 & 0 & & 8 & 0 & \\
\hline 1966 & 7 & 0 & & 8 & 0 & & 5 & 0 & \\
\hline 1968 & 6 & 0 & & 7 & 0 & & 9 & 0 & \\
\hline
\end{tabular}


Appendix 2. (Continued). Mean abundance indices $[\log 10(x+1)]$ with 1 standard error (SE) of different zooplankton taxa by year and section. Abbreviations shown in Table $2 . \mathrm{N}=$ number of stations with zooplankton hauls.

\begin{tabular}{|c|c|c|c|c|c|c|c|c|c|}
\hline \multirow[b]{2}{*}{ Year } & \multicolumn{3}{|c|}{ Section 1} & \multicolumn{3}{|c|}{ Section 2} & \multicolumn{3}{|c|}{ Section 3} \\
\hline & $\mathrm{N}$ & Mean & SE & $\mathrm{N}$ & Mean & SE & $\mathrm{N}$ & Mean & $\mathrm{SE}$ \\
\hline \multicolumn{10}{|c|}{ RED (Continued) } \\
\hline 1969 & 6 & 0.1 & 0.06 & 8 & 0.22 & 0.13 & 5 & 0.12 & 0.07 \\
\hline 1970 & 6 & 0 & & 7 & 0 & & 15 & 0 & \\
\hline 1971 & 8 & 0 & & 7 & 0 & & 10 & 0 & \\
\hline 1972 & 7 & 0 & & 7 & 0 & & 9 & 0.07 & 0.07 \\
\hline 1973 & 5 & 0 & & 5 & 0.12 & 0.07 & 5 & 0 & \\
\hline 1974 & 7 & 0 & & 6 & 0 & & 5 & 0 & \\
\hline 1975 & 6 & 0 & & 6 & 0 & & 5 & 0.06 & 0.06 \\
\hline 1976 & 6 & 0 & & 6 & 0 & & 5 & 0 & \\
\hline 1977 & 4 & 0 & & 6 & 0 & & 5 & 0 & \\
\hline 1978 & 6 & 0 & & 6 & 0 & & 5 & 0 & \\
\hline 1979 & 7 & 0 & & 6 & 0 & & 6 & 0.05 & 0.05 \\
\hline 1980 & 5 & 0 & & 5 & 0 & & 5 & 0 & \\
\hline 1981 & 5 & 0 & & 5 & 0 & & 5 & 0 & \\
\hline 1982 & 2 & 0 & & 5 & 0 & & 5 & 0 & \\
\hline 1983 & 4 & 0 & & 4 & 0 & & & & \\
\hline 1984 & 5 & 0 & & 5 & 0 & & 4 & 0 & \\
\hline \multicolumn{10}{|c|}{ PLA } \\
\hline 1950 & 8 & 0.06 & 0.06 & 7 & 0.47 & 0.18 & 3 & 0.10 & 0.10 \\
\hline 1952 & 6 & 0.24 & 0.16 & 4 & 0.65 & 0.43 & 3 & 0 & \\
\hline 1953 & 11 & 0.36 & 0.16 & 6 & 0.72 & 0.27 & 6 & 0.20 & 0.13 \\
\hline 1954 & 6 & 0.87 & 0.25 & 7 & 1.25 & 0.13 & 6 & 0.10 & 0.06 \\
\hline 1955 & 8 & 0.44 & 0.19 & 6 & 0.51 & 0.13 & 3 & 0.30 & \\
\hline 1956 & 3 & 0.43 & 0.30 & 3 & 0.61 & 0.31 & 6 & 0 & \\
\hline 1957 & 5 & 0.23 & 0.16 & 3 & 0.59 & 0.32 & 5 & 0.14 & 0.14 \\
\hline 1958 & 4 & 0.5 & 0.12 & 5 & 0.72 & 0.12 & 5 & 0.12 & 0.07 \\
\hline 1959 & 5 & 0.79 & 0.31 & 4 & 1.26 & 0.28 & 6 & 0 & \\
\hline 1960 & 2 & 0.30 & 0.30 & 2 & 1.41 & 0.3 & 2 & 0 & \\
\hline 1961 & 6 & 0.41 & 0.19 & 4 & 0.31 & 0.19 & 3 & 0.20 & 0.20 \\
\hline 1962 & 1 & 0 & & & & & 3 & 0 & \\
\hline 1963 & 13 & 0.71 & 0.18 & 26 & 0.46 & 0.10 & 14 & 0.29 & 0.12 \\
\hline 1964 & 6 & 0.73 & 0.18 & 6 & 1.11 & 0.16 & 8 & 0.1 & 0.07 \\
\hline 1966 & 7 & 0.85 & 0.35 & 8 & 0.95 & 0.15 & 5 & 0.41 & 0.34 \\
\hline 1968 & 6 & 0.18 & 0.11 & 7 & 0.58 & 0.28 & 9 & 0 & \\
\hline 1969 & 6 & 0.15 & 0.1 & 8 & 0.49 & 0.24 & 5 & 0.28 & 0.17 \\
\hline 1970 & 6 & 0.08 & 0.08 & 7 & 0.42 & 0.21 & 15 & 0.02 & 0.02 \\
\hline 1971 & 8 & 0.88 & 0.2 & 7 & 0.95 & 0.11 & 10 & 0.15 & 0.08 \\
\hline 1972 & 7 & 0.20 & 0.07 & 7 & 0.09 & 0.06 & 9 & 0 & \\
\hline 1973 & 5 & 0.14 & 0.14 & 5 & 0.28 & 0.21 & 5 & 0.20 & 0.14 \\
\hline 1974 & 7 & 0.61 & 0.21 & 6 & 0.67 & 0.11 & 5 & 0 & \\
\hline 1975 & 6 & 0.86 & 0.23 & 6 & 0.4 & 0.17 & 5 & 0 & \\
\hline 1976 & 6 & 0.33 & 0.21 & 6 & 0.5 & 0.2 & 5 & 0.30 & 0.16 \\
\hline 1977 & 4 & 0.08 & 0.08 & 6 & 0.28 & 0.1 & 5 & 0.18 & 0.07 \\
\hline 1978 & 6 & 0 & & 6 & 0 & & 5 & 0 & \\
\hline 1979 & 7 & 0.29 & 0.15 & 6 & 0.38 & 0.14 & 6 & 0 & \\
\hline 1980 & 5 & 0.88 & 0.36 & 5 & 1.15 & 0.39 & 5 & 0.16 & 0.16 \\
\hline 1981 & 5 & 0.40 & 0.25 & 5 & 0.34 & 0.14 & 5 & 0.10 & 0.10 \\
\hline 1982 & 2 & 0.90 & 0.05 & 5 & 1.78 & 0.24 & 5 & 0.06 & 0.06 \\
\hline 1983 & 4 & 0 & & 4 & 0 & & & & \\
\hline 1984 & 5 & 0.06 & 0.06 & 5 & 0.62 & 0.27 & 4 & 0.08 & 0.08 \\
\hline
\end{tabular}


Appendix 2. (Continued). Mean abundance indices $[\log 10(x+1)]$ with 1 standard error (SE) of different zooplankton taxa by year and section. Abbreviations shown in Table $2 . \mathrm{N}=$ number of stations with zooplankton hauls.

\begin{tabular}{|c|c|c|c|c|c|c|c|c|c|}
\hline \multirow[b]{2}{*}{ Year } & \multicolumn{3}{|c|}{ Section 1} & \multicolumn{3}{|c|}{ Section 2} & \multicolumn{3}{|c|}{ Section 3} \\
\hline & $\mathrm{N}$ & Mean & SE & $\mathrm{N}$ & Mean & SE & $\mathrm{N}$ & Mean & SE \\
\hline \multicolumn{10}{|c|}{ WOLF } \\
\hline 1950 & 8 & 0 & & 7 & 0.17 & 0.06 & 3 & 0.26 & 0.14 \\
\hline 1952 & 6 & 0.05 & 0.05 & 4 & 0.19 & 0.12 & 3 & 0.30 & 0.17 \\
\hline 1953 & 11 & 0.05 & 0.04 & 6 & 0.10 & 0.06 & 6 & 0.10 & 0.06 \\
\hline 1954 & 6 & 0.20 & 0.06 & 7 & 0.22 & 0.09 & 6 & 0.15 & 0.07 \\
\hline 1955 & 8 & 0.17 & 0.07 & 6 & 0.29 & 0.10 & 3 & 0.10 & 0.10 \\
\hline 1956 & 3 & 0.26 & 0.14 & 3 & 0.10 & 0.10 & 6 & 0.15 & 0.07 \\
\hline 1957 & 5 & 0.19 & 0.12 & 3 & 0.20 & 0.10 & 5 & 0 & \\
\hline 1958 & 4 & 0.15 & 0.09 & 5 & 0.22 & 0.09 & 5 & 0.06 & 0.06 \\
\hline 1959 & 5 & 0.12 & 0.07 & 4 & 0.08 & 0.08 & 6 & 0.05 & 0.05 \\
\hline 1960 & 2 & 0 & & 2 & 0 & & 2 & 0 & \\
\hline 1961 & 6 & 0.05 & 0.05 & 4 & 0.08 & 0.08 & 3 & 0 & \\
\hline 1962 & 1 & 0 & & & & & 3 & 0 & \\
\hline 1963 & 13 & 0.14 & 0.06 & 26 & 0.13 & 0.04 & 14 & 0.08 & 0.04 \\
\hline 1964 & 6 & 0.17 & 0.12 & 6 & 0.23 & 0.08 & 8 & 0.04 & 0.04 \\
\hline 1966 & 7 & 0.18 & 0.09 & 8 & 0.23 & 0.07 & 5 & 0.12 & 0.07 \\
\hline 1968 & 6 & 0.52 & 0.13 & 7 & 0.18 & 0.09 & 9 & 0.09 & 0.06 \\
\hline 1969 & 6 & 0.05 & 0.05 & 8 & 0.08 & 0.05 & 5 & 0 & \\
\hline 1970 & 6 & 0 & & 7 & 0.09 & 0.06 & 15 & 0.02 & 0.02 \\
\hline 1971 & 8 & 0.04 & 0.04 & 7 & 0.33 & 0.09 & 10 & 0.03 & 0.03 \\
\hline 1972 & 7 & 0.04 & 0.04 & 7 & 0.26 & 0.08 & 9 & 0.09 & 0.06 \\
\hline 1973 & 5 & 0.12 & 0.07 & 5 & 0.36 & 0.12 & 5 & 0.12 & 0.07 \\
\hline 1974 & 7 & 0.07 & 0.07 & 6 & 0.08 & 0.08 & 5 & 0.10 & 0.10 \\
\hline 1975 & 6 & 0.05 & 0.05 & 6 & 0.15 & 0.07 & 5 & 0.18 & 0.07 \\
\hline 1976 & 6 & 0.05 & 0.05 & 6 & 0.13 & 0.09 & 5 & 0.19 & 0.12 \\
\hline 1977 & 4 & 0.08 & 0.08 & 6 & 0.23 & 0.11 & 5 & 0 & \\
\hline 1978 & 6 & 0.12 & 0.12 & 6 & 0.13 & 0.09 & 5 & 0.12 & 0.07 \\
\hline 1979 & 7 & 0 & & 6 & 0.05 & 0.05 & 6 & 0.05 & 0.05 \\
\hline 1980 & 5 & 0.06 & 0.06 & 5 & 0.96 & 0.19 & 5 & 0.18 & 0.07 \\
\hline 1981 & 5 & 0 & & 5 & 0.25 & 0.11 & 5 & 0.37 & 0.18 \\
\hline 1982 & 2 & 0 & & 5 & 0.76 & 0.15 & 5 & 0.55 & 0.20 \\
\hline 1983 & 4 & 0 & & 4 & 0 & & & & \\
\hline 1984 & 5 & 0 & & 5 & 0.19 & 0.12 & 4 & 0 & \\
\hline
\end{tabular}

\begin{tabular}{|c|c|c|c|c|c|c|c|c|c|}
\hline 1950 & 8 & 0.39 & 0.11 & 7 & 0.22 & 0.08 & 3 & 0 & \\
\hline 1952 & 6 & 0.16 & 0.10 & 4 & 0.29 & 0.18 & 3 & 0 & \\
\hline 1953 & 11 & 0.51 & 0.16 & 6 & 0.42 & 0.28 & 6 & 0 & \\
\hline 1954 & 6 & 0.10 & 0.06 & 7 & 0.04 & 0.04 & 6 & 0.05 & 0.05 \\
\hline 1955 & 8 & 0.20 & 0.09 & 6 & 0.17 & 0.12 & 3 & 0 & \\
\hline 1956 & 3 & 0.36 & 0.18 & 3 & 0 & & 6 & 0.05 & 0.05 \\
\hline 1957 & 5 & 0.24 & 0.06 & 3 & 0 & & 5 & 0 & \\
\hline 1958 & 4 & 0.19 & 0.12 & 5 & 0.68 & 0.28 & 5 & 0.16 & 0.1 \\
\hline 1959 & 5 & 0.30 & 0.16 & 4 & 0.08 & 0.08 & 6 & 0.16 & 0.16 \\
\hline 1960 & 2 & 0.15 & 0.15 & 2 & 0.24 & 0.24 & 2 & 0 & \\
\hline 1961 & 6 & 0.08 & 0.08 & 4 & 0.08 & 0.08 & 3 & 0 & \\
\hline 1962 & 1 & 0 & & & & & 3 & 0.26 & 0.14 \\
\hline 1963 & 13 & 0.85 & 0.23 & 26 & 0.25 & 0.06 & 14 & 0.29 & 0.13 \\
\hline 1964 & 6 & 0.62 & 0.29 & 6 & 0.10 & 0.06 & 8 & 0.36 & 0.2 \\
\hline 1966 & 7 & 1.37 & 0.23 & 8 & 0.62 & 0.17 & 5 & 0.19 & 0.12 \\
\hline 1968 & 6 & 0.71 & 0.26 & 7 & 0.61 & 0.27 & 8 & 0.11 & 0.11 \\
\hline
\end{tabular}


Appendix 2. (Continued). Mean abundance indices $[\log 10(x+1)]$ with 1 standard error (SE) of different zooplankton taxa by year and section. Abbreviations shown in Table 2. $\mathrm{N}=$ number of stations with zooplankton hauls.

\begin{tabular}{|c|c|c|c|c|c|c|c|c|c|c|c|c|}
\hline \multirow[b]{2}{*}{ Year } & \multicolumn{5}{|c|}{ Section 1} & \multicolumn{4}{|c|}{ Section 2} & \multicolumn{3}{|c|}{ Section 3} \\
\hline & $\mathrm{N}$ & & Mean & SE & & $\mathrm{N}$ & & Mean & SE & $\mathrm{N}$ & Mean & SE \\
\hline \multicolumn{13}{|c|}{ SAND (Continued) } \\
\hline 1969 & 6 & 0.98 & 0.32 & 8 & 1.36 & 0.31 & 5 & 0.66 & 0.25 & & & \\
\hline 1970 & 6 & & 0.8 & 0.35 & & 7 & & 0.65 & 0.25 & 15 & 0.54 & 0.18 \\
\hline 1971 & 8 & & 0.32 & 0.12 & & 7 & & 0.37 & 0.14 & 10 & 0.89 & 0.27 \\
\hline 1972 & 7 & & 1.45 & 0.12 & & 7 & & 1.13 & 0.17 & 9 & 1.04 & 0.22 \\
\hline 1973 & 5 & & 1.34 & 0.17 & & 5 & & 1.29 & 0.44 & 5 & 1.38 & 0.47 \\
\hline 1974 & 7 & & 0.41 & 0.18 & & 6 & & 1.22 & 0.38 & 5 & 0.80 & 0.36 \\
\hline 1975 & 6 & & 1.46 & 0.17 & & 6 & & 0.85 & 0.23 & 5 & 0.34 & 0.12 \\
\hline 1976 & 6 & & 0.63 & 0.26 & & 6 & & 1.62 & 0.24 & 5 & 0.61 & 0.37 \\
\hline 1977 & 4 & & 0.83 & 0.32 & & 6 & & 0.13 & 0.09 & 5 & 0.06 & 0.06 \\
\hline 1978 & 6 & & 0.55 & 0.15 & & 6 & & 0.53 & 0.2 & 5 & 0.06 & 0.06 \\
\hline 1979 & 7 & & 0.25 & 0.17 & & 6 & & 0.13 & 0.09 & 6 & 0 & \\
\hline 1980 & 5 & & 0.55 & 0.17 & & 5 & & 0.12 & 0.12 & 5 & 0 & \\
\hline 1981 & 5 & & 0.16 & 0.10 & & 5 & & 0.24 & 0.11 & 5 & 0.12 & 0.07 \\
\hline 1982 & 2 & & 1.07 & 0.60 & & 5 & & 1.37 & 0.42 & 5 & 0.87 & 0.41 \\
\hline 1983 & 4 & & 1.06 & 0.33 & & 4 & & 0.75 & 0.26 & & & \\
\hline 1984 & 5 & & 0.88 & 0.21 & & 5 & & 1.25 & 0.39 & 4 & 0.27 & 0.27 \\
\hline
\end{tabular}

